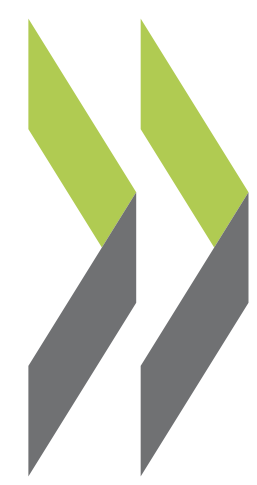

OECD Local Economic and Employment Development (LEED) Papers 2011/03

\title{
Entrepreneurship, SMEs and Local Development in Andalusia, Spain
}




\section{Entrepreneurship, SMEs and Local Development in Andalusia, Spain}

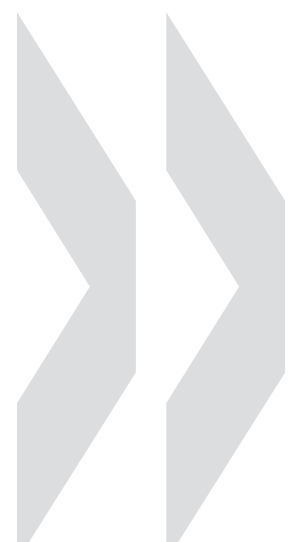

LAED LOCAL ECONOMIC AND EMPLOYMENT DEVELOPMENT LAED LOCAL ECO LOCAL ECONOMIC AND EMPLOYMENT DEVELOPMENT LEED LOCAL ECONOMIC AND EMPLOYMENT DEVELOPMENT LEED LOCAL ECONOMIC AND EMPLOYME MENT DEVELOPMENT LEED LOCAL ECONOMIC AND EMPLOYMENT DEVELOPME DEVELOPMENT LEED LOCAL ECONOMIC AND EMPLOYMENT DEVELOPMENT LEE D LOCAL ECONOMIC AND EMPLOYMENT DEVELOPMENT LEED LOCAL ECONO NOMIC AND EMPLOYMENT DEVELOPMENT LEED LOCAL ECONOMIC AND EMPI AND EMPLOYMENT DEVELOPMENT LEED LOCAL ECONOMIC AND EMPLOYMEN NT DEVELOPMENT LEED LOCAL ECONOMIC AND EMPLOYMENT DEVELOPMENT NT LEED LOCAL ECONOMAL AND EMPLOYMENT DEVELOPNENT LEED LOCAL E
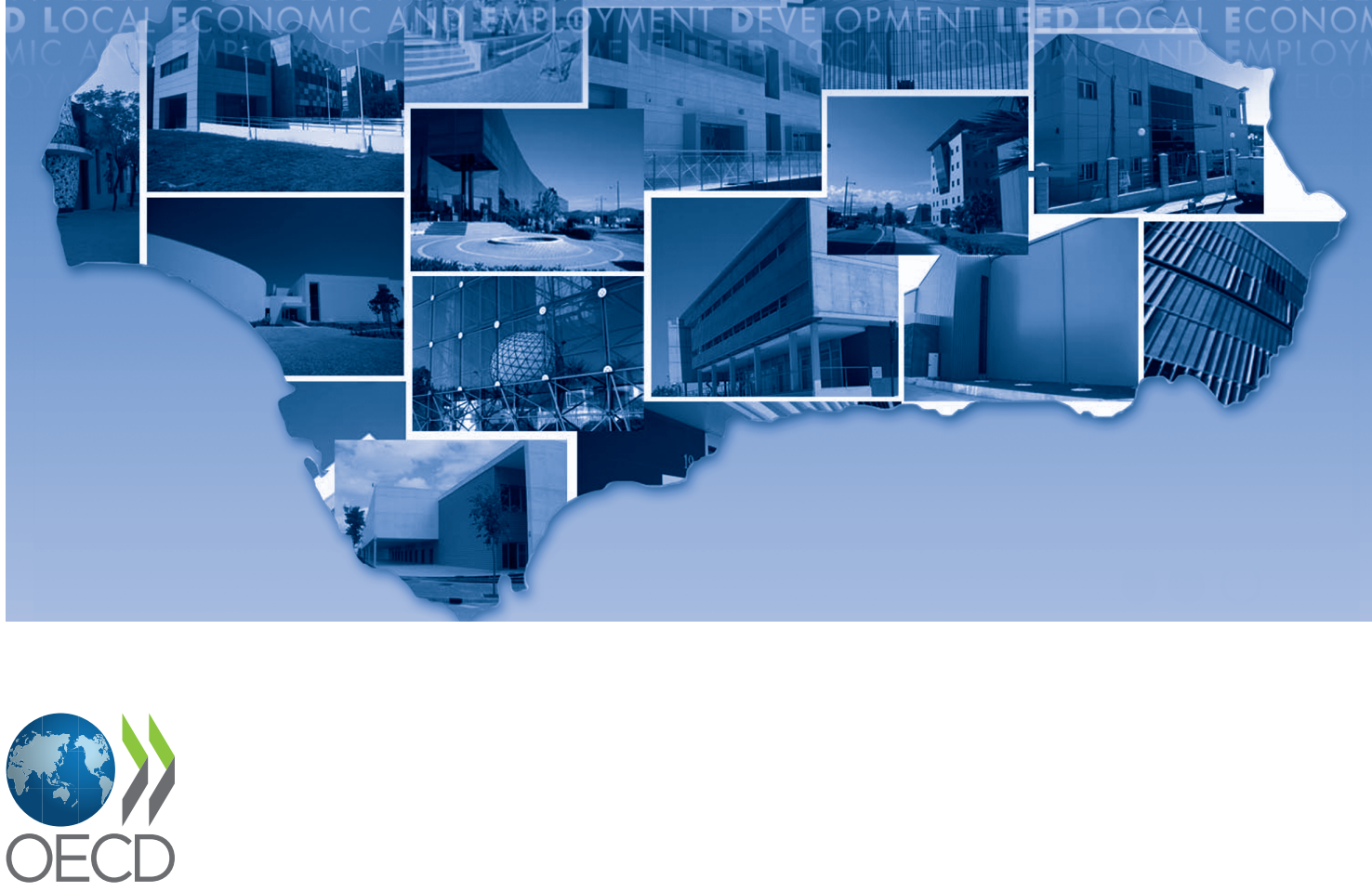
Photo credits: Red de Espacios Tecnológicos de Andalucía (RETA)

(C) OECD 2011

You can copy, download or print OECD content for your own use, and you can include excerpts from OECD publications, databases and multimedia products in your own documents, presentations, blogs, websites and teaching materials, provided that suitable acknowledgment of OECD as source and copyright owner is given. All requests for public or commercial use and translation rights should be submitted to rights@oecd.org. Requests for permission to photocopy portions of this material for public or commercial use shall be addressed directly to the Copyright Clearance Center (CCC) at info@copyright.com or the Centre français d'exploitation du droit de copie (CFC) at contact@cfcopies.com. 


\section{Foreword}

The OECD Centre for Entrepreneurship has always considered entrepreneurship to be a key driver of economic growth and job creation. In the current phase of economic recovery, entrepreneurship is helping to create new jobs to counter job losses as well as providing people with career opportunities that fit their preferences better than waged employment. The OECD Local Economic and Employment Development (LEED) Programme review series on "Entrepreneurship, SMEs and Local Development" examines the capacity of local economies to support new enterprise creation and SME development and how they can be enhanced through local economic and employment development policies. The ultimate goal is the development of local economies that are more entrepreneurial, offering improved employment opportunities and job creation, increased growth and adaptability to shocks, as well as innovative ways of meeting their social needs.

This case study on "Entrepreneurship, SMEs and Local Development in Andalusia, Spain", has been undertaken by the LEED Programme of the Organisation for Economic Co-operation and Development (OECD) in collaboration with Red de Espacios Tecnológicos de Andalucía (RETA). In addition to existing material about the Andalusia economy, this report draws on a week-long study visit that took place in Seville and Malaga from 12 to 16 April 2010. The review was supervised by Marco Marchese, who also edited the report, and Jonathan Potter, who led the study visit, of the OECD LEED Secretariat. This report would not have been possible without the support, insights, and comments of RETA's management and staff. In particular, special thanks go to Mr. Felipe Romera, Ms. Lourdes Cruz, Mr. Daniel Gonzalez-Bootello, and Ms. Silvia Serrano-Fernandez.

Additional thanks go to the representatives of the following institutions that took the time to meet with the OECD review team and provided invaluable insights on the Andalusia entrepreneurship and SME development system: the Andalusia Technology Park (PTA) of Malaga; the Cartuja 93 Technology Park of Seville; the Technology Transfer Office of the University of Malaga; the Technology Transfer Office of the University of Seville; the Centre for Technological Investigation and Innovation (CITIUS) of the University of Seville; the General Secretariat for "Innovation" of the 
regional Ministry of Economy, Innovation and Science (MEIS); the General Secretariat for "Telecommunications and Information Society" of the MEIS; the General Secretariat for "Industrial and Environmental Development" of the MEIS; the General Secretariat for "University, Investigation and Technology" of the MEIS; the office FEDER (EU funds management) of the MEIS; the Entrepreneurship Agency (ANDALUCIA EMPRENDE); the Andalusia Entrepreneur Confederation (CEA); the Andalusia Innovation and Development Agency (IDEA); the Andalusia Social and Economic Council (CES); the Investment Promotion Agency (EXTENDA); the Andalusia Institute of Technology (IAT); the Andalusia Technological Corporation (CTA); the JEREMIE Funds programme; the BECAS TALENTIA programme; the leading regional company AT4 Wireless.

In addition to Marco Marchese and Jonathan Potter of the OECD LEED Secretariat, the review team consisted of the following experts: Prof. Jaime del Castillo, University of the Basque Country and INFYDE, Spain; Prof. Karen Chapple, University of California at Berkeley, USA; Prof. Andrew Cumbers, University of Glasgow, UK; Prof. Jay Mitra, University of Essex, UK; Dr. Ricardo Pinto, Pinto-Consulting, Hamburg, Germany; Prof. David Wolfe, University of Toronto, Canada.

The review team was initially informed about the main features of Andalusia's economy and entrepreneurship support system by a diagnostic report prepared by Prof. Vicente Granados-Cabezas of the University of Malaga.

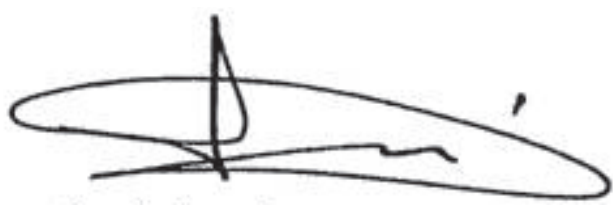

Sergio Arzeni

Director, OECD Centre for Entrepreneurship

Head, OECD LEED Programme 


\section{Contributors to the chapters}

- Introduction, by Jay Mitra.

- Chapter 1: Economic and institutional overview of Andalusia, by Vicente Granados-Cabezas, Jaime del Castillo, and Marco Marchese.

- Chapter 2: Human capital and the labour market, by Karen Chapple and Sergio Montero-Muñoz.

- Chapter 3: The contribution of research organisations, by David Wolfe.

- Chapter 4: Entrepreneurship and start-ups, by Ricardo Pinto.

- Chapter 5: SME development, by Andrew Cumbers.

- Conclusions, by Marco Marchese and Jay Mitra.

The editors of the report are Mr. Marco Marchese and Dr. Jonathan Potter of OECD LEED Secretariat. For information on similar reviews in other regions, please contact:

Dr Jonathan Potter, senior economist, OECD LEED Programme, jonathan.potter@oecd.org

Mr. Marco Marchese, policy analyst, OECD LEED Programme, marco. marchese@oecd.org 



\section{Table of contents}

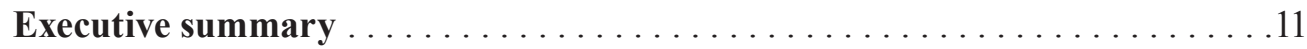

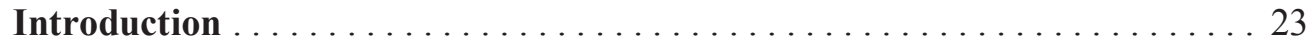

The local background. ............................... 23

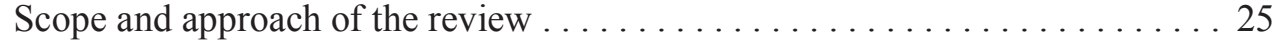

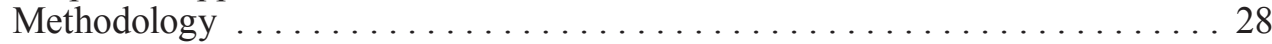

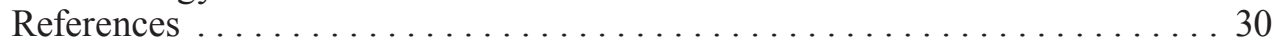

Chapter 1. Economic and institutional overview of Andalusia ...........31

The socioeconomic context . . . . . . . . . . . . . . . . . . . . . 31

The regional institutional and policy framework . . . . . . . . . . 39

References ................................44

Chapter 2. Human capital and the labour market $\ldots \ldots \ldots \ldots \ldots$

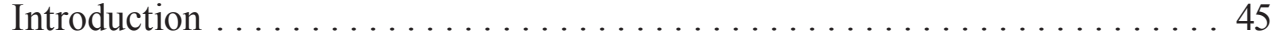

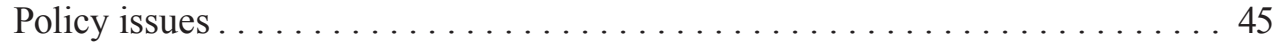

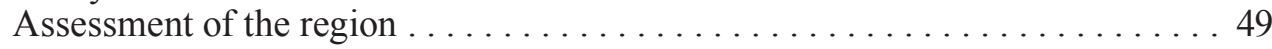

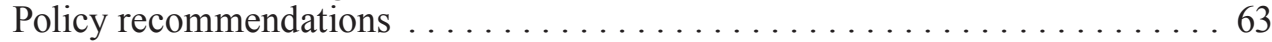

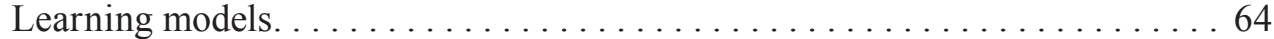

References ................................ 71

Chapter 3. The contribution of research organisations $\ldots \ldots \ldots \ldots \ldots 75$

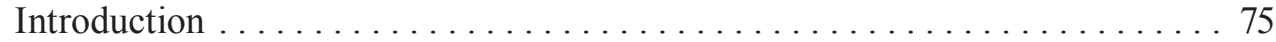

Policy issues . . . . . . . . . . . . . . . . . . . . . 76

Assessment of the region . . . . . . . . . . . . . . . . . . . . 81

Policy recommendations . . . . . . . . . . . . . . . . . . . . 99

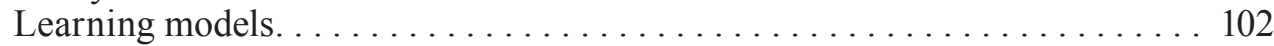

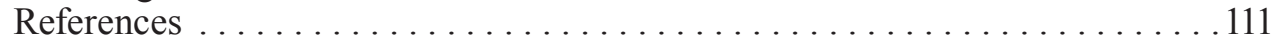


Chapter 4. Entrepreneurship and start-ups $\ldots \ldots \ldots \ldots \ldots \ldots \ldots \ldots \ldots \ldots$

Introduction . . . . . . . . . . . . . . . . . . . . . . . . . . . . . . 115

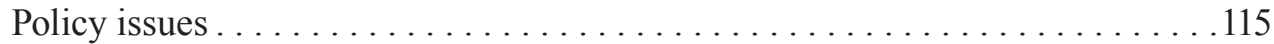

Assessment of the region . . . . . . . . . . . . . . . . . . . . . . . . . 119

Policy recommendations . . . . . . . . . . . . . . . . . . . . . . . . 131

Learning models. . . . . . . . . . . . . . . . . . . . . . . . 135

References .................................... 144

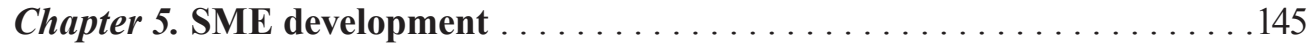

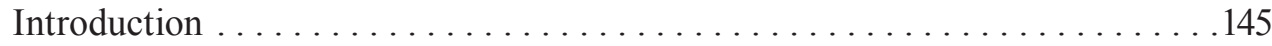

Policy issues . . . . . . . . . . . . . . . . . . . . . . . . . . . . . . . .

Assessment of the region . . . . . . . . . . . . . . . . . . . . . . 147

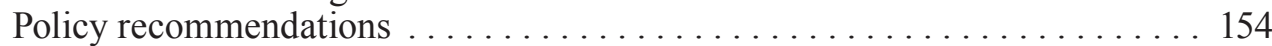

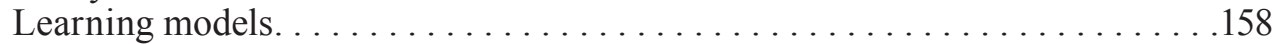

References ......................................

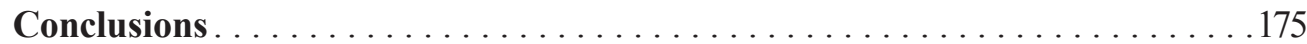

Human capital and labour market . . . . . . . . . . . . . . . . . 176

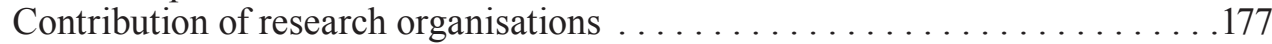

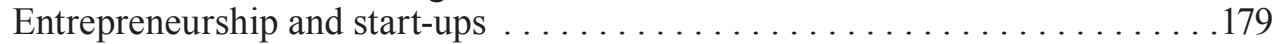

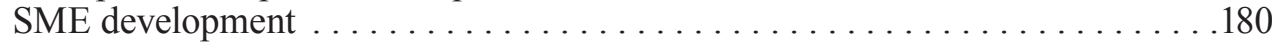

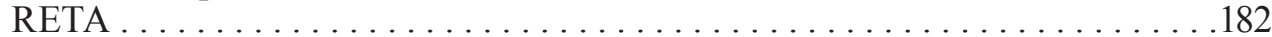

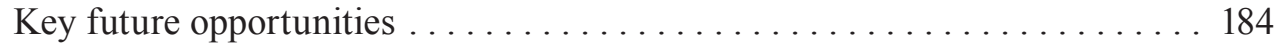

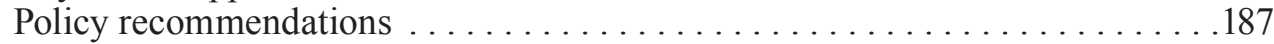

\section{Figures}

Figure 0.1 A diagram for reviewing the Andalusian economy . . . . . . . . 26

Figure 1.1 Population growth in Andalusia, 1998-2009 . . . . . . . . . . . . 32

Figure 1.2 Andalusia's foreign trade and trade balance (1990-2008)

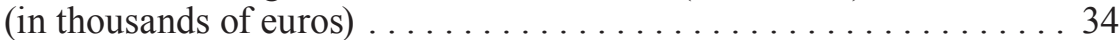

Figure 1.3 Andalusia's GVA trends by sector, $2001-2009$. . . . . . . . . . . 34

Figure 1.4 R\&D expenditure as a percentage of GDP, $1987-2008 \ldots \ldots \ldots \ldots 37$

Figure 1.5 R\&D expenditure by sector in thousands of euros (1987-2008) . . . . 37

Figure 1.6 The Andalusia Innovation System . . . . . . . . . . . . . . . . . . . 43

Figure 2.1 Regional Agencies involved in human capital development . . . . . 52

Figure 2.2 East Bay Green Corridor Partnership Policies . . . . . . . . . . . . . . 66

Figure 4.1 Number of enterprises in Andalusia, 1999-2008 . . . . . . . . . . 120 


\section{Tables}

Table 1.1 Andalusia: key statistics . . . . . . . . . . . . . . . . 31

Table 3.1 Interactions with universities of Andalusian innovative firms . . . . 96

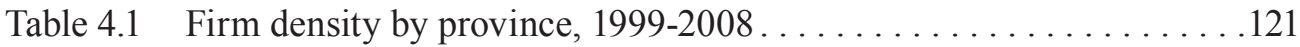

Table 4.2 Firm distribution by sector in Andalusia, 2001-2008 . . . . . . . . 122

Table 4.3 Firm Dynamism in Andalusia and Spain, 2005-2008 . . . . . . . . 122

Table 4.4 Summary of key EU business incubator benchmarks . . . . . . . . . 140

Table 5.1 Size structure of firms in Andalusia, 2008. . . . . . . . . . . . . . . . 147

\section{Boxes}

Box $0.1 \quad$ Main policy recommendations .................. 21

Box 1.1 Key functions of main Andalusian development agencies. . . . . . . . 40

Box $2.1 \quad$ RETA's main provision of training . . . . . . . . . . . . . 61

Box 4.1 Summary of key EU business incubator qualitative factors. . . . . . . . 141

Box 5.1 The Andalusia Stone Technology Centre . . . . . . . . . . . . . . 155

Box $6.1 \quad$ Main policy recommendations ..................... 188 



\section{Executive summary}

The OECD Local Economic and Employment Development Programme (LEED) has undertaken a review on entrepreneurship, SMEs and local development in Andalusia, Spain, working in collaboration with RETA (Red de Espacios Tecnológicos de Andalucía - Andalusia Technology Network). The present document summarises the key results of the review, which took place from autumn 2009 to autumn 2010.

The overall review objective was to analyse the capacity of Andalusia to support entrepreneurship and SME development and how such capacity is affected by regional and local policies. Further specific objectives were to: (i) identify the challenges faced by new and small firms in growing and thriving in the region; (ii) analyse the set of policies implemented by regional and local organisations to support entrepreneurship and SME development; (iii) assess how to fill policy gaps and improve existing policies and make policy recommendations; and (iv) provide illustrations of international good practices that could provide inspiration for the implementation of recommendations. In addition, the review has examined the role of RETA in supporting entrepreneurship and SME development, and how its impact can be enhanced.

The study was carried out by an international review panel consisting of 6 international experts and 2 members of the Secretariat of the OECD LEED Programme. It investigated four main themes: (i) the impact of human capital and the labour market on entrepreneurship and SME development; (ii) the contribution of research organisations to entrepreneurship and SME development; (iii) direct policies for entrepreneurship and start-ups; (iv) direct policies for SME development. The key findings for each theme are summarised below, together with the main observations on the role of RETA in entrepreneurship and SME development. 


\section{Human capital and the labour market}

\section{The Andalusia labour market is affected by structural weaknesses}

High levels of unemployment, large numbers of temporary workers and low productivity undermine the performance of Andalusia's labour market. Although the overreliance of the region on the construction industry and the subsequent housing bubble has clearly contributed to these problems, even the sectors that employ highly educated workers are affected by structural problems.

\section{Regional human capital needs to be upgraded}

Despite the recent catch-up effect driven by higher levels of business activity (e.g. in the agriculture, construction and tourism sectors) and increasing levels of GDP per capita (now $80 \%$ of the EU average), the quality of human capital has not improved proportionally. The region has actually experienced a reduction in post-compulsory school and university attendance, the latter declining from $14.7 \%$ in $1997 / 8$ to $12.2 \%$ in $2007 / 8$. Human capital needs to be upgraded so as to compete with the rest of Spain and the EU.

\section{The quality of universities needs to be enhanced}

The university system - 10 public universities with a total of approximately 230000 students - depends on the Regional Ministry of Economy, Innovation and Science, and this has created greater pressure for industryuniversity collaboration. In general terms, however, Spanish universities do not rank well in international quality rankings. The only two listed among the top 500 universities are the University of Granada and the University of Seville, while Malaga and all other local universities do not make it in any of the major world rankings. One attempt to compensate for the weakness of Spanish universities is the Talentia program, which offers young college graduates financial support for their graduate work at top international universities, on the condition that they return to the region to work for at least four years. By 2009 the program had funded about 500 young Andalusians and was considered largely successful in generating skilled workforce for local companies.

\section{Attendance of vocational training is on the rise}

In Andalusia a total of nearly 95000 students attend vocational training, less than half the number that attend public universities. The II Andalusia Plan for Vocational Training, currently being prepared by the Ministry of Education, seeks to adapt vocational training to the new economy and new 
demand of jobs and occupations. This will involve expanding online training; cooperating more closely with businesses, unions and others through advisory councils; teaching more foreign languages; and creating at least one vocational centre of excellence in each of the eight Andalusia provinces to improve connections with businesses. Vocational training has been very successful in the last decade in placing students in a job. That has resulted in an increased number of students during the 1990s and 2000s just as the number of university students in Spain has been decreasing and the number of dropouts increasing.

\section{There is a schism between economic development and workforce development}

Andalusia experiences a chronic schism between economic and workforce development programmes that makes it difficult for businesses to obtain appropriately trained labour and, most pertinent for innovation, develop the pipeline of highly skilled workers that help transmit knowledge in regional clusters. This schism manifests itself in three ways: a poor connection between the regional innovation system and the Andalusian vocational system; a separation between ministries concerned with entrepreneurship, education, and employment; and the lack of a workforce strategy tied to business cluster strategies.

\section{Contribution of research organisations}

\section{Universities play a key role in the design and implementation of the regional innovation strategy}

A key focus of the regional innovation policy is to encourage and reinforce technology transfer and cooperation between the public R\&D system and private companies, and to promote the creation of spin-off companies from publicly financed research in the university. Universities occupy a key position in this strategy and are, as a result, the chief beneficiary of funding under the Innovation and Modernisation Plan for Andalusia (PIMA). Public universities have thus been the primary source of $R \& D$ spending in the region as well as the principal beneficiaries of the increase in public funds for research and in technology parks since the 1990s. Although the private sector share of R\&D spending in Andalusia has grown from 29.3\% in 1999 to $33.6 \%$ in 2008 , the proportion remains low compared to the Spanish average of $45.5 \%$ and the OECD average of $64.2 \%$. The privileged position of the public sector, and especially of the research universities, is strongly reinforced by the priority afforded to them in the region's strategic plans. 


\section{There is some disconnection between university research and industry needs}

A strong coordination between the research priorities of universities and those of regional strategic plans is missing, as indicated for instance by the relative absence of prioritizing of research in biotechnology, ICTs or tourism in regional universities. This is the result of universities not having their own research strategies; the latter are indeed often derived directly from the research groups, which are the main organisational unit and recipient of $R \& D$ funding in universities.

\section{OTRIs are the main link between universities and firms, but they lack sufficient and adequate staff}

Support for university research is provided through a range of institutions, including the industrial liaison offices (OTRIs). The OTRIs are responsible for channelling external research demands to the appropriate research groups within their own institutions and for promoting the transfer of research results into the private sector through patenting, licensing and spin-offs. The OTRIs also actively support university students, faculty and researchers who want to create their own companies, especially in the case of spin-offs derived from university research.

However, the function of OTRIs is hampered by limited staff to keep sufficient contact with local businesses. These offices are asked to serve the needs of their universities as a whole, while the requirements of individual departments can be very different. They also lack a cadre of technically trained people who can provide technical support to research teams and firms. This would correspond to an intermediate profile between academic and administrative staff that does not do research, but who can still provide technical assistance to research teams. These staff limitations make it difficult for OTRIs to work with small firms and prompt them to focus their efforts on working with more R\&D-intensive firms. This is an issue that needs to be addressed in the future to improve the relationships of universities with SMEs in the region.

\section{National legislation hinders university commercialisation and researcher mobility}

The challenge of promoting the commercialisation of intellectual property is made more difficult by the conditions established by the Spanish Patent Act. It designates that the ownership of discoveries made by university professors during their period of contract with the university, and which constitute part of their university duties, belong to the university. Professors have the right to share in the benefits that flow to the university from the use of the intellectual property rights derived from their inventions, but the precise share that they receive is governed by the statutes of the individual universities. Regional 
universities are critical of this legal framework as it provides little guidance for determining how benefits should be shared in the course of contractual work.

National regulations have also imposed restrictions on the mobility of university researchers between the public sector and private spin-off companies. University staff are prevented from holding more than a $10 \%$ interest in private companies, from being a member of a board of directors, or taking a temporary leave from the university to form a private company. The act governing universities was amended in 2001 to allow university researchers a five year leave of absence without giving up their university position to participate in technology-based spinoffs. However, the universities are still critical of the current law as they feel that the guidelines for implementing the regulations are insufficient to allow the integration of university researchers into technology-based spinoffs.

\section{Andalusia needs to recognise the role of less $R \& D$ intensive forms of industry-university cooperation}

R\&D-related activities do not play a major role in most of the firms considered as "innovative" within the Andalusian economy. It is important for universities and regional coordinating bodies to recognise that $\mathrm{R} \& \mathrm{D}$ activities, especially the commercialisation and exploitation of intellectual property derived from university research are just a portion of the firm's overall interactions with the higher education system. In fact, an interest in this aspect only emerges when firms have an absorptive capacity that has been built up through a wide range of previous interactions with universities. The policy implication is that there needs to be greater public support for less R\&D-intensive forms of interaction between the universities and private firms. This would require the universities providing greater support in the form of technical advice and problem solving. It could also be facilitated by more focused forms of cooperative education programs ensuring that the students being trained in the universities are familiar with the kinds of technical problems that local firms must overcome. It is through these lower orders of industry-university interaction that the absorptive capacity of firms, a prerequisite for R\&D engagement and IPR exploitation, will be developed.

\section{Some regional programmes are being successful in promoting technology-based start-ups}

The regional government has established two separate programmes to promote the creation of technology-intensive start-ups. The Atlantis Programme is geared toward identifying newly formed enterprises from across Spain and attracting them to establish themselves in Andalusia. The Campus Programme supports spinoffs from Andalusian universities by providing them with loans of up to EUR 100 000. These combined efforts have brought about some success, as 
the rate of formation of new technology-based firms has increased steadily over the past decade, with a cumulative total of more than 120 established by 2008 .

\section{New programmes hold the promise to strengthen industry-university collaboration}

The national government of Spain has recently launched a new programme called "Campus of International Excellence", which wants to reinforce the collaboration of universities with the local surrounding environment - firms, technology parks, technology centres, foundations, etc. - with a view to creating knowledge eco-systems that support local development, employment and social cohesion. Two projects from Andalusia - one jointly presented by the University of Seville and the University of Malaga and one from the University of Granada - have been in the restricted group of the selected initiatives. The first (Andalucía-TECH) will have an international horizon and a multidisciplinary focus, promoting research excellence in the areas of aeronautics, biotechnologies, communications, energy and environment, transport, and tourism. The active participation of technology parks (Cartuja 93 in Seville and PTA-Malaga) and technology centres, assets of the two provinces, is anticipated, together with that of private companies. The second (Biotic) will have a narrower focus on biotechnologies, tapping on the local competence base provided by the local University and the Health Sciences Technology Park. Both envisage attracting both talent (students, researchers, skilled workers, etc.) and investment (national and foreign).

\section{Entrepreneurship}

\section{Entrepreneurial culture is improving in the region}

There is a low but growing level of entrepreneurial culture in the region. The density of enterprises is approaching the national level and the population of the region has a fairly high level of interest in entrepreneurial activity. Although young people have traditionally seen the public sector as the natural route to the labour market, the sharp economic downturn in Andalusia may stimulate a greater willingness to embrace self-employment and other forms of entrepreneurship. This is clearly something to build on in the region via a greater focus on developing a culture of entrepreneurship at all levels of the education system: primary, secondary, vocational and tertiary.

\section{Immigration is an entrepreneurial resource that should be better exploited}

The growing levels of diversity, including the large influx of migrants to the region, can be utilised by the region. The previous growth period has pulled in migrants, both from other regions of Spain and from abroad. Some, such as 
the expat communities, are well educated, while others are less so. However, by their very nature, such migrants tend to be relatively young, willing to take risks and naturally entrepreneurial in mindset. The region could consider ways and means of harnessing this economic potential through new forms of policy support not restricted to Spaniards or Andalusians in the strict sense.

\section{Andalusia's support framework needs to adjust to a future with lower EU funding}

EU funds for the period 2007-2013 alone amounts to Euro 14 billion (excluding various national and regional contributions and programmes). The focus of the current programming period is on soft measures such as capacity building and institution building leading to greater competitiveness, innovation, and employment. In the future Andalusia is likely to lose its Objective 1 status and, in consequence, the level of EU structural funds will decline markedly beyond 2014. Given the extent to which the region, its institutions and its enterprises benefit from financial and non-financial subsidies directly emanating from the $\mathrm{EU}$, the region must initiate the transition to a more market-oriented enterprise policy combined with a more sustainable system of support for regional and enterprise development. This is a problem but it is also an opportunity: it would necessitate more efficient use of resources in the time available, such as minimising overlaps and improving the targeting of public business support.

\section{The current extensive entrepreneurship support framework results in institutional overlaps}

An extensive network of institutions, policies, programmes and projects exists that supports entrepreneurship in the region. This can lead to confusion for the business sector (multiplicity of organisations, programmes, etc.), potential crowding out of the private sector (delivery of activities which would normally be provided by the private sector, price distortion due to free delivery of services, etc.) and inefficiency (resources not necessarily deployed in a manner which maximises impact). The consequence of this level of public subsidy is that much of the regional economy is cushioned to some degree from general competition.

\section{SME development}

\section{The Andalusian business structure lacks medium-sized firms}

The Andalusia economy is dominated by SMEs with over $99 \%$ of firms having less than 500 employees. This places it well below both the Spanish and the EU averages. Of even greater significance is the disproportionate number of "micro firms" in the region - either self-employed or employing 
less than 10 people - accounting for over $95 \%$ of enterprises. While the region experienced a high rate of new business start-ups and a significant increase in jobs during the period of economic growth from the mid 1990s up until the present economic downturn, the continued lack of medium-sized firms between 50 and 500 employees demonstrates an underlying structural problem in growing local enterprises to a level that can contribute more significantly to employment creation and regional growth.

\section{Business internationalisation is at an incipient stage but on the rise}

It is estimated that only $1.4 \%$ of Andalusian firms are involved in export markets, compared to the national average of $4 \%$. Andalusia, the largest region of Spain, only accounts for approximately $9 \%$ of Spanish exports, worth approximately EUR14 billion, ranking it $5^{\text {th }}$ behind the Madrid region, Catalonia, the Basque Country and the Valencia region. Regional government officials suggest that around 16000 firms are involved in export markets, but only 3000 on a regular basis, as opposed to the 100 that have also foreignbased establishments. Despite this small base, exports increased as a proportion of the total activity in the regional economy over the decade 1995-2005, rising from $20.8 \%$ to $24.9 \%$ of GDP.

\section{Technology parks are key to SME development in the region}

At the core of the regional innovation policy are the 11 science and technology parks, alongside the 21 technology centres which have a more sectoral focus. The employment impact is certainly significant in a region that had hitherto been lagging in terms of new technology sectors; the Malaga Technology Park for example, has 530 enterprises employing more than 10000 people. The focus upon particular sectors and clusters is appropriate and chimes with wider recent experience of the best models for encouraging SME innovation. Additionally, the parks provide excellent facilities and infrastructure for high tech SMEs with a sophisticated approach to support services that address the different needs of firms at different stages of maturity.

\section{Business linkages should be strengthened and harness global sources of knowledge}

While there is no doubt that firms have benefited from the excellent facilities and infrastructure available in the region, primarily technology parks and technology centres, there are doubts as to whether their "clustering" has fostered a more collaborative culture of learning and knowledge exchange. While in technology parks there is a relatively high level of collaboration with universities and government research centres, the degree of collaboration 
with other SMEs is much lower, with a much higher level of collaboration with firms in other parts of the region.

Besides, where high technology firms are concerned, the most successful innovators are usually plugged into more global knowledge pipelines and networks. The most dynamic firms are in this sense the ones that are able to capitalise on both the local support environment and to access non-local sources of information and knowledge about new development and processes in their markets. Here too, there are reasons for concern. The impression is that much of the activity on the technology parks is still embedded within regional and national firm and innovation networks. As a result, existing policy agendas seeking to internationationalise these activities by developing links with foreign companies and universities should be encouraged and extended.

\section{Cluster development strategies need to be refocused}

The regional focus on cluster is appropriate, although there is a degree of "overkill" in the number of sectors and initiatives that receive support at present. Around 25 clusters have been identified with the aim to create technology centres in each, a policy that seems over-ambitious and is likely to spread diminishing public resources too thinly. There is a discussion of 5-6 key strategic clusters that could become the focus of policy, including agro-food, biotechnology and health sciences, information technology, aeronautics, and renewable energy. This would be a welcome step. However, there is a sense of unrealistic expectations of providing "world class" innovators in fashionable high-tech sectors rather than building on existing regional strengths, some of which may lie in more traditional activities.

\section{A territorialised approach to SME international is to be favoured}

Evidence from regional clusters elsewhere suggests that many successful regions have a territorialised approach to internationalisation whereby SMEs are able to "piggyback" on the backs of larger customers into international markets. Existing policies that seek to strengthen the linkages between SMEs and local large companies, both locally- and foreign-owned, should be encouraged and developed further as part of broader cluster building strategies.

At the same time, given the paucity of internationally competitive firms, an over-emphasis upon internationalisation may run the risk of "running before you can walk" for many SMEs. Other policies which focus upon improving productivity, enhancing basic innovation processes (such as improving the quality and efficiency of production processes), and strengthening business linkages may be preferable for many more locally oriented SMEs. 


\section{RETA}

\section{RETA has played an important two-fold role}

RETA has played an important two-fold role in the Andalusian system of support to entrepreneurship and SME development. Firstly, it has coordinated and connected the policy support to entrepreneurship and SME development provided by all the actors of the Andalusian innovation system, including technology parks, technology centres and universities, and ensured that their support is coherent, meets needs on the ground and is accessed by local firms and entrepreneurs. Secondly, it has introduced a large number of traditional firms to innovation and R\&D activities thanks to a widespread network of agents signposting innovation programmes to firms outside of technology parks. This has enabled the regional government to broaden the scope and outreach of its innovation policies, "democratising" them beyond the small group of R\&Dintensive firms in the region. This socially cohesive approach to innovation and local development can be regarded, in itself, as a success.

\section{The future role of RETA needs streamlining}

In its first five years of existence RETA has carried out several functions. In addition to the two mentioned above, it has been tasked with the delivery of specific regional programmes. Its role in the future needs to be streamlined, and the forthcoming focus on innovative firms appears a wise choice. Thanks to its strong links with Andalusia's technology parks and technology centres, RETA will be able to cater for and offer adequate services to firms that have shown an innovative potential. The needs of traditional firms will be targeted by other organisations, and this will avoid some of the institutional overlaps that have characterised the entrepreneurship and SME support system in the past.

\section{The experience of RETA should be capitalised on}

The past work of RETA should be capitalised on for the future development of the region in at least three cases: (i) the innovation agents; (ii) the work of ICT literacy of SMEs; (iii) the survey of the innovative needs of local small firms. Firstly, RETA innovation agents have been instrumental in linking small firms to policy support for SME innovation and development. The innovation agent model should not be lost to the region, although there is scope for the numbers of agents to be reduced and for a stronger sectoral flavour to their work. Secondly, through the NOVAPYME programme, RETA has introduced small and peripheral firms to the use of simple ICT solutions (e.g. electronic signatures). This work could be followed up by ICT-specialised organisations that could assist small firms in introducing more complex solutions such as e-commerce. Thirdly, the survey of the innovative needs of small firms that RETA has undertaken could be matched with the available expertise in local 
universities and thereby serve as the basis for more effective industry-university relationships going beyond IPR-based interactions.

\section{Policy recommendations}

The analysis of the international review panel has led to the formulation of the following key policy recommendations to strengthen the entrepreneurship and SME development system of Andalusia.

\section{Box 0.1. Main policy recommendations}

\section{Human capital and labour market}

- Link training programmes more effectively with sectors in order to improve firm productivity and innovation, especially in the traditional sectors that are Andalusia's strengths.

- Work across the silos of business and employment agencies by connecting business incentives with job creation in strategic sectors.

- Refocus entrepreneurship education along the models of the best business schools, trying to attract immigrants and to exploit the advantage of Andalusia's geographical location.

- Train entrepreneurs for global e-commerce through, for instance, the development of a web localisation certificate programme.

\section{Contribution of research organisations}

- Build (RETA and OTRI) an integrated database of faculty research and consulting skills to match the existing survey of innovation needs of small firms.

- Establish co-operative education programmes engaging university students in alternating work terms with study terms throughout their undergraduate degrees.

- Stay abreast of recent developments in technology parks and consider moving the Andalusian model towards a format in which research occurs in "clouds" that virtually link together distributed and light research facilities. Consider the creation of virtual technology parks.

\section{Entrepreneurship and start-ups}

- Further develop entrepreneurial culture in the region, including by targeting the new unemployed through self-employment programmes. 


\section{Box 0.1. Main policy recommendations (continued)}

- Set-up a business incubation monitoring and evaluation system that assesses the performance of Andalusia incubators against EU current benchmarks.

- Think of promoting corporate spin-offs as an alternative to university spinoffs with stronger industry and market knowledge.

\section{SME development}

- Re-assess the competitive prospects of firms in technology parks, and try to further develop their linkages with both co-located firms and external smaller firms.

- Devolve technological advice to the sectoral level by, for instance, designing a new profile of innovation agent with more industry-specific knowledge. Align this measure with a more focused cluster development strategy.

- Address the lower-level innovation needs of SMEs through, for example, sector-based events on practical issues such as product development and marketing strategies. Involve in these events successful entrepreneurs, both from within the region and from outside.

- Apply a territorialised approach to business internationalisation whereby small firms internationalise their activities by "piggybacking" on the backs of large customers.

\section{RETA}

- Continue to co-ordinate policy actors in the Andalusian SME and entrepreneurship support system and ensure coherence in policy design and delivery. Ensure that best-practice policy principles are applied in local technology parks, including by strengthening the relationships of the latter with local universities.

- Focus work on firms with innovation potential, exploiting RETA's privileged relationships with local innovative SMEs and entrepreneurs and with technology parks and universities. Target these firms and entrepreneurs through both long-term R\&D and short-term problem-solving activities in innovation.

- Look increasingly at workforce development and skills upgrading as channels for the promotion of innovation in the region. This will include involvement in future co-operative education programmes and retention of talented foreign students from local universities in technology parks. 


\section{Introduction}

Regional economic development is increasingly regarded as critical to the growth of national economies in a globally connected environment. Spatial variations within countries suggest that not all geographical parts of a country achieve similar levels of employment, skills development, business formation, economic growth and infrastructure development. This is as true of Spain as it is of other economies round the world. Structural, spatial and temporal variations occur across regions because of differences in the human capital base, the industrial structure, relevant research and development capabilities, business formation, and the capacity of institutions to generate facilitative conditions for a productive and entrepreneurial economy.

\section{The local background}

Andalusia is the most populated Spanish region. Located in the South of Spain, it ranks in size somewhere between Portugal and Austria. In common with other Spanish regions Andalusia's emergence followed in part the pattern of industrial development (including foreign trade and investment flows) in Spain post-1959 and the Stabilisation Plan ending two decades of autarchy and its concomitant political and economic limitations. However, a major consequence of the industrial development together with the absence of any regional policy for a primary sector-oriented and relatively backward economy was the outflow of human capital to Spanish growth poles, especially to the North and North-east regions and to Madrid. Relatively low levels of investment in the region accompanied this exodus of 1.6 million people over 30 years between 1955 and 1985. Only positive economic outcomes in the agricultural, building and tourism sectors enabled the region's per capita income levels to rise from $67.8 \%$ to $73.2 \%$ of the national one in these three decades. Since that period, partly because of the impact of the volatility of the Spanish economy and of the global economic crisis which hit Spain disproportionately, the regional economy of Andalusia has faltered badly with sharp drops in both gross domestic product (GDP) and employment. 
Andalusia's European economic identity mirrored that of Spain just before the economic crisis as the nation began an impressive catch-up race with its more prosperous European counterparts. However, major structural differences could be found in the macroeconomic indicators with high levels of household, public sector, and total consumption expenditure. Real improvements in the living conditions as evinced in the gains in real disposable income were undermined by an excessive reliance on external debt financing (annual growth rate of $24.57 \%$ as against a rate of $9.59 \%$ for private deposits). Only the construction and services sector showed growth rates but they were far too low to obviate for the drop in other sectors.

It was in this climate of volatility that firm creation actually grew at a steady rate of $7.35 \%$ and from 1641 firms in 1980 to 12481 in 2009, offsetting only partially job losses and possibly accounting also for large numbers of self-employed workers in the construction and tourism industries. In part it also suggests a degree of buoyancy in the construction sector which enjoyed relative protection together with the services sector. Against a backdrop of high financial leverage and low private deposits coupled with relatively low levels of exposure to the dynamics of competition in other sectors it is difficult to see anything beyond a highly vulnerable and fragile economic environment for these firms. The rapid growth in the real estate component of Gross Capital Formation during 2000 to 2005 reinforces this notion of fragility as the collapse of those economies dependent on property price inflation has been the worst among others across Europe.

The reliance on the temporary growth areas of construction and tourism also point to a major problem in the labour market. Temporary, low skilled jobs cannot find shelter in the storms of recession. They do not also contribute to the creation of more sustainable, high-growth firms with their inevitable dependence on high skills levels. Andalusia's ability to innovate its way out of the recession and seek a different trajectory of innovative growth is hampered by these deficiencies. Moreover, in a climate of global change affecting local development in regions, firstly because of the immediacy of the crisis, and secondly due to emerging environmental, technological, and structural changes necessitating new forms of economic activity, there is a greater push for new types of skills, businesses and governance. These new developments depend on policies and actions that can induce change in the regions and help them to emerge as strong players in the global market place.

It is against this background of the Andalusian economy that a review on Entrepreneurship, SMEs and Local Development has been carried by the OECD Local Economic and Employment Development (LEED) Programme in partnership with the Andalusian Technology Network (Red de Espacios Tecnologicos de Andalucía - RETA). 


\section{Scope and approach of the review}

The review focuses attention on entrepreneurship, SMEs and local development. In examining these components of the regional economy and the extent to which entrepreneurship and SMEs contribute to innovation, the review aims to investigate the capacity of the region to support new firm formation, the sustainable growth of existing firms, and the policies necessary to create and foster this capacity in an innovation-friendly environment. To help achieve this aim, the main objectives of the review are to identify and explain:

- The challenges faced by new and small firms in terms of emergence and growth in a knowledge-based global economy with specific reference to human capital; its capacity for research and development; and soft infrastructure issues such as governance.

- The range of policies implemented in the region to support new firm creation and SME development;

- The gaps in current policies and how these gaps could be filled with appropriate references to good practice learning models implemented in other OECD countries;

- The current and future role of RETA in the local development framework.

A schematic representation of the conceptual framework underlying the review is shown in Figure 0.1. The three critical input factors in a region that impact on and influence new firm creation and innovative growth of SMEs are human capital, R\&D and institutional capability. Appropriate framework conditions ensure their availability and effective use. Both new and existing firms need to acquire or grow absorptive learning capacities to make best use of the factors individually and collectively in networks, which can then contribute to sustainable economic development. Four of the input factors together with their effect on SME development and entrepreneurship constitute individual chapters for this report, while the aspect of governance is mainstreamed in all four thematic chapters.

What follows in the rest of this introductory chapter is a summary of the key issues emanating from the review including those that address the critical input factors and how they blend together to make an effective contribution to the Andalusia economy.

\section{Human capital and the labour market}

It is now well recognised that the set of technical, cognitive, facilitative and operational skills competencies and knowledge, often referred to as "human capital" play a key role in the formation of a labour market and 
Figure 0.1. A diagram for reviewing the Andalusian economy

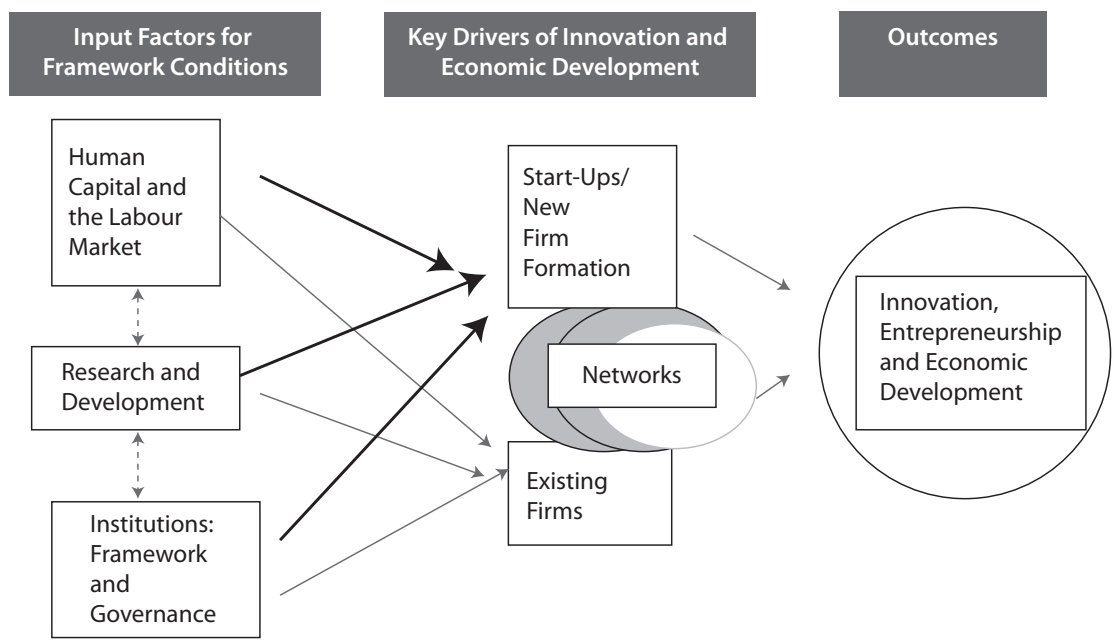

more generally in the development of an economy. This fact has acquired a particular poignancy in recent times in our so-called knowledge economy where "brain power" and the ensuing set of "knowledge-based" skills have gained a higher profile than the offering of traditional manual, semi-skilled and technically skilled labour.

The higher the level of human capital the greater is the return for both the firm (in terms of productivity) and the individual (in terms of higher wages). This simple equation is prevalent in most of the literature on the subject of human capital. The importance attached to education provision and educational attainment acquires a premium in relation to the economy. Its importance has gained momentum with the advent of the knowledge economy. The overall premium to higher education has increased sharply as the main drivers of these economies, the knowledge-based industries, demand higher levels of skills in the workforce with which to manage technological change productively. It is also argued that higher levels of human capital help to generate new, high impact firms and it is this group of firms that create new jobs and make a direct contribution to economic development (Acs, 2008)

More recently it has been noted that human capital also plays a key role in promoting or affecting new firm formation and the innovative growth of firms in a region. The formation of human capital in this context is a function of both formal skills development and experiential forms of learning by doing. The propensity of firms to be innovative through technological development is inevitably dependent on the skills levels of its employees and its owner-managers. A combination of the two forces (education and experience) 
might be more appropriate for encouraging adaptiveness to entrepreneurship. Experience also generates other intangible assets, such as social capital and networks vital to both the creation and growth of firms in regions dominated by a high concentration of firms. As more closely discussed in the thematic chapter on human capital, there are four labour market-related factors most critical to entrepreneurship in all its forms: (1) higher education; (2) extensive work experience; (3) interaction with a variety of actors in the regional innovation system; and (4) openness to immigration.

\section{Research organisations}

Research organisations include universities and private and public research institutes. The role of universities in producing cutting edge research and prospects of new technology development is now well recognised. The traditional notion of universities carrying out research activity first, with the private sector then commercialising the outcomes of the research as part of a linear process of knowledge and technology development, has given way to a more rounded approach which brings all stakeholders of knowledge creation and commercialisation together at all points in the process of making new goods and services and generating economic growth. Universities now engage in industrial innovation through a variety of channels, including learning by researching, learning by interacting and learning by doing, and not always at beginning in terms of early stage, blue-sky research activities.

\section{Institutions and governance}

Institutions play a key role in producing highly skilled and competent individuals through their universities and related institutions. Policies to attract the "creative" class (Florida, 2002) is another way of generating talent in the local economy. Attracting talent to a local economy is enabled by making an environment and the quality of local life conducive to entrepreneurial economic activity. The emphasis a region puts on any one of the two approaches is to some extent dependent on their capacity to pursue each approach, depending on local institutional capacity, the value of human capital, the structure of the local industry, national immigration policy, local framework conditions, and political or social constraints. This suggests a mix of national and local factors affecting a region's ability to adopt a specific approach.

\section{Entrepreneurship and SME development}

Entrepreneurship covers a huge territory of theory and practice concerned with opportunity identification and realisation, innovation in the form of new products and services, as well as new forms of organisation to 
realise opportunities, new firm formation to help organise innovation, and value creation for the economy and for society. Entrepreneurship is evident in both small and medium-sized enterprises (SMEs), as well as large ones, in the formal and informal economy; in legal and illegal activities, in innovative and traditional firms; in high and low-risk ventures, and in pretty much all sectors and sub-sectors of the economy (OECD, 2001). This spectrum of involvement can lead to both productive and unproductive or even destructive entrepreneurship (Baumol, 2006).

Entrepreneurship is local in the sense that new firms are formed in specific locations. It is national and global in that new firms make new products and services in these markets and often source technologies and other resources from across a country and sometimes globally. The ability of regions to create new firms in their territories is an attractive option for sustainable economic development because it uses local resources and talent to make it happen, thereby energising local economic activity. Increasingly even economically less prosperous regions such as Andalusia are being exhorted to court entrepreneurship as part of an effective economic development strategy. According to the revised Lisbon Strategy, this is possible through a focus on making a place attractive for living and working, facilitating or increasing knowledge flows in the region through human capital development, $R \& D$, innovation and new business creation, and generating policies that enable better forms of sustainable job creation.

\section{Methodology}

This report provides advice from an international perspective on how to strengthen SME and entrepreneurship policies in Andalusia. It identifies the major considerations for policy development in this field, assesses the current performance of Andalusia, and advances recommendations to improve policies and programmes in the region. Each chapter also describes 'learning model' programmes from other countries with the aim of helping to illustrate how other places have addressed similar challenges.

The four main themes that have been reviewed refer to the conceptual framework outlined above and are: (i) human capital and labour market issues affecting entrepreneurship and SME development; (ii) the contribution of research organisations to entrepreneurship and SME development; (iii) policies for entrepreneurship and start ups; and (iv) policies for SME development. The governance aspect is embedded in each of the four thematic chapters. The report is based on observations, discussions and recommendations collected through an OECD peer review process which took place in April 2010, as well as on the desk analysis of relevant documents 
(reports, strategies, academic papers, etc.). The key steps of the methodology are briefly described below:

\section{Local diagnostic report}

A diagnostic report was prepared by a local expert (Prof. Granados, University of Malaga) to provide an initial analysis of the key facts about the Andalusia economic system and the entrepreneurship and SME policy context. This report has contributed to chapter 1, outlining the main economic and institutional aspects of Andalusia.

\section{Review panel visit}

The OECD Secretariat led an international panel of experts in a oneweek peer review visit in Andalusia from 12 to 16 April 2010. During the study visit, the expert team interviewed regional policy makers and other relevant actors in the entrepreneurship and SME development system, and obtained their views on issues to entrepreneurship and SME development. A wide range of issues were discussed with stakeholders, providing a variety of perspectives on the region and its policies.

\section{Draft report}

A draft report was prepared, drawing on the results of the diagnostic report, the panel review exercise, and additional literature and material about the Andalusia economy. The draft report was submitted for comments and approval to the local partner, the Andalusia Technology Network (RETA).

\section{Final report}

This final report incorporates the comments and feedbacks received on early drafts and it is structured as follows: chapter 1 provides an economic and institutional overview of Andalusia that helps the reader contextualise the following thematic chapters. Chapters 2-5 focus on the key thematic areas of analysis: (i) human capital and the labour market; (ii) contribution of research organisations; (iii) entrepreneurship and new start ups; (iv) SME development. Each thematic chapter contains a description of general policy issues; an assessment of the current situation in Andalusia; a set of policy recommendations; international 'learning model' programmes addressing the policy recommendations. A final chapter summarises main conclusions and policy messages on entrepreneurship promotion and SME development for the region of Andalusia. 


\section{References}

Acs Z., 2008, "Foundations of High Impact Entrepreneurship", Jena Economics Research Papers, n. 2008-60.

Baumol W., "Entrepreneurship: Productive, Unproductive, and Destructive", Journal of Political Economy, n. 98, pp. 893-921.

Florida R., 2002, The Rise of the Creative Class, Basic Books, New York. OECD, 2001, Fostering Entrepreneurship, OECD, Paris. 


\section{Chapter 1}

\section{Economic and institutional overview of Andalusia}

\section{Table 1.1. Andalusia: key statistics}

\begin{tabular}{lcc}
\hline Indicators & Spain & Andalusia \\
\hline Population (million) (2008) & 47.2 & 8.4 \\
GDP per capita (EUR current prices) (2008) & 23457 & 18150 \\
Population density per squared km (2008) & 89 & 92 \\
R\&D expenditure as a \% of GDP (2007) & 1.3 & 1 \\
Private R\&D as a \% of GDP (2007) & 0.7 & 0.4 \\
Govt. R\&D as a \% of GDP (2007) & 0.2 & 0.2 \\
University R\&D as a \% of GDP (2007) & 0.3 & 0.4 \\
Secondary education as \% of labour force (2008) & 20.7 & 16.8 \\
Tertiary education as \% of labour force (2008) & 29.8 & 24.9 \\
High-tech manufacturing as a \% of employment (2008) & 4.8 & 2 \\
Knowledge-intensive services as \% of employment (2008) & 28.9 & 26.9 \\
Active population (thousands) (2008) & 31143 & 5562 \\
Labour market participation rate (2008) & 73.4 & 68.9 \\
Employment rate (2008) & 65.1 & 56.6 \\
Unemployment rate (2008) & 11.3 & 17.8 \\
Youth unemployment rate (2007) & 18.1 & 23.3 \\
\hline
\end{tabular}

Source: OECD Regional Database.

\section{The socioeconomic context}

Andalusia is the southernmost region of peninsular Spain and has traditionally lagged behind the rest of the country by most economic variables. Table 1.1 shows that Andalusia's GDP per capita is only $77 \%$ of the national one and 
generally depicts a scenario of lower than average performance in R\&D and innovation, education, and employment. Nevertheless, thanks also to generous support from the EU Structural Funds, the performance of Andalusia in most of these indicators has been improving over the last decade; the 2008 crisis has imposed a halt to such general improvement in economic conditions.

\section{People and human capital}

Andalusia is the most populated region of Spain with 8.4 million of inhabitants, corresponding to $17.8 \%$ of the overall national population. What was traditionally a region of outmigration -1.6 million Andalusians migrated between 1955 and 1985 - has recently become a region of immigration of mainly low-skilled workers. This has come to reinforce labour intensive sectors such as tourism, construction, and partly agriculture. Figure 1.1 illustrates population growth during the last eleven years, and shows how the immigration process has mainly interested the coastal areas (darker in the map).

Figure 1.1. Population growth in Andalusia, 1998-2009

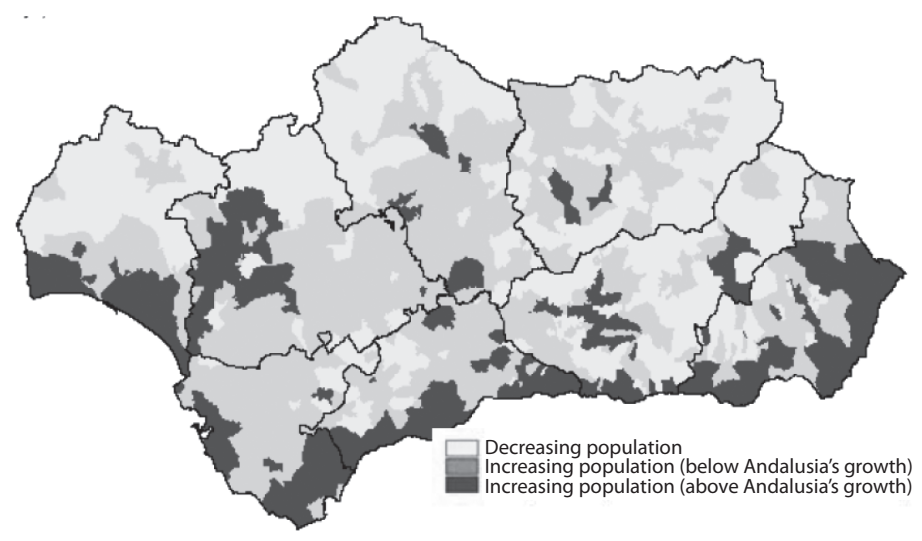

Source: Andalusia's Institute of Statistics (IEA).

The level of education of Andalusia's population has converged towards the national average in the long term but differences still exist, and the last decade has seen a decrease in the number of people with post-compulsory education out of the total population. This is in part the result of the influx of low-skilled migrant workers, but also a consequence of the growth of low added-value sectors that do not require high-level qualifications. In particular, the share of university graduates has shrunk significantly by 3 percentage points, from $14.7 \%$ in 1998 to $11.7 \%$ in 2009 , whereas vocational training has followed an opposite trend (from $4.1 \%$ in 1998 to $5 \%$ in 2009). The percentage of students 
leaving education with the lowest compulsory degree is also among the highest in the country (38\%). This might be an indicator that that Andalusia has not yet fully undertaken its transition to a knowledge-based economy.

\section{Labour utilisation and labour productivity}

The recent economic crisis has struck Spain severely, and Andalusia has been no exception. Whilst between 1997 and 2007 regional employment had increased at an annual rate of $6.6 \%$, higher by $2 \%$ than the national average, since 2008 the labour market situation has strongly deteriorated, with unemployment rising from $11 \%$ to $27.2 \%$ in early $2010(+16.2 \%)$ compared to $+12.7 \%$ for Spain as a whole. The rapid soaring of unemployment has been the result of the industrial and labour market structures of the region. On the one hand construction, which had been one of the main sectors driving the economy in the booming period, has also been one of those hit hardest by the recession, shedding in Andalusia a far higher number of jobs than at the national level. ${ }^{1}$ On the other hand, nearly half of new employment contracts over the last decade had been of fixed-term nature, many of which have been discontinued once the crisis has reached Andalusia. Arguably, large regional unemployment also conceals a remarkable share of labour informality, which negatively impacts on labour productivity. Andalusia is ranked $14^{\text {th }}$ amongst the 17 Spanish regions (i.e. Autonomous Communities) with regard to labour productivity. This is the outcome of the local industry structure but also of low levels of formal tertiary education (see Table 1.1). Low labour productivity has also a dent on regional GDP per capita, which we have seen being much lower than the national value. According to estimates by Reig (2010), differences in labour productivity accounted for $83 \%$ of spatial variation in GDP per capita in Spain.

\section{Business demography and industrial structure}

Until the outbreak of the crisis, between 2005 and 2008, Andalusia had experienced a remarkable $10.6 \%$ growth in the number of registered businesses, with finance/insurance $(+33 \%)$ and construction $(+22 \%)$ standing out as the most dynamic sectors. The crisis has however slowed down this process. In 2009 the region had already lost $4.6 \%$ of its firms as compared to the previous year, most of which of micro or small size (10 000 altogether). Today, Andalusia's economy has approximately 510000 firms, corresponding to $15.9 \%$ of the national total against a population that is $17.8 \%$ of the total. Micro firms (less than 10 employees) dominate the economy, representing over $90 \%$ of the total. This is typical of peripheral economies which generally find it difficult to penetrate international markets. Indeed only $1.4 \%$ of regional firms are engaged in foreign trade, as against $4.6 \%$ nationally and $11 \%$ in Catalonia, Spain's best performing region as to foreign trade. With regard to the industrial structure, until the 1970s agriculture was still playing an important role in the Andalusian economy, but its contribution to regional Gross Value Added (GVA) has much diminished over 
Figure 1.2. Andalusia's foreign trade and trade balance (1990-2008) (in thousands of euros)

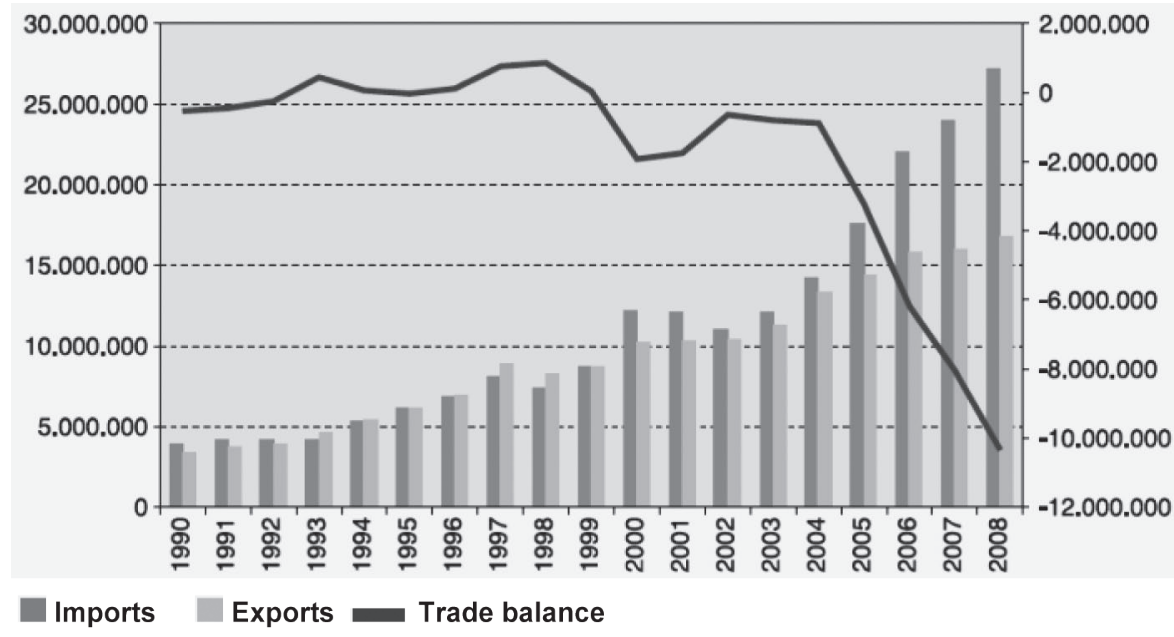

Source: ESECA, 2009.

Figure 1.3. Andalusia's GVA trends by sector, 2001-2009

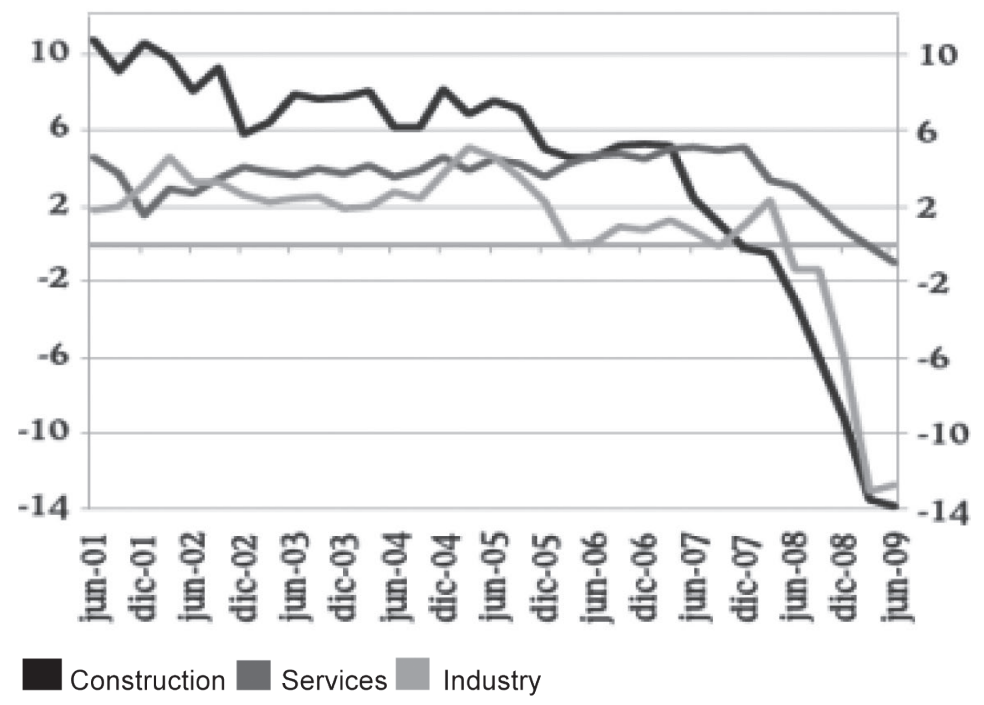

Source: Banco Bilbao Vizcaya Argentaria (BBVA), 2009. 
the last twenty years. Nowadays Andalusia's industry structure resembles much more closely that of any modern economy, though the very low contribution of manufacturing (11\%) and the disproportionate impact of services (71\%) on regional GVA flag an imbalance that can undermine the competitiveness of the region due to lower capital investments and lower internationalisation that are both typical of economies overly reliant on services.

\section{Key sectors}

Since the 1980s the regional government of Andalusia has bolstered the development of sectors considered strategic for the future development of the region. Originally, the emphasis was on traditional low added-value sectors such as marble quarrying, leather, and agro-food industries, while more recently the focus has also shifted to knowledge-intensive industries.

At present the regional government is mainly geared towards the promotion of the sectors listed below. Whilst some are new to the regional economic landscape, others build on competencies already existing at the local level. A strategy based on economic diversification through the principle of "related variety" should enhance the likelihood for the region to succeed at the national and international levels.

\section{Aeronautics}

Andalusia is the second biggest manufacturer at the national level and in the top positions of the EU-wide ranking. Approximately 130 firms comprise the sector, which specialises in mechanical activities, engineering and consulting services. EADS-CASA and Airbus are the main actors in the cluster. The sector employs nearly 9000 people and has an annual turnover of almost EUR 1541 million.

\section{Biotechnologies}

Andalusia is placed second in Spain by number of biotechnology-devoted companies, contributing to $19 \%$ of the sector at the national level. The "biotech" sector includes more than 100 companies, which generate 2800 jobs and a turnover above EUR 586 million. At the university level, there are 270 research groups that specialise in biomedicine, 170 in life sciences and 120 in agrobiotechnologies. The regional government supports biotech-oriented activities at both the university and industry levels, with a view to nurturing the emergence of a strong and internationally competitive local biotech clusters. The Granada technology park focusing on health sciences is an example of this strategy. 


\section{Renewable energies}

Andalusia is the leading region of Spain in photovoltaic installations and biomass production, as well as one of the pioneers in the country to install windmills. Favourable weather conditions and possible linkages with the agro-food industry give Andalusia a competitive advantage in many areas of renewable energies. The latter have therefore an important role to play for the future economic development of the region.

\section{IT \& communications}

Nearly 1400 companies comprise this sector, with a turnover of EUR 4.6 million and a workforce of 34000 people in 2007 prior to the crisis. Telecommunications is the biggest subsector, whereas the most innovative trends are in the areas of nano-electronics and domotics.

\section{Food industry}

The food industry has traditionally been one of the linchpins of the Andalusia economy. Over 5000 firms make up the sector, which generates more than 52000 jobs and accounts for $22 \%$ of value added in manufacturing. The support infrastructure deployed by the Region is remarkable, with a number of technology centres backing the development of the sector through $\mathrm{R} \& \mathrm{D}$ projects and consulting activities aimed at the improvement of products and processes (e.g. aquaculture centre in Cadiz, meat-processing technology centre in Huelva, etc.).

\section{Metalworking and mechanics}

Here, 9000 companies generate 75000 jobs and make up 40\% of the national production. Defence is an important subsector, with a turnover of more than EUR 1500 million and over 11000 workers employed.

\section{The R\&D system}

Andalusia underperforms Spain as whole in most R\&D-related indicators. Whilst innovation goes beyond R\&D investment, poor progress in this field jeopardises the future development of the region. Trends in R\&D expenditure (Figure 1.4) show that over the last twenty years Andalusia has not converged to the national average. Despite clear progress, Andalusia's R\&D spending reached the $1 \%$ threshold of GDP only very recently in 2008 and continues to represent a modest $11.2 \%$ of Spain's R\&D expenditure, far below its potential both in terms of production (13.5\% of the national one) and population (17.8\% of the national one). The break-down of R\&D expenditure by sector (Figure 1.5) additionally points out how universities and higher education institutions (HEIs) have traditionally been the main sources of 
Figure 1.4. R\&D expenditure as a percentage of GDP, 1987-2008

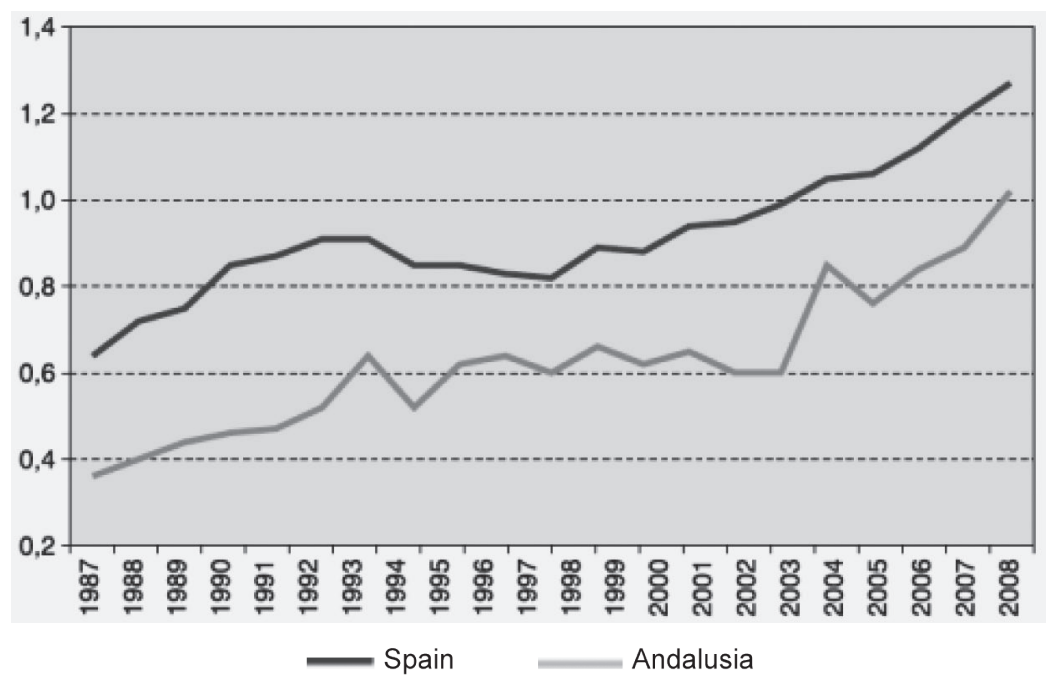

Source: National Institute of Statistics (INE).

Figure 1.5. R\&D expenditure by sector in thousands of euros (1987-2008)

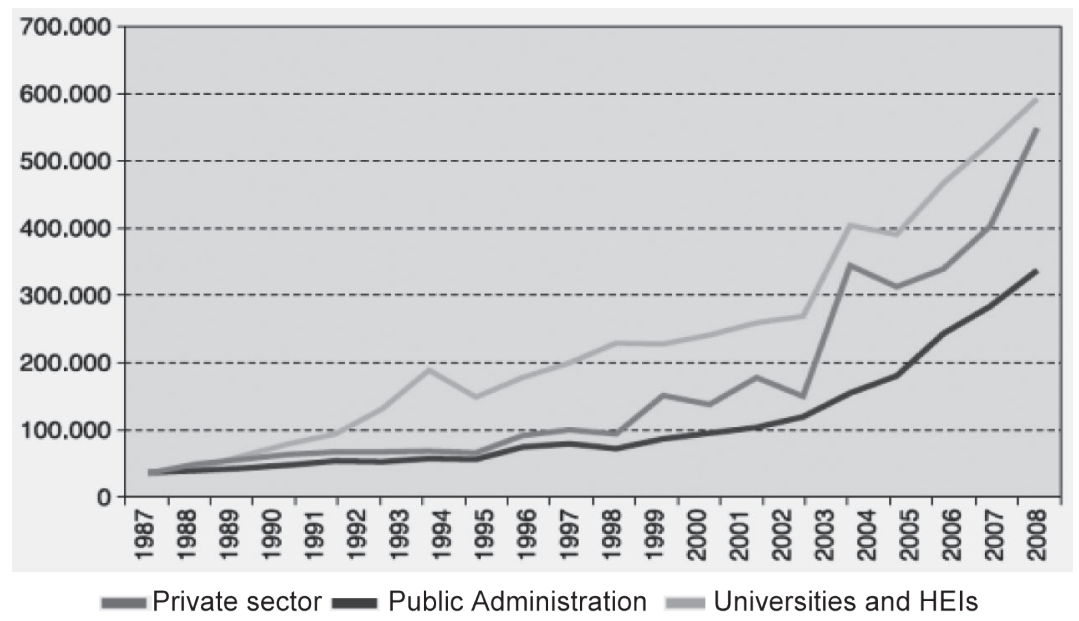

Source: National Institute of Statistics (INE). 
R\&D spending, whilst the private sector lags behind despite experiencing an upsurge since 2002 thanks to policy efforts to increase business enterprise R\&D (BERD). Finally, the number of R\&D personnel is below the Spanish average ( 7 vs. 10 per thousand people), and this also leads to a very low number of patents, merely $7.5 \%$ of the national total.

On the whole, the Andalusia R\&D system has made strides in the last twenty years, but it has failed to achieve full national convergence. In particular, private investments in R\&D are still too low and marginal $(0.38 \%$ of regional GDP, compared to $0.71 \%$ nationally), and this is possibly the result of the business and industrial structures of the region. Small-sized firms are likely not to pursue long-term R\&D strategies because of limited internal competencies, lack of time, poor management resources, and restricted budget. In addition, the sectors that have driven the Andalusian economy over the last decades - mainly construction and tourism - are not known for being R\&D-intensive and rather employ a low-skilled workforce. It does not come as a surprise, therefore, that the regional government has emphasised R\&D penetration in firms, including of small size, as one of the linchpins of its development strategy.

\section{Industry-university relationships}

With its nine public universities, 17000 teaching and research staff and 250000 students, higher education institutions (HEIs) take the lion's share in the R\&D system (Figure 1.4). Universities account for $45 \%$ of R\&D expenditure, and $61 \%$ of researchers in the region are employed by the HEI system. Hence, universities have the key role of trickling down the R\&D benefits to the private sector in the development strategy of the region.

A recent research project by the Institute for Advanced Social Studies (IESA) of the Spanish Council of Scientific Research (CSIC) has taken to investigate the existing relationships between the regional university systems and local firms. As part of this project, a survey of over 700 Andalusian firms that had received some form of innovation support concluded that more than half of the sample did not engage in any type of collaboration with universities, while slightly above $40 \%$ entertained some forms of collaboration. Among these, the most common was the training of university personnel inside the firm (27.5\%), which was also the outcome of a regional policy boosting the training of postgraduates in businesses. Consultancies, joint research projects and university training programmes for employees were also relatively common, involving between $15 \%-25 \%$ of the surveyed enterprises. Between 5\%-15\% of the firms contracted R\&D projects, use university facilities or exchanged staff, whilst only less than $5 \%$ licensed patents or undertook joint start-ups with university staff (Fernandez-Esquinas et al., 2008). 
Three main conclusions can be entailed from these results. Firstly, a large number, indeed the majority of innovation-oriented firms - i.e. firms that had received some public support to introduce innovations in their products or operations - do not keep active relationships with public research organisations (PROs). Secondly, informal and non R\&D-intensive types of collaboration are the norm rather than the exception among those firms that engage with PROs. Thirdly, the formal exploitation of intellectual property rights only involves a very small minority of firms, even when the most innovative and R\&Dintensive firms of the region are taken into consideration. Such a scenario clearly points to the need for an encompassing approach to innovation policy that goes beyond mere R\&D support, and that seeks to enhance the absorptive capacity of local firms to increase the number of firms able to interact with universities.

Other investigations show that Andalusia firms are largely oriented towards process rather than product innovation, and that the main barriers to innovation are perceived to be the cost of innovation but also a mere lack of interest on the part of business owners (INE, 2008). Difficult access to credit and an undeveloped equity market further complicate the road to increased business innovation.

\section{The regional institutional and policy framework}

\section{Regional institutions}

Spanish regions have generally strong devolved powers and Andalusia, being a historic Autonomous Community, enjoys a statute of autonomy with strong competences. The regional government - i.e. la Junta de Andalucia consists of 13 ministries, the most relevant for the scope of this study being the Ministry of Economy, Innovation and Science (MEIS). This is the result of the recent merger between the Ministry of Economy and the Ministry of Innovation, Science and Enterprise (MISE). This decision signals the decision of the regional government to better coordinate its economic policies as well as the importance given to business innovation and entrepreneurship as the main drivers of local development.

Within the remit of the MEIS, and more specifically of the Department of Science and Innovation, fall some of the main regional organisations committed to the promotion of economic development, among which the regional development agency IDEA, the trade promotion agency EXTENDA, the entrepreneurship agency ANDALUCIA EMPRENDE, the R\&D-oriented CTA (Corporación Tecnológica de Andalucía) and RETA (Red de Espacios Tecnologicos de Andalucia), which was given by the regional government an important function of coordination and governance of the entrepreneurship and innovation system. Box 1.1 provides a glimpse of the main activities of these organisations. 


\section{Box 1.1. Key functions of main Andalusian development agencies}

IDEA: Being the official RDA of Andalusia, IDEA has quite a large mandate that encompasses: promotion of business clusters in strategic sectors for the region; attraction of domestic and international investments; support of business innovation and enterprise development; protection of regional intellectual property through advice on IPRs; improvement of productive land and infrastructure; assistance to large firms undergoing industrial restructuring; enhancement of high-growth companies through direct aid and an enabling framework. In addition to this wide spectrum of competences, IDEA also keeps a direct stake in some large companies in strategic sectors for Andalusia (e.g. ICT and aeronautics). By doing so, it becomes an instrument of MEIS to implement its sector-based strategies.

EXTENDA: Through its network of 21 promotion offices in 19 countries, it provides information, consulting, training and funding for business internationalisation. Funding can cover both "structural" costs (personnel, rentals, equipment, etc.) and "promotional" costs (dissemination, advertising, participation in fairs, etc.). The agency equally supports small firms that approach international markets for the first time and consolidated businesses with an established international presence. The main objectives are to improve export performance - by increasing both the number of exporting companies and the total value of exports - and attraction of FDI. The agency focuses on four main sectors (agro-food, consumer goods, industrial goods, and services), which enclose several subsectors.

ANDALUCIA EMPRENDE: The mission of this foundation is to fuel the entrepreneurial culture of the region. Through its extended network of 200 business development centres, the foundation backs up the creation, consolidation, and modernisation of Andalusian small firms. Business services include training, business plan assessment, incubation, and sourcing funding. The Foundation keeps quite a targeted approach, unfolding entrepreneurship programmes aimed at specific social groups (e.g. women, youth, university graduates, disadvantaged people, etc.), emerging and strategic industries (e.g. technology-based firms, creative industries, aeronautics, green technologies, etc.), and the social economy sector. EMPRENDE also maintains a network of 37 Corporate Development Support Centres (CADEs) providing a decentralised BDS support across the region.

CORPORACION TECNOLOGICA (CTA): This is a private foundation sponsored by the regional government with the aim to boost collaboration between $\mathrm{R} \& \mathrm{D}$-intensive companies and the university research groups. CTA provides resources and advice for the identification and generation of industry-university cooperation projects. Projects backed by CTA are integrated into the PAIDI (see below).

RETA: This is a non-profit association established in 2005 with a twofold mission: (i) improving the governance and coordination of the overall regional innovation system, especially technology parks, technology centres, and business and innovation centres; (ii) providing traditional small companies in industrial estates and peripheral/rural areas with similar technology development opportunities of those provided within technology parks. The first objective implies that RETA itself is a networked agency, having 67 associated members that 


\section{Box 1.1. Key functions of main Andalusian development agencies (cont.)}

include science and technology parks, technology centres, business centres, etc. The second objective has led to the emergence of a network of 85 "innovation agents" linked to industrial estates, technology parks, technology centres or rural areas. This network has been in place until mid-2010 and its main role has been to help traditional firms first approach innovative activities by signposting available public support programmes and by delivering public schemes such as NOVAPYME (i.e. ICT access for small firms), EVA (i.e. online business management training), and small-scale innovation vouchers.

\section{Technology parks, technology centres, and business innovation centres}

These three different institutions are important players in the entrepreneurship and innovation system of Andalusia. Technology parks have a longstanding tradition in the region that dates back to the early 1990s. The first to be established was in 1991 the Andalusian Technology Park (PTA) of Malaga, which is today also the largest of Andalusia's technology parks with over 500 firms employing nearly 14000 people. The second largest is Cartuja-93, which is based in Seville and hosts approximately 350 firms. Both PTAMalaga and Cartuja-93 are "generalist" parks in the sense they do not have an industry-focus, whereas others in the region are rather sector-oriented (e.g. Seville's Aerópolis specialised in the aeronautics industry or Granada's based on health sciences). Technology parks also host business incubators, which only accept firms that are innovative, environmental friendly, and in the case of firms in traditional sectors are willing to collaborate with universities for at least two years. Today there are 11 science and technology parks in the region, with a contribution to GDP estimated at $3.67 \%$.

Whilst not all technology parks are sector-based, the 21 technology centres are generally linked to an industry that is relevant in the region, and are located in a place where this industry is consolidated. Technology centres are therefore a pillar of regional cluster development. They work both in advanced areas such as biotechnologies and in traditional sectors such as marble quarrying. Despite their name, they provide a wide range of business development services that go beyond mere technology development.

Business innovation centres (BICs) were also set up in the early 1990s through a European Community Commission initiative, to support innovation in existing SMEs and the creation of new innovative firms. They provide partly subsidised and partly fee-based services, which include business consulting, training, and business incubation. As part of a network, Andalusia's BICs collaborate with similar entities in other EU countries. 


\section{Regional economic development policies}

Andalusian economic development policies have evolved over the last 30 years, trying to adjust to what were perceived as the most urging needs from time to time. In the 1980s the emphasis was on the restructuring of labourintensive sectors such as shipbuilding, chemicals, metalworking, etc., mainly with a view to preserving jobs and improving the competitiveness of large companies. In the 1990s, further importance was given to promoting local business competitiveness and addressing regional disparities. Finally, in the current decade, the 2000 EU Lisbon Agenda has ushered Andalusia to the whole new theme of entrepreneurship and innovation, and the 2003 Second Modernisation Plan for Andalusia acknowledged this by stressing start-ups, ICT access, and business innovation as the new objectives of regional development policies.

The regional government has produced a number of strategic documents that set objectives and roles in the area of economic development. The four most relevant to entrepreneurship and SME development are those listed below which, with the exception of PIMA (2005-2010), cover the period of EU structural funds 2007-2013.

- The Plan for Competitiveness. With a budget of EUR 55 billion, this document sets out the main areas of public spending on economic development. The allocation of funding is as follows: (i) human capital enhancement: $21.2 \%$; (ii) accessibility and energy balance: $15.8 \%$; (iii) local and urban sustainable development: 14.1\%; (iv) environment, rural development, water sources and land risk prevention: $12.4 \%$; (v) food and fisheries: $10.6 \%$; (vi) social cohesion: $10.6 \%$; (vii) knowledge society: $8.9 \%$, (viii) business development and enterprise innovation: $6.3 \%$. Based on these figures, the regional government directly devotes EUR 3.5 billion to entrepreneurship and SME development over six years, with other complementary areas such as "knowledge society" and "human capital" that also benefit local firms.

- The Innovation and Modernisation Plan for Andalusia (PIMA): The mission of PIMA is to create the conditions to make Andalusia more innovative and thereby reduce the welfare gap with the most competitive economies. It establishes the framework for the region's research and innovation agenda and encourages universities to cooperate more intensively with the private sector. The objectives of stronger industry-university knowledge transfer and of more research-based spinoffs are made explicit, especially in sectors considered strategic for the region. The overall budget for the implementation of PIMA is approximately EUR 5.7 billion, of which 2.7 (or nearly half) is designated for the support of knowledge-based industries and universities. 
- The Andalusian Plan for Research, Development and Innovation (PAIDI). Adopted in 2007, it provides an overview of innovation and SME development activities for the period 2007-2013. Being closely interwoven with PIMA the objectives are the same: i.e. reinforcing industry-university collaboration as one of the key elements for the development of the region. Interestingly, PAIDI sets out the role and functions of the key actors of the Andalusia entrepreneurship and innovation system, which are garnered in four categories: (i) technology and knowledge spaces (e.g. technology parks); (ii) knowledge generation organisations (i.e. universities, research centres, private R\&D labs, etc.); (iii) knowledge transfer institutions (i.e. technology centres); (iv) coordinating and managing organisations (e.g. IDEA, RETA, CTA, etc.). Finally, PAIDI also singles out the main priority research areas for the region, which include: aeronautics, biotechnologies and bio-engineering, health sciences, ICT, nanotechnologies and advanced materials, and tourism.

- The Economic and Entrepreneurial Enhancement Plan. The longterm objectives of this plan are the modernisation and competitiveness of the regional economy. However, the emphasis is here on entrepreneurship, including reduced barriers to business creation (administrative burdens, start-up finance, etc.), technology-intensive firms, business survival, and the internationalisation of local companies.

Figure 1.6 takes a snapshot of the regional innovation system of Andalusia.

Figure 1.6. The Andalusia Innovation System

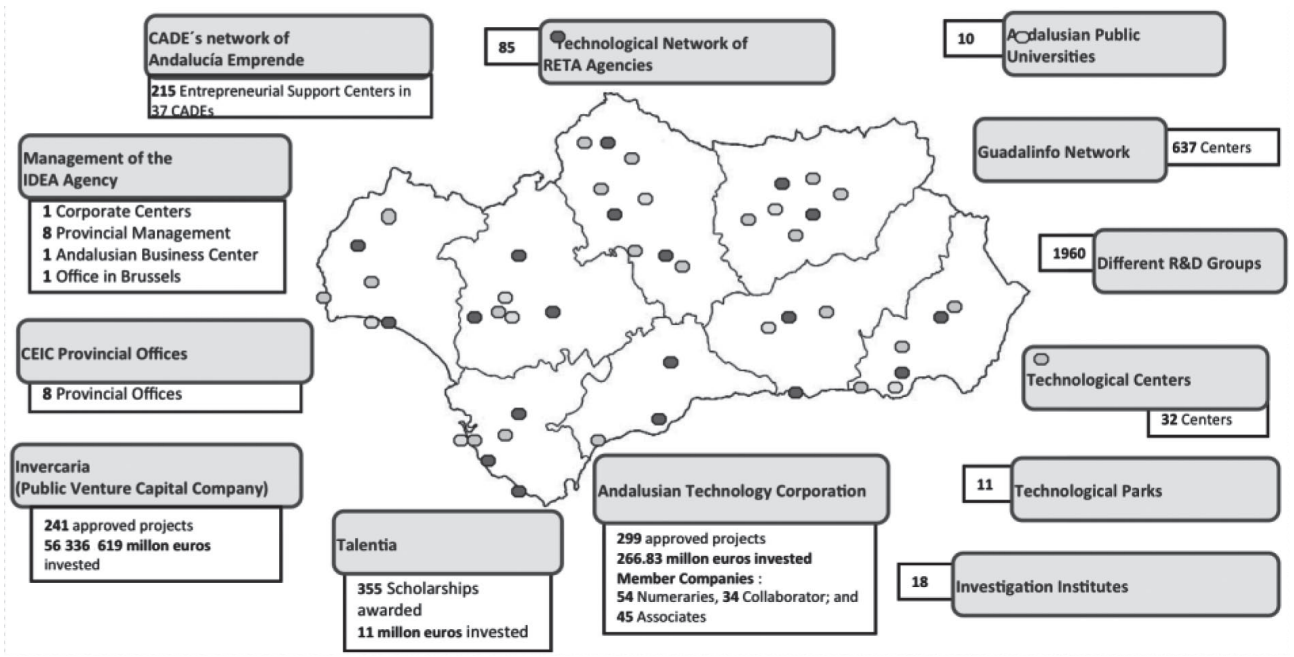

Source: Consejería de Economía, Innovacíon y Ciencia. 


\section{Note}

1. Employment in the Andalusia construction sector decreased in 2008 on annual basis by $13.6 \%$, as against $9 \%$ at the national level.

\section{References}

Banco Bilbao Vizcaya Argentaria (2009), Situación Andalucía, www.bbva.es

Fernández-Esquinas M., I. Ramos-Vielba, M. Jiménez-Buedo, and E. Espinosade-los-Monteros (2008), Unfolding the Complexity of Interactions between Industry and University, CSIC-IESA paper, Madrid.

ESECA (2009), Informe Económico Financiero de Andalucía, Granada.

Instituto Nacional de Estadística (INE) (2008), Encuesta sobre Recursos Humanos en Ciencia y Tecnología: 2006, Madrid.

Reig E., (2010), The Competitiveness of the Spanish Regions, in J. R. Cuadraro (ed.), "Regional Policy, Economic Growth and Convergence", Springer, Heidelberg. 


\section{Chapter 2}

\section{Human capital and the labour market}

\section{Introduction}

Human capital development and labour market dynamics play a key role in a knowledge-based global economy. Yet, one of the greatest challenges in regional economic development is developing a coherent set of policies and programmes that link a region's complex educational and training system effectively with its driving economic sectors.

This chapter describes the state-of-the-art in academic research on human capital, with a particular focus on the labour market characteristics of successful regional innovation systems. It then outlines the complex landscape of education and training, and entrepreneurship training specifically, in Andalusia. Though the system is hampered by many redundancies in training programmes, it also is experiencing gaps among different types of institutions, and most importantly, between these institutions and Andalusia's strategic sectors. After describing the array of challenges and opportunities the region confronts, the chapter concludes with recommendations illustrated by three international learning models.

\section{Policy issues}

A rich literature debates the role of human capital formation and labour market dynamics in fostering entrepreneurship and innovation. The following sections examine these debates, with particular focus on the role of education and labour policy in regional innovation. We first examine debates about human capital generally, then turning to the debates about labour market preparation for entrepreneurship. A final section describes the Spanish context. 


\section{Role of human capital in the knowledge economy: Debates in the literature}

Higher levels of human capital create returns not only in terms of worker productivity but also of higher wages (Becker, 1965). With the advent of the knowledge economy, the overall premium to higher education has increased sharply (Carnoy, 1994). Knowledge-intensive industries are now the key drivers of international competitiveness, and the growth of these industries has fundamentally altered the labour market (Aoyama \& Castells, 2002). In this new informational mode of development "the source of productivity lies in the technology of knowledge generation, information processing, and symbol communication" (Castells, 1996).

Technological change is skill-biased, in that it privileges occupations relying on technical expertise, resulting in rising demand for college-educated workers relative to their supply (Katz \& Murphy, 2002). Because this explanation follows a neoclassical model of market clearance, wages are bid up for those workers who possess high levels of human capital while, due to falling demand, wages fall or stagnate for less educated workers. Yet, institutions also play a role: national policies and international bodies regulate trade flows and structure the relationships between trading partners, constraining the role of technological change (Osterman, 1999).

One path to competing in the global knowledge economy is through using local universities to develop a high-skilled workforce to serve local firms and attract new ones. Another is to attract an elite workforce (the creative class) to the cities and regions in which they choose to live based on their own preferences for a certain quality of life (Florida, 2002; Glaeser \& Resseger, 2009). Regions differ in their capacity to pursue each approach, depending on local institutional capacity, national immigration policy, political constraints, and so forth. In general, the evidence from the study visit is that Andalusia has emphasised the role of universities rather than local quality of life.

\section{Role of human capital in entrepreneurship and innovation}

Although research has long confirmed the importance of human capital to business productivity, less is known about the role of human capital in fostering entrepreneurship. From the few studies that exist, it is clear that successful entrepreneurship stems from a relatively broad conception of human capital as not just education and training, but also skills developed through experience and understanding that comes with age, all interacting with what might be called innate potential.

Higher education is of course critical for R\&D and technological creativity, and may also contribute to the longevity of start-up firms, especially those outside of skilled service sectors (Bates 1990, 1995; Cuadrado-Roura 
\& Garcia-Tabuenca, 2009). The technical qualifications of employees (among other factors) even affect a company's attitude toward innovation (Coronado, Acosta, \& Fernández 2008). Not surprisingly, then, investment by firms in their employees" human capital has been shown to encourage innovation and entrepreneurship (Sevilier, 2006).

Human capital that combines education and experience gives employees the adaptiveness so key to entrepreneurship (Wright, Hmieleski, Siegel and Ensley, 2007). The more prior business ownership experience an entrepreneur brings, the more likely the new ventures will be initiated and expanded. Team experience is particularly important to the long-term performance of high-tech start-ups (Madsen, Neergaard and Ulhøi, 2003; Shrader and Siegel, 2007).

Work experience is important to innovation in part because a long career path brings broader social networks and effectiveness in building new ties (Mosey \& Wright 2007). Firms that interact with a greater variety of actors and across diverse institutional environments, are more likely to innovate, particularly via informal relationships: "contacts that occur in different kinds of events are the breeding ground for future interchanges" (Ramos-Vielba, Fernández-Esquinas, and Espinosa-de-los-Monteros, 2009, p. 663).

Such interaction turns out to be far more important than collaboration with universities, particularly for regions dominated by low-tech businesses. A recent example of this is innovation in California's clean energy economy, in which the most innovative firms interact more with nonprofits, local governments, other local businesses, local trade associations, and local chambers of commerce than with universities (Chapple and Hutson, 2010). Where university relationships matter, it is more for their human resource development than for R\&D (Ramos-Vielba, Fernández-Esquinas, and Espinosa-delos-Monteros, 2009). This supports the idea that knowledge creation and application is a socially embedded process in which social and interpersonal networks with a variety of regional and global agents, including universities (but not only for R\&D purposes), might be the key (Saxenian, 1994).

Increasingly, researchers interested in regional innovation have focused on the role of labour mobility, particularly transnational immigration patterns. In particular, Saxenian's work on Silicon Valley has drawn attention to the role of Chinese and Indian immigrants in fostering innovation not only in Silicon Valley, but also in their home countries. This process of "brain circulation," or immigrants embarking in entrepreneurial activity in their home countries, facilitates the knowledge transfer that increases the pace of both innovation and globalisation (Saxenian, 2007).

To wrap up, the four labour market-related factors most critical to entrepreneurship appear to be: (1) higher education; (2) extensive work experience; (3) interaction with a variety of actors in the regional innovation system; and 
(4) openness to immigration. As described further below, Andalusian policies and programs have instead mostly emphasised the first, the role of higher education and university-industry linkages, rather than the latter three.

\section{Spain in the global context}

Spain and the rest of EU countries are currently immersed in a major higher education reform aimed at harmonizing and standardizing their systems. Two main frameworks are guiding this ongoing restructuration: the Bologna Process and the Lisbon Strategy. The Bologna Process seeks to harmonise the different European higher education systems and to promote collaboration and technology transfer between universities and the private sector. The Bologna process will introduce a new structure for university degrees in Spain, similar to that of the US and the UK, based on a three level system: Grado (4 year undergraduate degree), Master (1 or 2 year graduate education) and Doctorado (3-4 year post-master graduate education). The idea is to adopt a system of easily comparable university degrees that would allow overcoming the current bureaucratic obstacles to the recognition of degrees and movement of students, researchers, faculty and staff within European universities. The Bologna Process is linked to the broader Lisbon Strategy, agreed in 2000, that seeks to make Europe the most competitive knowledge-based economy in the world by 2010. Accordingly, INTERREG IV, the EU regional development programme for 2007-2013, was redesigned to bring the Lisbon Strategy onto the stage of interregional cooperation. The new INTERREG regional development programs are currently based on two main priorities: innovation and the knowledge economy, on the one hand, and the environment and risk prevention on the other.

The Spanish labour market differs somewhat from that of most European countries. Immigration to Spain from Latin American and EU15 countries has increased rapidly in the last decade. However, a 1985 immigration law restricts the ability of immigrants to work, forcing them to obtain a job offer before seeking work visas and residency permits. A 2005 opinion survey of the Spanish public found significant opposition to loosening immigration laws for workers, particularly among less-skilled Spaniards (Martínez i Coma and Duval-Hernández, 2009).

Social protection systems play a crucial role in reducing poverty and inequality in Spain, as in most European countries. However, Spain offers less of a safety net for the poor than most Northern European countries (de Neubourg, Castonguay and Roelen, 2005). Interestingly, Spain's unemployment benefits constitute a disproportionately large share of its social benefit package, relative to the EU15 countries on average. 
Historically, Spanish labour market regulation has been notoriously rigid; the high costs of terminating employees are in part responsible for a shift towards temporary hiring contracts, which are easier to end. As of June 2010, major labour market reform became provisionally effective; this will reduce the cost of permanent contracts and increase that of temporary contracts. Employers will also have more flexibility in reducing working hours (and salary) of employees. These reforms may force Spanish labour market regulation to begin to converge with that of its northern European neighbours.

Although labour and immigration policies and programs come under the purview of the national government, regions can still take action to attract immigrants by fostering a positive climate. For instance, the regional government of Madrid produced a business plan supportive of immigrants called "New Madrileños, Future Entrepreneurs" after they realised that one out of four applicants for entrepreneurial assistance was foreign (Diario Independiente de Madrid, 2010).

\section{Assessment of the region}

\section{Local labour market conditions}

The Andalusian labour market contains several structural weaknesses that distinguish it from the rest of the Spanish economy, namely: the high level of unemployment, large reliance on temporary workers, and low productivity. Although the overreliance of the region on the construction industry - and the subsequent collapse of the housing bubble - clearly contributes to these factors, even the sectors that employ highly educated workers are experiencing structural problems. Andalusia presents an example of "badly used human capital': as the educational attainment of resident workers has increased, this is not employed appropriately enough to contribute significantly to economic growth (Cuadrado-Roura, 2010).

At present, Andalusia is experiencing an unemployment rate above $26.5 \%$ (as compared to $18 \%$ in Spain as a whole). Already by 2009 , unemployment among young adults (16-24) was considerably higher (38\%), and among those with just a high school diploma, the unemployment rate stood at 56\% (Instituto Estadístico de Andalucía, 2010). The unemployment rate is closely related to the impermanence of much of the labour market: in $2007,45 \%$ of employed residents were in temporary jobs, $13.5 \%$ above the national average (Granados-Cabezas, 2010).

Overall, the level of educational attainment in Andalusia has increased rapidly and is converging with Spain as a whole (Granados-Cabezas, 2010). At the same time, as discussed further below, the last decade has seen students increasingly selecting traditional vocational training rather than 
university education (Junta de Andalucía, 2009). In a decade (1999-2009), Andalusian universities lost 46852 students. Still, there are returns to higher education: college graduates constitute $29 \%$ of the employed population in Andalusia, but just $15 \%$ of the unemployed (Laurent, Periáñez and Petit de Gabriel, 2010). During the recent economic crisis, Andalusian universities have seen enrolment increase by over $2 \%$.

In addition, the changing demographic structure in the region has affected labour market dynamics. The regional workforce is aging, while birth rates remain relatively low. Overall, college-age population has declined, while locals who do obtain a college education often emigrate to Madrid, Barcelona, or other EU destinations.

In the context of these demographic shifts, and the dominance of the construction and tourism sectors in the regional economy, it is not surprising that Andalusia has in recent decades switched from a region from which uneducated workers out-migrate to one which attracts immigrant workers to work in unskilled occupations. The immigrant population has increased from less than $1 \%$ of the total population in the early 1990s (mostly British and German retirees) to $8.8 \%$ in 2009, mostly Latin Americans (32\%), African (24\%) and EU-15 (20\%), but also Romanians and other Eastern European countries members of the EU (17\%). Since the recession began, immigration to Spain has decreased faster than that to other countries, but there has not yet been a rapid outflow of the immigrants that arrived in the last decade.

The immigrant population includes a substantial increase in the number of foreign university students coming to Andalusian universities for undergraduate studies (EU/Erasmus and Moroccan students) and for graduate studies (from Latin America, EU and North Africa). Despite the fact that Andalusian universities might be lagging behind in international rankings, the quality of life of Andalusia seems to be attracting foreign students. In fact, the share of immigrants from the EU-15 that hold a college degree (42\%) is more than double that among Andalusian residents (20\%) (Instituto Estadístico de Andalucía, 2010). Some immigrants are disproportionately likely to be self-employed relative to native Andalusians: $32 \%$ of EU-15 and $28 \%$ of Asian immigrants are selfemployed, compared to just 16\% of Andalusians (Centro de Estudios Andaluces, 2010). The popularity of Andalusian universities, coupled with the attraction of immigrant entrepreneurs, may constitute key opportunities for RETA and the region. 


\section{The local landscape of education and training related to entrepreneurship and SMEs}

The educational system in Andalusia is currently experiencing a restructuring that will affect not only the future of education and human capital in the region but also the entire Andalusian system of innovation. Three important processes will be framing the landscape of training and education in Andalusia in the next decade: (a) the restructuration of the European higher education system due to the Bologna Process; (b) a renewed focus in innovation, technology transfer, public-private partnerships and knowledge-based activities due to the Lisbon strategy; (c) the decentralisation and restructuration of education, training and innovation policies at the regional level in an attempt to shift the Andalusian economic base to a new knowledge-based productive system. The next sections will review the current landscape of training and education in Andalusia and how these processes might change it.

\section{Restructuring of the education/training system}

The arrival of democracy in Spain in 1975, as well as the political decentralisation processes that followed in the 1980s and 1990s, transferred significant power and resources from the national government to the 17 regional governments. Andalusia, the largest region in Spain, now has full responsibility for innovation, economic development and education policies. There are three Regional Ministries involved in human capital development in Andalusia: The Ministry of Education; the Ministry of Employment; and the Ministry of Economy, Innovation and Science.

In the mid 1980s, after education policies were transferred to Andalusia, the Regional Ministry of Education and Science was created to manage the education and training system in the region, both at the university and nonuniversity levels. The Ministry expanded access to education by creating new public universities and vocational schools in each of the 8 provinces and increasing the number of degrees and availability of seats. Since the mid 1990s, however, a new set of issues has transformed the education agenda in the region. On the one hand, the decrease in the population under the age of 25, due to the declining birth rate in post-Franco Spain, has shifted the focus in education from quantity to quality. Furthermore, after Spain signed the Bologna process and the Lisbon Strategy in 1999 and 2000 respectively, concerns of globalisation, innovation and competitiveness have started to increasingly shape education and regional economic development policies. The 2003 Plan for the Second Modernisation of Andalusia revealed the regional government's focus on promoting scientific research, technology transfer and entrepreneurship culture as engines of growth and economic development. This new economic development paradigm is also reflected in the 2007 Andalusia Plan for Research, Development and Innovation (PAIDI in Spanish), which 
maps out the potential for R\&D and innovation in the region from 2007 to 2013 (Junta de Andalucía, 2007). PAIDI's main focus is on technology transfer and the promotion of public-private partnerships between Andalusia public universities (dependent on the regional government) and companies. In this context, the agency RETA is assigned the responsibility of serving as the network manager of the Andalusia system of innovation.

In 2004, the Ministry of Innovation, Science and Enterprise assumed responsibility for universities, university research and technology transfer in Andalusia. ${ }^{1}$ For the first time, university and non-university education were separated in the Andalusia government, with vocational training and non-university education remaining in the Ministry of Education. The idea was to use universities as innovation and economic development tools and facilitate a shift towards an economy based on knowledge. ${ }^{2}$ On March 22, 2010, the Regional Ministry of Economy merged with the Ministry of Innovation, Science and Enterprise. ${ }^{3}$ The newly created Ministry of Economy, Innovation and Science confirmed the commitment of the regional government to make technology transfer between the 10 Andalusia public universities and Andalusia companies the key regional economic development strategy. Accordingly, the regional government put Andalusia public universities at the centre of the Andalusia system of innovation.

Finally, the Regional Ministry of Employment has a less visible role in the Andalusia system of innovation described above, despite having responsibility for employment policies, skills training for unemployed and employed workers (Formacion Profesional por el Empleo - FPL), entrepreneurship education (partly), and integration of immigrant workers.

\section{Figure 2.1. Regional Agencies involved in human capital development}

\begin{tabular}{|c|c|c|}
\hline $\begin{array}{l}\text { Department of } \\
\text { Education } \\
\text { (Consejeria de Educación) }\end{array}$ & $\begin{array}{l}\text { Department of } \\
\text { Economics, Innovation } \\
\text { and Science } \\
\text { (Consejeria de Economia, Innovación } \\
\text { yCiencia) }\end{array}$ & $\begin{array}{l}\text { Department of } \\
\text { Employment } \\
\text { (Consejeria de Empleo) }\end{array}$ \\
\hline$=5$ & COMAPETENCES & $z=$ \\
\hline $\begin{array}{l}\text { VOCATIONAL EDUCATION } \\
\text { - Vocational Education and Training } \\
\text { (Formación Profesionol) } \\
\text {-Andalusian Institute of } \\
\text { Occupational Qualifications } \\
\text { EDUCATION COMPETENCES } \\
\text { - Promotion of the quality of primary } \\
\text { and secondary education } \\
\text { TRAINING OF TEACHERS } \\
\text { PARTICIPATION } \\
\text { - Promote participation of different } \\
\text { local actors in the management and } \\
\text { curriculum of schools and vocational } \\
\text { training schools }\end{array}$ & $\begin{array}{l}\text { INNOVATION and SCIENCE } \\
\text { - Universities } \\
\text { - Science and Technology } \\
\text {-ICT } \\
\text {-Energy } \\
\text { - Entrepreneur ship Education } \\
\text { - Industry } \\
\text { - Businesses } \\
\text {-Information Society } \\
\text { ECONOMIC DEVELOPMENT } \\
\text { - Regional Economic Development } \\
\text { and Economic Policies } \\
\text { - Socio-Economic Studies } \\
\text { - EU Funds Management } \\
\text { - Financial Policies }\end{array}$ & $\begin{array}{l}\text { EMPLOYMENT POLICIES } \\
\text {-Promotion of local and regional } \\
\text { employment } \\
\text { - Andalusian Employment Agency } \\
\text { WORKERS TRAINING } \\
\text { - Skills training for unemployed and } \\
\text { employed workers (FPO/FPE) } \\
\text { - Entrepreneurship education for } \\
\text { workers and SMEs } \\
\text { WORKPLACE SAFETY } \\
\text { - Workplace inspection and safety } \\
\text { IMMIGRANT WORK POLICIES } \\
\text { - Integration of immigrant workers }\end{array}$ \\
\hline
\end{tabular}

Source: Personal elaboration based on the competencies of the three regional ministries as listed in www.juntadeandalucia.es as of July 2010. 


\section{The university system}

There are currently 10 public universities in Andalusia with a total of approximately 230000 students. The Universities of Seville and Granada dominate enrolment, with 57000 and 56000 students, respectively; the University of Malaga is a distant third, with 33000 students, and the others are substantially smaller.

Inter-university cooperation is fluid but sometimes sensitive because these regional universities are competitors: they are not specialised but rather generalist universities. The availability of competitive EU and national research projects that favour inter-university cooperation is improving this issue by enabling collaboration among Andalusia universities and between Andalusian and other European universities.All Andalusia public universities are part of the so-called Unified Andalusia University District (Distrito Universitario Único Andaluz), which is now dependent on the Regional Ministry of Economy, Innovation and Science. This has created greater pressure for industry-university collaboration.

Traditionally, student mobility was very weak in Spain and geographic proximity rather than reputation was the criteria by which students chose their university. However, the Bologna Process and the new plans of the regional government to increase the specialisation of universities is expected to bring more competition for student recruiting and make Andalusia universities more specialised than generalist. This is also trying to stop the "brain drain" of Andalusia students going to private university institutions and business schools in Madrid and Barcelona to get their graduate degrees.

In general terms, Spanish universities do not rank well in international quality rankings, which are reputedly skewed towards larger and Englishspeaking universities. The 2009 Academic Ranking of World Universities, elaborated by the Institute of Higher Education of Shanghai, China, places the first Spanish centre, the University of Barcelona, in the 151-202 band. The first Andalusia institution mentioned is the University of Granada, followed by the University of Seville (both in the 402-501 band). Another popular international ranking, The Times QS, placed Barcelona in the $171^{\text {st }}$ position, Granada in the 401-500 band and Seville in the 501-600 band. Neither ranking mentioned Malaga or other Andalusia universities. While university rankings have been present in the U.S. for a long time, over the past decade they have become increasingly important in countries in Europe and around the world, despite the critiques that they do not recognise university quality and dynamism.

An important and effective regional programme to upgrade local talent is Talentia, by which the regional government offers young college graduates financial support for their graduate work at top international universities, on 
the condition that they return to the region to work for four years. By 2009, the program had funded about five hundred young Andalusians (Laurent, Periáñez and Petit de Gabriel, 2010).

At the same time, despite the lagging position of Spanish universities in quality rankings, they are the favourite destination for Erasmus exchange students: 8 out of the top 10 exchange institutions in Europe are Spanish, with the University of Granada being number one, the University of Seville number 6 and the University of Malaga number $34 .{ }^{4}$ Graduate programs also attract an increasing number of foreign students to Andalusia universities: $20 \%$ are of foreign origin, with $8 \%$ coming from Latin America, $4 \%$ from the EU, 3\% from North America, and about 2\% from North Africa (Instituto Estadístico de Andalucía, 2010). The universities of Granada, Seville and Malaga have become a magnet for attracting international students and yet few efforts are made by the regional government to retain this talent from going back to their countries once they graduate.

\section{Vocational training and apprenticeship programs}

The different systems of vocational training in Andalusia are as follows:

- Vocational training (Formación Profesional or FP) serves young people as a professional alternative to the Baccalaureate and university education. Managed by the Regional Ministry of Education, it includes skills training of one-two years for youth unable to graduate high school, high school graduates, or older students with some college education or a degree.

- Vocational training for employment (Formación Profesional para el Empleo or FPE) serves either dislocated or incumbent workers. Initially conceived as an employment policy, it is now managed by the Regional Ministry of Employment in coordination with the Ministry of Education. Unions also collaborate in the training of workers with the Ministry of Employment. ${ }^{5}$

Recently, the government has created a new institution to regulate vocational training in the region: the Andalusia Institute for Occupational Qualifications (Instituto Andaluz de Cualificaciones Profesionales). The Institute will be in charge of integrating the different vocational training systems (FP and FPE) based on a common system of occupational qualifications in collaboration with the national government and unions.

In Andalusia, a total of 94710 students attend vocational training - less than half the number that attend the public universities. The II Andalusia Plan for Vocational Training, currently being prepared by the Ministry of Education, seeks to adapt vocational training to the new economy and new 
demand of jobs and occupations. This will involve expanding online training; cooperating more closely with businesses, unions and others through advisory councils; teaching more foreign languages; and creating at least one vocational centre of excellence in each of the eight Andalusia provinces to improve public support and connections with businesses.

Vocational training has been very successful in the last decade in placing students in a job. That has resulted in an increased number of students during the 1990s and 2000s just as the number of university students in Spain has been decreasing and number of dropouts increasing (Laurent, Periáñez and Petit de Gabriel, 2010). For the 2009-10 course, the number of students at technical and vocational schools in Spain increased 9.3\% compared to 3.2\% of Baccalaureate students. ${ }^{6}$

\section{Opportunities in the landscape}

This overview of the landscape of education and training in Andalusia suggests several opportunities to build upon. First, the reorganisation of the system into three ministries presents an opportunity particularly for hightech innovation. However, the risk in this restructuring is that it does not address the innovation needs of traditional sectors. The region might find a role in countering this, by helping a variety of businesses access resources, such as information technology, that will increase their innovativeness.

Changes in the university system present another opportunity. Increasing specialisation, particularly in the flagship universities of Granada and Seville, should help attract even more foreign exchange students for the region. RETA and other regional stakeholders might work to encourage potential entrepreneurs among them to stay in the region, perhaps by facilitating a relationship with technology parks.

Finally, the region might support the local residents who are increasingly choosing vocational over university training to obtain skills that will improve entrepreneurship. The II Andalusia Plan for Vocational Training will address several gaps in the system that can help link vocational training better to innovation and entrepreneurship - for instance, offering expanded on-line and foreign language training.

\section{Entrepreneurship education}

The EU generally lags in entrepreneurship education, and Andalusia is no exception (Twaalfhoven and Wilson, 2004). Different public and private actors in Andalusia from across the regional innovation system promote entrepreneurship education in the region (see Annex 1). While the university offerings focus mostly on connecting high-tech workers and start-ups to 
entrepreneurship skills, a variety of other programs help traditional businesses and low-skilled workers gain the capabilities they need to innovate more effectively. Below is a description of what some main regional actors do in the field of entrepreneurship education and training.

\section{Public universities}

Universities support entrepreneurship in four ways: (1) providing workshops on starting a business for free or at very low rates; (2) at seven of the ten universities, supporting the Bancaja Young Entrepreneur Chairs, with special seminars, networking with entrepreneurs, and training opportunities; (3) offering entrepreneurship fairs to connect different stakeholders; and (4) conducting research on promoting entrepreneurship in higher education (Laurent, Periáñez, and Petit de Gabriel, 2010). Each university has also created specific initiatives and courses to promote entrepreneurship. For instance, the Economics Department at the University of Malaga (UMA) started offering a course on entrepreneurship in 2009. This is an elective course that all university students can take, although only 200 students took and most of them came from the Economics Department. This figure is small compared to the approximately 33000 UMA students. UMA recognises the poor participation rates in these courses and is trying to expand them to other departments such as ICT and applied scientific research. On the other hand, the University of Seville, in collaboration with its OTRI (Technology Transfer Office), supports entrepreneurs involved in the creation of university spin-offs by paying part of the fees of an MBA program.

\section{Business schools}

In Spain, the public university system has a better reputation than the private system, except in the field of business education. Private business schools in Spain lead all the quality rankings in business and executive education. This is especially true for the top schools situated in Madrid and Barcelona such as the Instituto de Empresa, IESE and ESADE, which are ranked among the top 10 business schools in Europe according to the Financial Times" ranking. Andalusia has lacked high quality education in business and entrepreneurship and even more so at the graduate level. Economics and business administration departments in public universities are often disconnected from the local business community and, in response, business associations and chambers of commerce have created their own small private business schools in different cities. The best-ranked business schools in Andalusia are private and concentrated in Seville (San Telmo Institute, EOI and ESIC) and in Malaga (ESESA and ESIC). Other private business schools exist in Córdoba (ETEA) and Granada (Escuela Europea de Negocios and Escuela de Gerencia/ESIC). Most of them offer courses on entrepreneurship and business leadership, but not official degree programmes. 


\section{Technology Transfer Offices (OTRIs)}

Andalusia Technology Transfer Offices (OTRIs) have seen their responsibilities and budget grow in the last decade thanks to the regional government's push for innovation. Apart from their function of promoting technology transfer, public-private cooperation and creation of spin-offs, OTRIs are increasingly paying attention to promote entrepreneurial activity among students as a way to increase the number of companies originated in the university. For instance, the OTRI of the University of Granada offers a program called $L a$ Ruta Emprendedora (The Entrepreneurial Route) that supports visits to technology parks and related workshops organised by sector (ITC, Biotechnology and health sciences, Environment, Renewable Energies and Agriculture, Cultural and Creative Industries).

\section{ANDALUCIA EMPRENDE}

ANDALUCIA EMPRENDE has a network of 1000 people to assist, advance, mentor, and train very small firms in the region. It is the main provider of entrepreneurship training in the region. The main target is the entrepreneur, but it also targets students (in high school, vocational training schools and universities) and women. ANDALUCIA EMPRENDE has more than 200 business incubators (Centros de Apoyo al Desarrollo Empresarial, or CADE) around the Andalusia region, including rural areas. They also have a very extensive catalogue of entrepreneurship education. For youth, their training programs promote entrepreneurship culture in primary schools, high schools, baccalaureate programs, and vocational training schools, teaching students how to create and manage cooperative firms. For the highest level of vocational training students, ANDALUCIA EMPRENDE offers a business plan competition in which the winners spend three days training in the business incubators. In collaboration with EXTENDA, they offer four training programs: a course on how to internationalise a company for new entrepreneurs; a study tour of a foreign country; internships with companies abroad in strategic sectors for the Andalusia economy (aeronautics, biotechnology, ICT, culture industries, renewable energies); and support for Andalusia expatriates to establish their company home in Andalusia. Finally, they also collaborate with Becas Talentia in order to help entrepreneurs that studied abroad establish themselves in Andalusia.

\section{Confederación de Empresarios de Andalucia (CEA)}

CEA is the main business association of Andalusia, which promotes entrepreneurship in vocational training schools and secondary schools. Their training is based on improving the skills of employed people (in collaboration with the Ministry of Education) and inspiring young people to become 
self-employed entrepreneurs. They have two main training programs: (1) a program to promote business education at vocational training centres; and (2) a university program promoting entrepreneurship, held at all public universities in Andalusia. They also host gatherings called "Let's Speak about Enterprise" in different educational institutions in Andalusia, with 99000 people taking part in 2007 and 2008.

\section{Corporación Tecnológica de Andalucía (CTA)}

CTA is a private foundation, basically a business association of the largest technological companies based in Andalusia (Abengoa, Endesa, Airbus, Iberdrola, etc.) but with the collaboration of the Regional Ministry of Economy, Innovation and Science. CTA recently began a new program to support the doctoral education of researchers within their member companies. They also have specific agreements with universities and technology centres to support their IT and technology activities.

\section{Opportunities in entrepreneurship education}

Andalusia has a significant infrastructure for entrepreneurship training in place, providing a foundation upon which the region and RETA can build. Many of the region's public universities are already engaged in entrepreneurship education, from special workshops to support for MBA programs to internship programs at the technology parks. Of particular note are the sectorrelated educational activities of the OTRIs, such as La Ruta Emprendedora at the University of Granada, as well as RETA's own digital cluster program with CITIC (see below). Another key strength that the region might develop more is FUNDACION EMPRENDE's extensive entrepreneurship training programmes, including its collaborations with the Talentia programme and the agency EXTENDA to improve international ties for local entrepreneurs.

\section{Main issue: a schism between economic development and workforce development}

Although the duplication of training is understood to be problematic, only a few regional stakeholders describe the many different organisational disconnects in the region as issues as well. Yet, such disconnects may hinder communication, foster more redundancy, and prevent training programs from adopting appropriate curricula - thus constituting a key weakness in training provision. Andalusia experiences a chronic schism between economic and workforce development programming that makes it difficult for businesses to obtain appropriately trained labour and, most pertinent for innovation, develop the pipeline of highly skilled workers that help transmit knowledge in regional clusters. This schism manifests itself in three ways: a poor connection between 
the regional innovation system and the Andalusian vocational system; a separation between ministries concerned with entrepreneurship, education, and employment; and the lack of a workforce strategy tied to "cluster" strategies. The following describes this threefold disconnect in more detail.

\section{Poor connections between the innovation and vocational systems}

As described above, entrepreneurship training in Andalusia takes place in multiple venues. But most commonly emphasised by stakeholders in the Andalusian regional innovation system is the training available at the universities. Focusing nearly exclusively on university R\&D and technology transfer, regional actors seem to have missed the more modest but important contribution of vocational training and education. While hiring PhD-level workers might be key for highly innovative companies in IT or biotechnology sectors, the reality is that most SMEs in Andalusia are highly dependent on personnel without a university degree. Innovation - defined in a broad sense by OECD's Oslo Manual as “the implementation of a new or significantly improved product (good or service), process, a new marketing method, or a new organisational method in business practices" workplace organisation or external relations" - takes place at these low-tech firms just as it does in high-tech (OECD and Eurostat 2005).

For instance, despite the fact that Renewable Energies is one of the main clusters defined by the Ministry of Economy, Innovation and Science, there is only one vocational training diploma in Andalusia included under the Energy and Water professional family. The diploma, Superior Technical Degree in Energy Efficiency and Solar-Thermal Energy, was only established very recently in $2008 .^{8}$ Yet, in order to foster this energy cluster, it will be important to involve SMEs in various part of the production chain. Some firms will require R\&D capabilities, while others will benefit from skilled workers trained in energy efficient technologies. Bolstering the production chain of the cluster via training strategies will allow the expansion of the local market for these services and products - a result just as crucial in developing an energy cluster in the region as having an isolated energy efficiency patent or spin-off with no regional market.

\section{Limited coordination amongst the Ministry of Economy, Innovation and Science and the Ministry of Employment}

Second, as noted above, the regional ministries have undergone multiple reorganisations in the past decade, with the Ministry of Science and Innovation taking responsibility for universities away from the Ministry of Education in 2004, and the Ministry of Economy merging with Innovation and Science in 2010. The Ministry of Employment remains separate. This new configuration 
clearly reflects and structures how regional actors think about labour markets, innovation, and training in the region. The regional innovation system separates itself from the general education and employment systems, suggesting that the official view of innovation is exclusively about R\&D. It is not clear how this affects the distribution of resources, as well as regional economic outcomes. However, given the importance of non-university-related innovation, as well as the depth of the region's economic problems, it is unfortunate that this separation of agencies may hinder strategic coordination, for instance of vocational training and industry clusters. In fact, many agencies in other parts of the world are moving in the opposite direction, consolidating efforts for efficiency purposes (National Centre on Education and the Economy, 2007).

\section{Limited synergies between cluster strategies and workforce strategies}

Finally, in part because of this agency balkanisation, the region's cluster strategy lacks strong connections to its workforce strategy. There are certainly training efforts in the region that are coordinated with sectors, for instance the English and entrepreneurship education available at technology centres like the Andalusian Stone Technology Centre. But for the most part, the agencies that offer different types of entrepreneurship training do not target the region's 25 clusters, or even the six innovation hubs. This contradicts established best practices about sector-based workforce development that tailors training to employer needs in specific industry sectors (Zandniapour and Conway, 2003; Giloth, 2000; Marano and Tarr, 2004).

\section{RETA's training}

Since its inception, RETA has provided four main types of training that are briefly described in Box 2.1.

The perception during the study visit is that training offered by RETA may have been too generic to be useful. For instance, the 85 agents came mostly from an engineering background so had to receive some training in entrepreneurship from RETA. Yet, given the breadth of agent involvement in the Andalusian economy, as well as the rotation of agents between clients, it was not possible to give in-depth sectoral assistance. RETA has engaged with over 80000 firms since its inception, or almost 1000 firms per agent, and agents maintained ongoing relationships with 3000 firms, or almost 40 per agent. Thus, they worked with many different types of industries, each with different entrepreneurship opportunities and constraints. Likewise, RETA offered basic IT training to its firms. RETA focused mostly on basic IT services, teaching its firms how to use electronic signatures and anti-virus software rather than, for instance, how to develop e-commerce capabilities. 


\section{Box 2.1. RETA's main provision of training}

EVA Online Training Tool: EVA was an online site that intended to implement advanced and innovative training programs for the changing needs of SMEs and government officials through two courses. One course combined online and onsite training, in collaboration with the International University of Andalusia (UNIA), in "Entrepreneur Advice" (Experto Universitario en Asesoramiento a Emprendedores). The other course they offered was called "Applied Creativity for Businesses", which taught SME executives how to develop innovative ideas for their businesses.

Digital Cluster Program: This pilot program, offered in collaboration with the Malaga-based CITIC (ICT Innovation Centre - Centro Andaluz de Innovación y Tecnologías de la Información y las Comunicaciones), provided training in information technologies to SMEs that were part of a relevant cluster in Andalusia. The strategy was based on a CITIC study of the IT needs of SMEs in seven productive sectors linked to Andalusian technology centers (stone, ceramic, wood/ furniture, textile, plastic, metal-mechanic, and agro auxiliary industry).

NOVAPYME. The NOVAPYME program was coordinated by RETA and discontinued in 2008. This was aimed at making Andalusian SMEs incorporate IT in their businesses. It utilised FUNDACION EMPRENDE's schools as well as a network of 250 consultants. The main IT solutions offered were antivirus (to $29 \%$ of clients), business management software (to 28\%) and web and email (to 19\%).

Training of RETA agents: RETA agents were considered the "sale representatives" of the regional innovation system. Until they existed, they were in charge of connecting SMEs all over the region with innovative businesses and research teams located in Andalusian technology parks. After training by RETA, the agents maintained contact with SMEs and identified needs related with IT or innovation, using online support tools.

\section{Opportunities for RETA}

Despite the challenges - the redundancy in overall education and training system, the lack of university savvy about technology and entrepreneurship, and the many disconnects in the system - there are opportunities for RETA to assume a new role in the region. RETA could help fill the clear vacuum in terms of coordinating the various training systems and linking them to the cluster strategy. At present, although many individual agencies work to coordinate their own educational and training programs with relevant actors, the siloed agency structure means that no one agency oversees the programs and ensures that they relate to the region's clusters. To support RETA's efforts, there are multiple existing strengths in the region, including the commitment 
of regional stakeholders to improving the innovation system, the enthusiasm of foreign students for the region, and the existing sector-based models which might be built upon.

Because RETA plays the role of innovation system manager, it has the opportunity to help coordinate training programs across agencies, universities and schools and advocate for more sophisticated training programs. There is an opportunity to coordinate more university activity regionally and link it better to regional needs. The preparation of the II Andalusian Plan for Vocational Training, which will link training better to the new economy, also presents an opportunity for RETA to provide input and help coordinate training along the entire production chain. In particular, opening the regional centers of excellence gives RETA an opportunity to help link such training better with the regional innovation system. With several agencies offering different forms of entrepreneurship training in the region, there is a real need for an intermediary to assist with strategic planning that links the training better with the region's other flagship programs, such as the innovation hubs. Even just documenting the programs, identifying overlaps, and mapping out synergies would help the region use its training resources more effectively. As the literature on entrepreneurship and human capital indicates, RETA is particularly well suited for this role because of the breadth of its networks, which span beyond the university system to include business associations and government.

There is also considerable existing energy, enthusiasm, and experience in the region that RETA might capitalise on. The university system is committed to support labour policy, technology, and entrepreneurship. While most effort of the regional government to promote entrepreneurship and talent seem to be focused in improving sending Andalusian students to top universities abroad (as in the Talentia program), there is also a remarkable opportunity to retain the large number of foreign students that are attracted to Andalusian universities every year. The Universities of Granada and Sevilla alone received over 3000 exchange students in 2007-08, placing Andalucia ahead even of Barcelona in popularity. As research elsewhere has found, immigrants are disproportionately likely to become entrepreneurs. RETA might work as an intermediary to facilitate a longer stay in the region for these students, by helping them obtain legal residency and connecting them to entrepreneurship resources (for instance in the technology parks).

Finally, there is significant infrastructure already in place to link the training system more effectively to a regional sector strategy. Numerous sector-based training models already exist, at the OTRIs, the technology parks and centres, FUNDACION EMPRENDE, the unions, etc. Internship programs at the technology parks, EMPRENDE, and elsewhere might be expanded to better link students with businesses. The regional government 
seems to be supporting this approach already, not only by trying to link the technology parks with its high-tech sector strategies, but also by fostering low-tech innovation. ${ }^{9}$

\section{Policy recommendations}

In the area of human capital and the labour market, the most important contribution RETA can make is to become the glue that binds the separate pieces of the education and training system and links them to a sector strategy for the region. Thus far, RETA has struggled to find a niche in training, offering small-scale entrepreneurship and IT training programs typically in collaboration with other agencies. RETA need not conduct training itself, but should help coordinate the regional conversation about human capital development related to entrepreneurship. In particular it can play a pivotal role by helping to link vocational training to the many other efforts. In addition it might join forces with FUNDACION EMPRENDE, already the leader in regional entrepreneurship training, to promote innovation and IT training in low-tech SMEs. This would give it a role distinct from the technology parks and OTRI agents, which are well supported by the regional and national governments.

We offer four specific recommendations, which are supported by the learning models in the final section.

\section{Link training programs more effectively with sectors}

In order to improve firm productivity and innovation, particularly in the traditional sectors that are Andalusia's strengths: ceramics, marble, textiles, agribusiness, etc. Sector-based training initiatives are programs that target specific industry sectors, trying to create a win-win situation by restructuring employment practices in a way beneficial to both employers and lowskilled workers (Marano and Tarr, 2004). RETA could help build this link by conducting a strategic planning process for the region's entrepreneurship training system. Ultimately, however, better information and planning will not lead to results unless the regional government offers incentives to coordinate economic and workforce development. Again, the role for RETA might be to help the regional government design a program structure that leads to implementation.

\section{Connect business incentives with job creation}

Work across the silos of business and employment agencies by connecting business incentives with job creation in strategic sectors. Fostering entrepreneurship alone does not guarantee that Andalusia can capture the 
benefits for its distressed labour market. During economic crisis, it is particularly important to stimulate business to create more jobs. RETA might help the regional government identify examples of programs from other countries (such as the East Bay Green Corridor Partnership described below) that link incentives to job creation, and then help businesses participate in the program, particularly in the technology parks. Again, given its role as innovation system manager, RETA could help ensure that resources are targeted appropriately.

\section{Refocus entrepreneurship training}

Refocus entrepreneurship training along the models of the best business schools, with a particular focus on attracting immigrant exchange students (though retaining immigrant entrepreneurs remains out of the region's purview). Although Andalusia's business schools cannot compete with the private schools in Madrid and Barcelona, they have the benefit of location in a region attractive to students from many other countries. Here RETA might play an intermediary role by helping to market the region in countries that it has already developed relationships with.

\section{Train entrepreneurs for global e-commerce.}

Businesses in traditional Andalusian sectors, such as ceramics, typically do not compete globally, resulting in low exports from the region. The IT training available from different Andalusian agencies is a first step towards becoming more competitive. However, traditional Andalusian businesses need to understand e-commerce better and would benefit from the development of a web localisation certificate program by an organisation with expertise in global e-commerce.

\section{Learning models}

\section{East Bay Green Corridor Partnership: Linking workforce and economic development in the regional green economy}

The East Bay Green Corridor Partnership in the San Francisco Bay Area provides an example of linking workforce and economic development, and also illustrates the potential of regional coordination around one emerging sector - in this case, the clean energy economy.

Workforce development and economic development goals, such as regional economic growth and competitiveness, can be contradictory. Job training seeks to help economically or educationally disadvantaged people access employment opportunities, while economic development programmes must help businesses 
become more competitive and expand, often through productivity increases that will require high-skilled workers. Training workers can take months or years, while firms need quick and flexible access to labour to compete in the global market.

Despite these issues, regions are seeking to link workforce development to economic development more systematically, in part to create jobs in a stagnant economy. In the U.S., cities and states have found several creative ways to include workforce development in economic development programmes. They may negotiate informally with businesses that seek retention or expansion assistance. They may adopt more strategic approaches, targeting specific industries identified via economic analysis. Structural strategies are a third approach, i.e. retooling agency programmes to link training and placement with permitting or development processes or condition business incentives on local hiring practices. It is this last approach that some U.S. cities are adopting in order to capitalise on federal economic stimulus funding to create local jobs. Whichever strategy is adopted, optimally it will be combined with a sectoral strategy as well.

Sector initiatives are so-called "dual customer" intermediaries that not only attempt to improve wages and advancement potential for workers, but also try to change internal labor market practices such as management and mentoring in order to make workers more productive (Giloth 2000). Because they focus on a single sector, these types of programs offer economies of scale and scope. They organise groups of firms that require similar worker skill sets, obtaining economies of scale by working across a variety of different firms in one industry. Additional synergies come from bringing employers together to share concerns and best practices, as well as help design appropriate curricula. When employers are directly involved in programs, curricula focus on the most appropriate skills, trainees become more familiar with workplace practices, and the intermediary may act as an employment broker, introducing workers to prospective employers. An impressive set of evaluations has shown that these initiatives have significant and positive impacts on the employability, wages, and upward mobility of their participants (Chapple, 2005; Elliott et al., 2001; Zandniapour and Conway, 2003). These initiatives are seen as demand-responsive, i.e. linked to firms, sectors, and clusters in the regional economy, and thus able to facilitate economic development.

In late 2007, the mayors of Oakland, Berkeley, Richmond, and Emeryville along with the U.C. Berkeley chancellor and the head of the Lawrence Berkeley National Laboratory (LBNL) announced an ambitious plan to foster and promote the green economy in the region. The so-called East Bay Green Corridor Partnership (EBGCP) has since expanded to include four more East Bay cities - Alameda, San Leandro, Albany, and El Cerrito, as well as three other educational institutions: the Peralta and Contra Costa community 
college districts, and Cal State East Bay. Each of these cities brings different economic strengths and policy approaches to the partnership, but they seek to develop through policy coordination and marketing a new collective identity for the region as the "Silicon Valley of Green."

The partnership resulted from a conversation about how to link campus resources to the cities more effectively. One major impetus was the USD 500 million investment by British Petroleum in biofuels research by a consortium including UC-Berkeley, LBL, and the University of Illinois. The partnership aims to capitalise on the East Bay's regional strengths and assets, as well as foster and retain start-up companies spawned by innovative research coming from U.C. Berkeley and LBNL. This would be done by creating a positive business climate and putting in place incentives for green businesses, as well as coordination among technology-transfer, economic development, and workforce development departments in the region.

The EBGCP began by coordinating its green policies regionally, in order to create a more unified regional identity. Figure 2.2 shows the initial policy differentiation among the cities; the aim is to offer all programmes in all cities.

The inclusion of funding for energy efficiency in the federal stimulus package has created a new opportunity for coordination and sectoral targeting. Generous grants are available for households of all income levels to conduct energy audits and perform minor repairs, such as sealing leaks and replacing windows. This in essence creates a new market for energy efficiency services - an approach which the regional government is already fostering. ${ }^{10}$ The

\section{Figure 2.2. East Bay Green Corridor Partnership Policies}

\begin{tabular}{|c|c|c|c|c|c|c|c|c|}
\hline Policy & Alameda & Albany & Berkeley & El Cerrito & Emeryville & Oakland & Richmond & $\begin{array}{c}\text { San } \\
\text { Leandro }\end{array}$ \\
\hline \multicolumn{9}{|l|}{ Climate Action Plan } \\
\hline \multicolumn{9}{|l|}{$\begin{array}{l}\text { Community Choice } \\
\text { Aggregation Study }\end{array}$} \\
\hline \multicolumn{9}{|l|}{$\begin{array}{l}\text { Municipal Zero Waste } \\
\text { Goal }\end{array}$} \\
\hline \multicolumn{9}{|l|}{$\begin{array}{l}\text { Municipal Green } \\
\text { Building Ordinance }\end{array}$} \\
\hline \multicolumn{9}{|l|}{$\begin{array}{l}\text { Green Building } \\
\text { Incentives or Permit } \\
\text { Streamlining }\end{array}$} \\
\hline \multicolumn{9}{|l|}{$\begin{array}{l}\text { Green Business } \\
\text { Program }\end{array}$} \\
\hline \multicolumn{9}{|l|}{$\begin{array}{l}\text { Solar Installation Fee } \\
\text { or Permit Reduction }\end{array}$} \\
\hline \multicolumn{9}{|l|}{$\begin{array}{l}\text { Solar Thermal Rebate } \\
\text { Program }\end{array}$} \\
\hline $\begin{array}{l}\text { Energy Efficiency Job } \\
\text { Training }\end{array}$ & & & & & & & & \\
\hline
\end{tabular}

$\begin{array}{lll}\text { Policy in place Policy in progress No policy in place } & \end{array}$ 
Partnership also helps to coordinate the many different green workforce development initiatives, raising awareness of redundancies and potential synergies.

The new market demand for energy efficiency will foster job creation in different ways. First, initial energy audits and the simplest home improvements are performed by disadvantaged youth from the eight cities trained at the Rising Sun Youth Center. Then, local firms certified to perform the more advanced work receive incentives if they hire locally. Ideally, they will be able to train and hire graduates of the youth program.

Though too recent to evaluate systematically, local stakeholders argue that the Partnership has created a friendlier business climate for green businesses and streamlined the many energy efficiency programs. Evidence of its success comes from the efforts of local cities to join the initiative, as well as the ability to garner state and federal funding. The example is instructive for Andalusia in several ways: it provides an example of how to stimulate the economy during a downturn by creating a new market; it targets green economy businesses, also a strength for Andalusia; it links workforce development to business incentive programs; and it builds upon regional coordination. RETA would be a natural intermediary to build such a regional policy network. Given the need for extensive coordination in this model, RETA might find a niche as a convener of the various stakeholders in each sector.

Implementation would likely take a different form in Andalusia. In the more decentralised U.S. context, where cities have significant administrative responsibilities and pursue economic development aggressively, grassroots efforts at collaborating across city boundaries frequently arise, often building on other shared functions, such as fire protection. The stronger regional government in Andalusia offers a strength in terms of capacity for regional coordination, but also an obstacle, as it may be more disconnected from the needs of businesses than individual cities are.

\section{For further information}

Executive Director Carla Din, Carla@eastbayeda.org;www.ebgreencorridor.org.

\section{Entrepreneurship training in Gothenburg, Sweden}

As described above, the Andalusian public universities offer a few entrepreneurship training programs, and have plans for entrepreneurship chairs, but in general the offerings are undersubscribed. Given the region's interest in entrepreneurship, as well as the concentration of foreign students and immigrant entrepreneurs, there may be potential to expand the offerings at the university level. 
Developing an entrepreneurial university takes time, and with limited resources, it may be best to focus on just one of the public universities. Such targeting is what Sweden did to counter its relatively weak entrepreneurial culture, as it invested in technology-based entrepreneurship at the University of Gothenburg and the nearby Chalmers University of Technology (Jacob, Lundqvist, and Hellmark 2003).

Sweden's emphasis on new technology-based firms is based on the understanding that they contribute to economic growth not just by producing own products but also input to other firms, allowing them to innovate in their processes or markets. The Gothenburg model is considered particularly successful because of the intensity of local collective learning spawned by the combination of spinoff firms from local corporate parents and technology staff mobility (Dahlstrand, 1999).

The Gothenburg model of entrepreneurship training is an action-based entrepreneurship education program, i.e. the project-based learning model (Rasmussen \& Sørheim, 2006). Programs at both the Chalmers School and the School of Economics and Commercial Law at the University of Gothenburg are highly selective. ${ }^{11}$ A small class of students engage in the entrepreneurship process, from idea development, team building, and venture capital attraction, to actual firm set-up. Local business entrepreneurs serve on the start-up firm's board of directors. The universities offer office space and access to a network of mentors. These programs not only offer degrees, but send students out into the world with their own start-up business.

Although there are significant attempts at regional coordination among the public universities in Andalusia, there is also much redundancy. The Gothenburg model provides a useful model for a region that has struggled to launch entrepreneurship programs at the universities. RETA might play a role in targeting entrepreneurship training resources, specifically a new learningby-doing program as has been so successful in Gothenburg, at one of the biggest universities. However, launching the effort would be challenging without significant resources. First, Andalusia universities lack the competitive specialisations of the many Gothenburg research institutions. Second, initiating the effort would require significant regional and national investment, likely diverting funding from other university-based innovation programs.

\section{For further information}

Chalmers School of Entrepreneurship, www.entrepreneur.chalmers.se/cse/

School of Economics and Commercial Law at Gothenburg University, www.hgu.gu.se/item.aspx?id $=17007$ 


\section{Web localisation certificate programmes: Training entrepreneurs for global e-commerce}

Although entrepreneurship programs have offered training in e-commerce for many years, experience with global markets has shown that many websites are not appropriate to attract consumers in foreign markets. Localizing websites, i.e. customizing them for local cultures, will improve comprehension, navigation, site visit duration, and most importantly, purchasing (Singh and Pereira, 2005).

The localisation industry - in 2006, a USD 9 billion business - helps businesses design multilingual websites that work in different national contexts. However, only a few localisation training programs exist, leading to a human capital deficit in this area. Certificate programs in the U.S., Ireland, Germany, the U.K, and Singapore offer instruction in localisation, typically in a combination of online and onsite instruction. Courses tend to be short (less than 100 hours) and complement other training and educational programs in international e-business, such as marketing, translation, and intercultural communication.

Although no systematic evaluation of localisation programs exists, localisation, and global e-commerce more generally, seems like a natural fit for Andalusia, given three factors: the attraction of students and tourists to the region, the need for internationalisation, and the lack of web and IT expertise among traditional businesses. Curious about the region, online visitors could be attracted to visit websites about local culture and products. At present, the region is served by two regional touristic websites, both of which do not reflect the state-of-the-art of web design and functionalities. Given its experience offering IT training, as well as its past role in the Digital Cluster program, RETA might be able to play a role in launching such training. The region has some resources to build upon, such as the Andalusia Lab, a technology center for touristic innovation, which already offers an e-commerce course to businesses. One possible partner would be FUNDACION EMPRENDE, given its extensive training resources. However, the lack of local capacity in e-commerce will likely present an obstacle to implementation, particularly in the rural areas most in need.

\section{For further information}

John Cook School of Business at St. Louis University, http://globalizationexecutive.com/

Austin Community College, www.austincc.edu/techcert/localization.php; California State University-Chico, http://rce.csuchico.edu/localize 


\section{Notes}

1. Decreto del Presidente $11 / 2004$, de 24 de abril, sobre reestructuración de Consejerías, available at www.juntadeandalucia.es/boja/boletines/2004/996/d/updf/ d1.pdf.

2. Professor Manuel Castells's work on the network society was and still is widely utilised as theoretical framework for the new regional development agenda in Andalusia. See Castells (1996) and Castells \& Hall (1992),

3. Decreto del Presidente 14/2010 del 22 de marzo de 2010, available at www.juntadeandalucia.es/boja/boletines/2010/57/d/updf/d1.pdf.

4. Erasmus is the EU flagship higher education program enabling 200000 European students to study in a university from another member country each year.

5. The two biggest unions in Andalusia (UGT and CCCO) offer vocational training and apprenticeships both autonomously and in coordination with the Regional Ministry of Employment. They conduct sector-based training in sectors they identify as in need for training or with growth expectations (such as the aeronautics sector) - with a focus on industrial sectors. For instance, in 2009 they took part in an initiative of the Regional Ministry of Employment to train more than 1000 students, workers and redundant workers of the aeronautic sector.

6. Spanish Minister of Education discourse in the Congress on February 2010, available at www.educacion.es/horizontales/prensa/discursos/2010/02/comparecencia-discurso. html.

7. For instance, in 1999, the San Telmo Institute with the support of MIT created the CREARA program to promote entrepreneurship and the creation of innovative companies in the region.

8. Técnico Superior en Eficiencia Energética y Energía Solar Térmica.

9. For instance, it recently started the Andalucía Lab, a small centre in Marbella that promotes innovation in small companies related to tourism.

10. This EUR 52 million program includes integral energy efficiency retrofit of existing residential units, incorporation of new energy efficiency criteria for already planned rehabilitation of historic centres, and improving EE certification in new affordable homes.

11. More recently, Chalmers University of Technology and the University of Gothenburg have joined forces to teach entrepreneurship at the higher education level in the region, with the support of the Swedish government, creating the Institute for Innovation and Entrepreneurship (IIE) (www.hgu.gu.se/item.aspx?id=17007); at present they are trying to integrate their entrepreneurship schools under the project G4E (Gothenburg for Entrepreneurship). 


\section{References}

Aoyama, Y. and M. Castells. 2002. An Empirical Assessment of the Informational Society: Employment and Occupational Structures of G-7 Countries. International Labour Review 141,1-2: 123-159.

Bates, T. 1990. Entrepreneur Human Capital Inputs and Small Business Longevity. The Review of Economics and Statistics, 72,4: 551-559.

Bates, T. 1995. Self-Employment Entry Across Groups. Journal of Business Venturing 10, 143-156.

Becker, G. 1965. Human Capital. New York: Columbia University Press.

Carnoy, M. 1994. Faded Dreams: the Politics and Economics of Race in America. New York: Cambridge University Press.

Castells, M. 1996. The Rise of the Network Society. Cambridge, MA: Blackwell.

Castells, M. \& Hall, P. 1992. Andalucía: Innovación tecnológica y desarrollo económico. Sevilla: Espasa Calpe.

Centro de Estudios Andaluces. 2010. La inmigración en Andalucía. Available at www.centrodeestudiosandaluces.es/index.php? $m o d=$ publicaciones\&cat $=18 \&$ $i d=2526 \& i d a=0 \& i d m=$.

Chapple, K. 2005. Promising Futures: Workforce Development and Upward Mobility in Information Technology. Monograph 2005-01. Institute of Urban and Regional Development, University of California-Berkeley, Berkeley, CA.

Chapple, K. \& Hutson, M. 2010. Innovating the Green Economy in California Regions. Berkeley: University of California-Berkeley,.

Coronado, D., Acosta, M. and Fernández, A. 2008. Attitudes to innovation in peripheral economic regions. Research Policy, 37, 6-7: 1009-1021.

Cuadrado-Roura, J.R. \& Garcia-Tabuenca, A. Innovative and Creative Entrepreneurship in Spain. International Journal of Foresight and Innovation Policy 5,1-3: 113-135. 
Cuadrado-Roura, J.R. 2010. Regional Growth and Regional Policies: Lessons from the Spanish Experience, Chapter 13, pp.285-311, in Cuadrado-Roura, editor, Regional Policy, Economic Growth and Convergence. Berlin: Springer-Verlag.

Dahlstrand, A.-L. 1999. Technology-based SMEs in the Göteborg region: their origin and interaction with universities and large firms. Regional Studies 33,4: 379-389.

de Neubourg, C., Castonguay, J. \& K. Roelen. 2005. Social Safety Nets and Targeted Social Assistance: Lessons from the European Experience. Washington, DC: The World Bank.

Diario Independiente de Madrid. 2010. Nuevos madrileños, futuros empresarios. www.madridpress.com/noticia/106049/INMIGRANTES/nuevosmadrile\%C3\%Blos-futuros-empresarios.html.

Elliott, M., Roder, A., King, E., \& Stillman, J. (2001). Gearing Up: An Interim Report on the Sectoral Employment Initiative. Philadelphia, PA: Public/Private Ventures.

Florida, R. 2002. The rise of the creative class: and how it's transforming work, leisure, community and everyday life. New York, NY: Basic Books.

Giloth, R. 2000. Learning From the Field: Economic Growth and Workforce Development in the 1990s. Economic Development Quarterly, 14, 340-359.

Glaeser, E.L. and M. Resseger. 2009. The complementarity between cities and skills. Cambridge, MA: NBER Working Paper.

Granados-Cabezas.V. 2010. Innovation and the Internationalisation of the Local Economies: Andalusia. Spain. Unpublished paper.

Instituto Estadístico de Andalucía. 2010. Cualificación del Mercado Laboral, Encuesta de población activa. Andalucía. Datos anuales 2009. Sevilla: Consejería de Economía, Innovación y Ciencia.

Jacob, M., Lundqvist, M. \& Hellsmark, H. 2003. Entrepreneurial transformations in the Swedish University system: The case of Chalmers University of Technology. Research Policy 32,9: 1555-1568.

Junta de Andalucía. 2007. Plan Andaluz de Investigación, Desarrollo e Innovación, available at www.juntadeandalucia.es/economiainnovacionyciencia//.../Plan Andaluz.../1497084_PlanAndaluzdeInvestigacionxDesarrolloeInnovacion_. pdf.

Junta de Andalucía. 2009. Arranca el curso 2009-10 en la Universidad de Málaga con más de 32.800 alumnos. Available at www.juntadeandalucia.es/compromisos20082012/principal_noticia.php?id_noticia=327. 
Katz, L. and K. Murphy. 2002. Changes in relative wages, 1963-1987: Supply and demand factors. Quarterly Journal of Economics 107, 33-60.

Laurent, J., Periáñez, I. \& I.W. Petit de Gabriel. 2010. Self-Evaluation Report. Paris: OECD Directorate for Education Programme on Institutional Management in Higher Education.

Madsen, H., Neergaard, H., \& J.P. Ulhøi. 2003. Knowledge-intensive entrepreneurship and human capital. Journal of Small Business and Enterprise Development 10,4:426-434.

Marano, C. \& Tarr, K. 2004. The workforce intermediary: Profiling the field of practice and its challenges. Chapter 4, in Workforce Intermediaries for the Twenty-first Century, R. Giloth (Ed.), pp. 93-123. Philadelphia, PA: Temple University Press.

Martínez i Coma, F. \& Duval Hernández, R. 2009. Hostility toward Immigration in Spain. IZA Discussion Papers 4109. Bonn, Germany: Institute for the Study of Labor (IZA).

Mosey, S. \& Wright, M. 2007. From Human Capital to Social Capital: A Longitudinal Study of Technology-Based Academic Entrepreneurs Entrepreneurship: Theory \& Practice 31,6: 909-935.

National Center on Education and the Economy, 2007, Under One Roof: New Governance Structures for Local Economic and Workforce Development. http://colosus.ncee.org/pdf/wfd/Under_One_Roof_FINAL.pdf.

OECD \& Eurostat. 2005. Oslo Manual: Guidelines for Collecting and Interpreting Innovation Data, 3rd edition. Paris: OECD. Available at www.oecd.org/sti/ oslomanual.

Osterman, P. 1999. Securing prosperity: the American labor market: how it has changed and what to do about it. Princeton, N.J.: Princeton University Press.

Ramos-Vielba, I., Fernández-Esquinas, M. \& Espinosa-de-los-Monteros, E. 2009. Measuring university-industry collaboration in a regional innovation system. Scientometrics 84,3: 649-667,.

Rasmussen, E. \& Sørheim, R. 2006. Action-based entrepreneurship education. Technovation 26, 185-194.

Saxenian, A. 1994. Regional advantage: Culture and competition in Silicon Valley and Route 128. Cambridge, Mass.: Harvard University Press.

Saxenian. A. 2007. Brain circulation and regional innovation: The Silicon ValleyHsinchu-Shanghai Triangle in Polenske, K. 2007. Geography of Economic Innovation. Cambridge: Cambridge University Press. 
Sevilir, M. 2006. Human Capital Investment, Entrepreneurship and New Firm Creation. Unpublished paper.

Shrader, R.C. \& Siegel, D. 2007. Assessing the Relationship between Human Capital and Firm Performance: Evidence From Technology-Based New Ventures. Entrepreneurship: Theory \& Practice 31,6: 936-950.

Singh, N \& Pereira, A. 2005. The culturally customized Web site: Customizing web sites for the global marketplace. Oxford: Butterworth-Heinemann.

Wright, M., Hmieleski, K.M., Siegel, D.S. \& D.M. Ensley. 2007. The role of human capital in technological entrepreneurship. Entrepreneurship Theory \& Practice 31,6: 900-910.

Zandniapour, L. \& Conway, M. 2003. Gaining Ground: The Labor Market Progress of Participants of Sectoral Employment Development Programs. Washington, DC: Aspen Institute. 


\section{Chapter 3}

\section{The contribution of research organisations}

\section{Introduction}

Universities and public and private research organisations play a crucial role in regional economies that rely upon growth-oriented entrepreneurship and business innovation. The funding, infrastructure and commercialisation activities of research organisations within these economies are increasingly important as they make the transition to a knowledge-intensive form of production. In particular, research spin-offs and industry-university knowledge transfer (labour mobility, research collaborations, technology transfer agencies, university technology licensing programs, etc.) are key elements of this process, given the importance of basic and precompetitive research for innovation. However, there is a growing recognition in studies of regional economic development that the traditional view of the innovation process, referred to as the linear model, provides a partial, and sometimes inaccurate, perspective on the full dimensions of the relationship between research organisations and private firms. The emergence of second and third generation perspectives on the innovation process has led to the formulation of more complex and sophisticated accounts of the ways in which universities and research organisations contribute to regional economic development.

These new models and the insights they afford for a catch-up region, such as Andalusia, are explored in this section. The section summarises some of the key insights from the recent analytical and policy oriented literature and highlights their relevance for the case of Andalusia. The current policy context of the region is summarised with respect to the role of research organisations in the regional economy. It documents the policy context for the regional economy and the role played by both the Andalusia university system and RETA within that context. The role of RETA in supporting the development of industry-university relationships is examined. Policy recommendations are based on the alternative perspectives on innovation and the knowledge 
transfer process, as well as the findings from the OECD-LEED Study Mission to the region in April, 2010. Three international learning models are described which complement the key policy recommendations in the chapter and provide some insight into how they can be implemented.

\section{Policy issues}

From a theoretical perspective, the linear and infrastructure approaches to technology transfer is being replaced by one that emphasises the interactive and social nature of the knowledge transfer process and the importance of tacit dimensions of knowledge. Perspectives that start from first and second generation innovation models frequently misapprehend the nature of the linkages between the training and research activities of higher education institutions and regional firms, and how those linkages can best meet the needs of innovative firms and increase their innovative capabilities. The recent literature suggests that the mechanisms for knowledge transfer between firms and research institutions are multifaceted and that students often provide the most effective means for strengthening the linkages in the innovation system. Firms interested in accessing the tacit knowledge embedded in university research have to build common ground that overlaps the context of the university laboratory with that of their own R\&D laboratories, design shops, and manufacturing plants. Understanding how this common ground is created and how it facilitates the reciprocal exchange of material and knowledge, tacitly embodied in people and technologies or codified in publications is key to understanding how university-industry knowledge occurs. A key aspect of the process of knowledge transfer from universities and research institutes is through personal connections given that the knowledge being transferred is "embodied". To deploy university-generated knowledge in a commercial setting, firms must capture both its tacit, as well as its codified, component (Wolfe and Lucas, 2001). As one of the business leaders in Waterloo, Ontario is fond of saying, "the best knowledge transfer mechanism is a pair of shoes".

Knowledge transfers between universities and other economic actors are highly personalised, and as a result, often highly localised, which underscores the significance of geographical proximity. Proximity to the source of the research is important in influencing the success with which knowledge generated in the research laboratory is transferred to firms for commercial exploitation, or process innovations are adopted and diffused across researchers and users. The proximity effect of knowledge transfer provides a strong clue as to why universities are increasingly seen as an essential element in the process of local and regional economic development. The importance of geographic and physical proximity also provides a strong justification for the role of research and technology parks as a mechanism to increase the degree of interaction among researchers, firms and supporting organisations, such 
as RETA. However, the literature on technology parks also suggests that while physical proximity may be a necessary condition to promote knowledge transfer, it is not always a sufficient condition without the accompanying social dynamics that facilitate the desired degree of interaction within the physical setting. The same insight holds true for the transfer of knowledge from research organisations to firms.

RETA occupies a critical position in the R\&D\&I system of Andalusia in terms of providing a coordinating mechanism for enhancing the overall linkages in the system. Its creation by the Andalusian government in 2005 signifies a shift in understanding from the more traditional linear model of innovation to what has been defined as second and third generation models of the innovation process. In the first generation model, innovation begins in the research laboratory and proceeds through successive stages before the newly discovered knowledge is transformed into a potential product or process and successfully commercialised in the market place (Stokes, 1997). In the second generation model, greater emphasis is placed on the role of systems and research infrastructures (Teubal, Foray, Justman et al., 1996). This model recognises the influence exerted by the broader policy context on the innovation process and the importance of feedback mechanisms by which market signals provide guidance on the appropriate direction to proceed for successful innovation. The third generation of innovation approaches focuses on the role of shared knowledge and learning processes and the importance of building relationships and social capital between key actors and institutions. The success of this approach depends on strengthening the interfaces between key actors in the regional innovation system and strengthening the role of coordinating mechanisms between those actors (Landabaso, Kuklinski and Roman, 2007). A recent review of regional innovation policies in the Spanish regions characterises the current state of regional plans as representative of second generation innovative policies. "In the case of Andalusia, the expected results regarding the development and diffusion of an innovation culture among the actors in the system have not been achieved. One of the reasons may stem from the fact that the initiatives have had different management units which have not been completely coordinated." (Fernandez de Lucio, Mas-Verdu and Tortosa, 2010, p. 758). If RETA is to fulfil its mandate and help overcome the existing obstacles to innovation in the Andalusian economy, it must do so on the basis of a more effective way to augment knowledge flows between research organisations and firms in the regional economy.

The preceding discussion suggests that the task of transferring knowledge from universities to industries is more complex, and the role of universities in economic development more varied, than the linear approach to the innovation process allows. Conventional approaches to the question of knowledge flows between universities and industry, including both first and second generation models outlined above, frequently treat knowledge itself as a universally available commodity, virtually as a free public good, and knowledge transfer as a 
commercial and legal transaction between clearly defined agents. This view simplifies the complex nature of scientific knowledge and the linkages and processes that facilitate knowledge flows across institutional boundaries and enable a firm to absorb and employ that knowledge. Successful knowledge transfer depends on the type of knowledge involved, and how it is employed. A careful examination of the existing research on university-industry knowledge transfer is essential for a more balanced perspective on this relationship. As Mowery et al. have recently argued, "Any assessment of the economic role of universities must recognise the numerous, diverse channels through which university research influences industrial innovation and vice versa" (Mowery, Nelson, Sampat et al., 2004, p. 176).

Research organisations, including universities, are not just generators of commercial knowledge or even highly qualified research scientists; they provide other equally critical mechanisms of knowledge transfer.

- First, they generate and attract talent, which contributes both to the stock of tacit knowledge in the local economy, as well as to the "thickness" of the local labour market (Gertler and Vinodrai, 2005).

- Second, in addition to the conduct of basic research, universities provide both formal and informal technical support, as well as specialised expertise and facilities for on-going, firm-based R\&D activities. A recent examination by the National Academy of Engineering documents the multiple ways in which universities contribute to the development and expansion of local industry: through the provision of skilled graduates who become key players in local industry; through the conduct of long-term fundamental research that contributes to the science base and understanding available to private firms; through the promotion of an atmosphere of intellectual diversity that tolerates different approaches to the solution of technical problems; through direct collaboration with industry both on specific projects and in longer term relationships; by serving as test beds for new technologies and research instrumentation that are ultimately transferred to industry; and finally as the nuclei for start-up companies that spin-off from universities to become the seeds of new business (National Academy of Engineering, 2003, pp. 46-48; Grossman, Reid, and Morgan, 2001).

- Third, as national science systems become more interconnected and as the knowledge base required to support the production of "complex technologies" becomes more globalised, university research becomes increasingly important to local firms not just for the transfer of knowledge generated through its own research activities, but also as a conduit enabling firms to access knowledge from the "global pipelines" of international academic research networks (Bathelt, Malmberg, and Maskell, 2004; OECD 1999). 
From this perspective, universities can be seen as multi-faceted economic actors who are embedded in regions, and not only produce codified knowledge and human capital, but also participate actively as important institutional actors in building and sustaining local networks and flows of knowledge, and in linking them with global ones. The impact of the university can extend beyond the provision of basic research but, in order for this to occur, the knowledge assets of the university must be properly aligned with the multifaceted needs of local firms. A large base of research and development is required but not sufficient. The university must also address the business, workforce, and community issues. The university must be aligned with regional interests and industry clusters across a broad spectrum, not just in terms of technical knowledge (Paytas, Gradeck, and Andrew, 2004, 34).

Throughout the week of the study visit to Andalusia, the expert team made much of the distinction between research and science-based forms of innovation and broader, more social and organisational forms of innovation. This distinction is closely related to two other dichotomies that have been discussed in the literature and may be relevant for an analysis of knowledge transfer between research organisations and private firms in Andalusia.

- The first is the distinction between synthetic and analytical knowledge bases and the implications of this distinction for the kinds of knowledge that are transferred to firms and the most effective ways in which that knowledge is transferred.

- The second is the distinction between the science and technology mode of innovation (STI) and the doing by using mode of innovation (DUI), highlighted by Lundvall and his colleagues.

Each of these modes is more appropriate to specific industrial sectors and the nature of the relationship between research organisations and firms differs considerably for the two modes of innovation. The relevance of this distinction will be examined for the broader role of research organisations within the Andalusia innovation system in general, and the specific role of RETA.

\section{Synthetic vs. analytical knowledge base \& STI vs. DUI mode of innovation}

The distinction between the different knowledge bases that underlie the innovation process in different industrial sectors is critical for understanding the kinds of knowledge produced by various scientific fields of investigation and their relevance for the innovation needs of firms in different industries. Recent analyses of this question adopt the distinction between "analytical" and "synthetic" knowledge bases (Laestadius 1998; Asheim and Gertler, 2005). A synthetic knowledge base dominates industrial settings where innovation 
takes place mainly through the application of novel combinations of existing knowledge. Innovation in such industries is driven by the need to solve specific problems arising in the interaction with clients and suppliers. Classic industry examples come from sectors within advanced industrial engineering (such as the development of specialised machinery). In such sectors, research is less important than development. University-industry linkages play an important role, but they tend to take the form of applied problem solving, rather than basic research.

In contrast, an analytical knowledge base refers to industrial settings which rely upon scientific knowledge and where the production process draws upon sources of knowledge that make extensive use of cognitive and rational models. Prime examples of industrial sectors that rely upon this type of knowledge base are found in information technology and biotechnology. While firms in these sectors use their own R\&D departments to select from the vast sources of codified knowledge available to them, they tend to draw upon research results from the higher education system or national laboratories as a source for potential innovations or product modifications. University-industry linkages are an essential part of the knowledge transfer for sectors that rely upon this type of knowledge base.

The distinction between analytic and synthetic knowledge bases closely parallels the typology recently introduced between two different modes of innovation. The mode of innovation for firms varies significantly depending on both the industries in which the innovation occurs and the knowledge bases from which it draws. This approach distinguishes between a science, technology and innovation mode (STI) that draws primarily on the basis of formal research and codified knowledge and a mode that involves doing, using and interacting (DUI) that draws primarily upon experience-based learning (Jensen, Johnson, Lorenz, et al., 2004). Innovation in the STI mode draws substantially upon existing bodies of codified knowledge, both those involved in previous research undertaken by the firm, as well as research drawn from external sources (the analytical knowledge base). This mode is team-based and draws upon discrete pieces of research whose results are combined into an overall product. The end result requires the transfer of results in a codified form both within the organisation and across the boundaries of cooperating organisations that contributed to the innovation. In contrast, the DUI mode depends upon an innovation process where the knowledge required is much more tacit, involves a process of learning-by-interacting and is much more local in nature (closer to the synthetic knowledge base). The DUI mode of innovation builds upon the skills and knowledge of employees throughout the firm, not just its research department. Both the diversity of knowledge bases that firms draw upon and the different modes by which they innovate reinforce the point that the "knowledge-based economy" consists of many "pools" of knowledge accessible to different knowledge "communities" within the broader economy (Lundvall, 2006). 
These distinctions between the different types of knowledge bases and different modes of innovation are important for understanding how firms utilise the results of university-based research as well as the role played by highly qualified personnel trained through university-based research. The existence of these different dimensions of the innovation process suggests there is considerable variation in how university research is taken up and applied by different industrial sector. Those sectors associated with the steel industry, machine tools and advanced manufacturing tend to draw upon a synthetic knowledge base and the DUI mode of innovation. University research is of value to innovative firms in terms of keeping them informed about where the knowledge frontier is moving in these disciplines and for the recruitment of highly trained personnel. The life sciences and biotechnology industries draw directly upon analytical knowledge bases and conform more closely to the STI mode of innovation. In these industries, the direct results of university research and their potential for commercialisation are much more relevant for the innovative activities of individual firms. The two distinctions also highlight the importance of the personembodied nature of knowledge transfer. The ability of firms to draw on both the tacit and codified components of university research, as well as to determine how to use the kinds of knowledge that emerge from different academic disciplines and integrate that knowledge into the mode of innovation which predominates in their industrial sector, depends on their direct access both to researchers and especially to students involved in generating that research. Two of the most low-cost and effective mechanisms to facilitate this kind of knowledge transfer - especially in industries that draw more on synthetic knowledge bases and engage in the DUI mode of innovation - are through faculty consulting and student placements or exchanges with industry. These are two areas where RETA might effectively leverage its role as a coordinating organisation within the Andalusia R+D+ I system.

\section{Assessment of the region}

This section examines the current context for research, development and innovation $(\mathrm{R}+\mathrm{D}+\mathrm{I})$ policy in Andalusia and the specific role assigned to the universities in promoting innovation. It pays particular attention to the current state of the technology transfer process between the universities and enterprises in the regional economy, especially in terms of the concentration of the industrial structure of the region in small and medium-sized enterprises. It draws on an important distinction that was made to members of the OECD-LEED Study Mission between the role of the largest universities in the region - especially the two visited by the study team, Malaga and Seville - and the remaining ones. In this context, the existing relations between the research organisations and other institutions in the network that composes RETA, such as the technology parks will be examined. 


\section{The context for R\&D\&I policy in Andalusia}

\section{The EU Lisbon Agenda}

We begin with an examination of the overall context of R+D+ I policy in Andalusia. Regional development and innovation policy is set in the broader policy context of the European Union which has been driven over the past decade by the Lisbon Agenda adopted in 2000. The key objective of the Lisbon Agenda was to bring Europe up to the same standard as the most competitive knowledge-based economies in the world by 2010, although it is now widely recognised that the EU has failed to achieve this ambitious goal. Accordingly, INTERREG IV, the EU regional development program for 2007-2013 was redesigned to bring the Lisbon Strategy onto the stage of inter-regional cooperation. The most recent and current programming period for Cohesion Policy is 2007-2013. This period has been marked by two major and somewhat contradictory trends that have given rise to a conflicting set of concerns within the EU - the first is a growing preoccupation with the rise of new international economic powers in Asia and the changing international terms of competition that have led to a growing concern with the overall innovativeness and competitiveness of the European economy. The second is the accession to membership of ten new countries from Eastern Europe, all of whom had significantly lower levels of income and GDP per capita. Following a period of lengthy negotiations, the main features of the new Cohesion Policy were agreed to in April 2006. Under the new agreement, Cohesion Policy was more tightly integrated into the Lisbon Agenda with a stronger focus on knowledge creation and innovation than had previously been the case. Four particular areas were identified to focus regional development spending more clearly on these objectives: investing more in knowledge and innovation; unlocking the business potential of small and medium-sized enterprises; improving employability through flexicurity; and the better management of energy resources (Koschatzky and Stahlecker, 2010, 9-10). There is greater emphasis in this period on earmarking resources towards expenditure categories that correspond to the objectives of the Lisbon Agenda, such as research, technological development and innovation, support to firms" investments and information society objectives (Manzella and Mendez, 2009, p. 19; Barca, 2009, pp. 60-68).

In those countries where the regional or territorial governments enjoy a strong degree of autonomy, principally Germany, Italy and Spain, the preponderance of the funds are managed at the regional level, but in the remainder the funds are managed at the national level. The current EU transfers for regional development to Andalusia are managed under the "Operational Program for the Andalusia region" for the period from 2007 to 2013. The operational program has a total budget of EUR 9.84 billion, of which EUR 6.84 comes from the European Regional Development Fund (ERDF), which accounts for more than $19 \%$ of total ERDF funding for Spain in this 
period. The remainder is the national contribution to the region's economic development objectives. Overall, $71 \%$ of the funding under the operational program is directed towards the realisation of the objectives set out in the Lisbon strategy. The operational program has seven objectives in total, of which the first two are most relevant for the current study and involve: (i) the promotion of the knowledge economy; (ii) entrepreneurial development and innovation. Total expenditures on these two objectives are authorised at EUR 2.38 billion over the life of the program.

\section{The Innovation and Modernisation Plan for Andalusia (PIMA) and the Andalusia Plan for Research, Development and Innovation (PAIDI)}

The development of R\&D\&I policy in Andalusia has been governed through a series of successive research plans since the mid-1980s that have gradually evolved towards the tighter integration of R\&D activities, particularly among public research institutions, with private firms in the public sector. The current framework for research and innovation was developed in the context of the Second Modernisation Plan for Andalusia which was adopted in December, 2003 and is governed by the Innovation and Modernisation Plan for Andalusia (PIMA) adopted in 2006. The PIMA sets out the framework for the region's research and innovation strategy which includes expenditures from the Junta's own funds, as well as those transferred under the Operational Program of the EU. It makes explicit reference to the objective of the Lisbon Agenda and situates the goals for the region within that broader context: "Andalusia has to participate in the development of this innovative Europe, actively contributing to the creation of an environment of innovation capable of reducing the gap with the most competitive economies" (Junta de Andalucía, 2006).

According to the strategy, a key focus of the state's innovation policy is to encourage and reinforce technology transfer and cooperation between the public system of R\&D\&I and private companies and to promote the creation of spin-off companies from publicly financed research in the university sector. The university system is designated as playing a key role in this strategy. The PIMA notes that there has been a significant investment in the system over the past ten years which has resulted in the creation of five new universities and a $28 \%$ increase in the number of students enrolled and a corresponding increase in the teaching staff of the universities. This increase in the size and level of enrolment in the Andalusia university system is part of a broader change process focused on adapting teaching in the universities to social and business needs and developing a first class research enterprise. These goals are to be operational through the financing of joint university-business $\mathrm{R}+\mathrm{D}+\mathrm{I}$ projects, targeted particularly on strategic business sectors and through the funding of high quality research projects. This is complemented by efforts to increase 
and promote the degree of technology transfer by promoting the role of the Industrial Liaison Offices (OTRIs) in the universities, by physically relocating some of them to the technological parks and by coordinating the network of Andalusia OTRIs. A related goal of the Plan is the strengthening of technological infrastructures partly through the creation of Technology Centres in key industrial sectors and through the development of Technological Parks to support the effective transfer of knowledge between the institutions based in the parks, their resident companies and the OTRIs. Finally, the Plan calls for the creation of a number of coordinating structures in the Andalusia innovation system, outlined in more detail below. The overall budget set out in the Plan is EUR 5.7 billion, of which approximately EUR 2.7 billion (or nearly half) is designated for the support of knowledge industry and universities (Junta de Andalucía, 2006, 116).

The guiding paradigm for economic development set out in the PIMA is further elaborated in the Andalusia Plan for Research, Development and Innovation (PAIDI), which was adopted in 2007 and provides an overview of R\&D\&I initiatives in the region for the period from 2007-2013. The main focus of PAIDI is on technology transfer and the promotion of public-private partnerships between Andalusia public universities (dependent on the regional government) and private companies. In March, 2010 the Ministry of Enterprise, Innovation and Science was merged with the Ministry of Economy, further reinforcing the key role of technology transfer and collaboration between the public universities and private companies as the central element of the regional government's economic development strategy in Andalusia. Following closely on the approval of both the PIMA and the PAIDI was the passage of the Science and Knowledge Act which established the SAC Agents Classification which covers the core actors in the innovation sector in Andalusia.

The PAIDI is an operational plan that elaborates on the specific institutional agents to implement the broader goals of the PIMA. These agents can be grouped into four broad categories: (1) technological and knowledge spaces; (2) organisations geared to the generation of knowledge; (3) organisations oriented towards knowledge and technology transfer; and (4) organisations supporting the coordination and management of knowledge and technology. Included in the first category are the technological and scientific parks which are equipped with advanced technological infrastructures and programs to support the development of innovative companies. The Cartuja Park in Seville and the Andalusia Technological Park in Malaga (PTA) are seen as among the most dynamic among these. The second category includes the ten public universities in the region, as well as public research organisations, research centres and the R\&D departments of private companies. ${ }^{1}$ The third category subsumes the advanced technology centres, the centres of innovation and technology and organisations for the transfer of knowledge. The final category of agents includes the Technological Corporation of 
Andalusia (CTA), the Andalusian Technology Network (RETA), the Agency of Innovation and Development of Andalusia (IDEA), INVERCARIA, CITAndalucia which supports the participation of research centres and enterprises in EU R\&D funding programs, as well as a number of other intermediary associations (Gomez, 2007; Laurent, Forte, and Petit de Gabriel, 2010). The end result of the PAIDI, as the members of the study mission discovered, is a dense network of technological infrastructures and technology support organisation that often overlap and sometimes compete in their efforts to support the innovative activities of a relatively small number of research intensive firms and to promote the transfer of research and technology out of the relatively privileged public sector into private hands.

\section{The key role of the public university system}

The public university system clearly occupies a key position at the centre of both the overall institutional design of the knowledge and innovation support system in Andalusia, as well as being the chief beneficiary of funding under the PIMA. Although the private sector share of R\&D spending in Andalusia has grown from $29.3 \%$ in 1999 to $33.6 \%$ in 2008 , the proportion remains low compared to the Spanish average of $45.5 \%$ and the OECD average of $64.2 \%$. This figure is not surprising, however, given the predominance of SME's in low-technology sectors in the industrial structure of the regional economy. Public universities have thus been the primary source of R\&D spending in the region as well as the principal beneficiaries of the increase in public funds for research and in technology parks since the 1990s.

The privileged position of the public sector, and especially the research universities, is strongly reinforced by the priority afforded to them in the region's strategic plans discussed above. A recent review of the evolution of science and innovation policies in the Spanish regions suggests that Andalusia is a case in which a strong academic policy community began to form as national and regional innovation strategies became more important. The academic sector formed links to the public institutions and came to play a key role in the design of regional science and technology policies. It concludes that, "in general, the higher the level of development of a region's academic system ... the harder the regional government finds it to impose the objectives of research and innovation policy geared to favouring economic growth first and thus to give priority to the pro industry approach." Although the academic sector retains its privileged position in the plans of the regional government, the recent direction has gradually evolved towards greater emphasis on innovation in industry and fostering greater collaboration between the universities and industry (Sanz-Menendez and Crus-Castro 2005, 24-25). 


\section{Research teams}

The Andalusia university system consists of ten public universities, of which one, the Universidad Internacional de Andalucia (UNIA) is devoted primarily to teaching and does not participate directly in the research related programs funded under the regional government's various initiatives. The regional system of universities is governed by statutes and regulations of the central government, although they rely on the regional government for their financing and the overall management of the university system. A key focus of the region's strategy has been to position university researchers to compete as effectively as possible for national and EU sources of research funding. This has led to an organisational focus on providing support for research teams within the universities as the principal basis for research funding, which in turn has had a strong impact on the organisational structure of the universities. The establishment of an official register of university research teams has de facto made the research team the key organisational unit responsible for the conduct of scientific research within the universities. This internal structuring has been formalised in the University Law of 2003 and regional regulations governing the university system, which now designate research teams as a core element in the internal structure of the universities (Ramos-Vielba and Fernandez-Esquinas, 2009). The nine research universities have drawn up their own research strategies in response to the PAIDI; however, the recent self-evaluation report prepared for the OECD review of higher education in the region notes that the relation between the universities' research priorities and those designated in the region's strategic plans lacks a strong degree of coordination, as indicated by the relative absence of the universities' prioritizing of research in biotechnology, ICTs or tourism. The self-evaluation report concludes that "this shows that the universities do not have their own research strategies, but rather that they are derived, to a large extent, from the research groups" (Laurent, et al. 2010, p. 29).

\section{The Technology Transfer Offices (OTRIs)}

Support for university research is provided through a range of institutions, including the OTRIs, the university foundations and the presence of the universities in the technology parks. The nine public research universities also develop their own strategies to meet regional demands, especially the needs of the SMEs through their association with other research organisations such as the Higher National Research Council (CSIC) or public and private research centres. Each of the nine universities, excepting UNIA, has an OTRI; these are in turn part of the National OTRI-Net and have also recently created their own regional network, Red OTRI Andalusia. The OTRIs are responsible for channelling external research demands to the appropriate research groups within their own institutions, as well as promoting the transfer of research results 
into the private sector through patenting, licensing and spin-offs. Andalusia Technology Transfer Offices have seen their responsibilities and budgets grow in the last decade thanks to the regional government's push for innovation. The OTRIs actively support university students, faculty and researchers who want to create their own companies, especially in the case of spin-offs derived from university research. They also support the university community in registering new patents. Apart from their function of promoting technology transfer, public-private cooperation and creation of spin-offs, they are increasingly paying attention to promoting entrepreneurial activity among students as a way to increase the number of companies originated in the university.

However, they are hampered in their performance of this role by the lack of sufficient and adequate staff to maintain contact with local businesses, as well as by structural impediments in national policies governing patenting and release time for university research to participate in start-up firms. One of the main difficulties experienced by the OTRIs in Andalusia is that they need to serve the needs of their universities as a whole, while the needs of individual departments might be quite different. As one of the university officials noted for the case of researchers and entrepreneurs in our site visit to the University of Seville, "one of the problems is the size of the University of Seville ... They have a centralised OTRI, but they would probably need an OTRI in each main department, or at least in the applied science departments."

\section{General factors inhibiting technology transfer}

The challenge of promoting the commercialisation of intellectual property is made more difficult by the conditions established by the Spanish Patent Act. It designates that the ownership of discoveries made by university professors during their period of contract with the university, and which constitute part of their university duties, belong to the university. Professors have the right to share in the benefits that flow to the university from the use of the intellectual property rights derived from their inventions, but the precise share that they receive is governed by the statutes of the individual universities. In general, the universities are critical of the current state of the legal framework governing intellectual property rights as it provides them with little guidance for determining how benefits should be shared in the course of contractual work.

National regulations have also traditionally imposed restrictions on the mobility of university researchers between the public sector and private spin-off companies, as it limits them from holding more than a $10 \%$ interest in private companies, from being a member of a board of directors, or taking a temporary leave of absence from the university to form a private company. The act governing universities was amended in 2001 to allow university researchers a five year leave of absence without giving up their university position to participate in 
technology-based spin-offs (Empresas de Base Tecnológica - EBT). However, the universities are still critical of the current law as they feel that the guidelines for implementing the regulations are insufficient to allow the integration of university researchers into the EBTs. The regional government has also established two separate programmes to promote the creation of EBTs. The Atlantis Programme, managed by the IDEA Agency is geared toward identifying newly formed enterprises from across Spain and attracting them to set up in Andalusia. The Campus Programme, also managed by IDEA supports the spinoff of EBTs from Andalusia universities by providing them with loans of up to EUR 100000 through the public venture capital fund Invercaria. The universities undertake to mentor the start-ups right from their inception, while IDEA provides the assessment needed to fund and develop the project and ensure a greater potential for success. The combined efforts of the universities and the regional government are clearly enjoying a certain degree of success as the rate of formation of new EBTs has increased steadily over the past decade, with a cumulative total of more than 120 established by 2008 (Laurent et al., 2010).

A final factor inhibiting the transfer of research results from the universities to the private sector is described as a cultural barrier. Many of the region's universities place a higher priority on the performance of basic research as well as judge scholarly success based on the international recognition of research outputs, rather than focus on the contribution of public research to local and regional economic development (an academic phenomenon which is not limited to Andalusia universities). One consequence of this cultural attitude is that the universities have been reluctant to direct research efforts in strategic directions related to areas of industrial strength in the regional economy, acquiescing to pressure from their researchers to afford all areas of research endeavour equal treatment (Laurent, et al. 2010).

The following sections summarise the relevance of these key themes as they emerged from the visits of the study team with the representatives of two of the leading universities in the region: Malaga and Seville.

\section{Technology transfer at the University of Malaga}

Malaga is the third largest university of Andalusia after Granada and Seville. It has 2300 professors on staff and 40000 students. The university has 270 active research groups, which is the third largest number in the region. The university has been working on technology transfer for quite a while, although the regional government has made this a high priority in the last five years, which has made more funding available to university. One problem that the university faces is that it has started up too many companies, but the government does not have sufficient funding available to support all of the start ups. Roughly $30 \%$ of the university funding is tied to the number of patents, spinoffs, and number of companies that the university provides technical assistance 
to. These performance indicators for research and technology transfer are valuable in helping universities obtain government funding. The University of Malaga is part of the network of technology transfer offices in Andalusia (Red OTRI) whose purpose is to help the individual universities collaborate more effectively. They have a parallel system in effect between the network of technology transfer offices and RETA. The connection with RETA is primarily through the University of Malaga, while the relationship between other universities is maintained through the network of technology transfer offices.

The University of Malaga's underlying strategy is to generate technology push by moving research out of the university into the private sector. They have generated 150 patents, but they also try to support a number of new spin-off companies every year. They choose 11 projects per year, and then provide support to the best three economically. They provide the spin-off companies with a place to work for one year and also offer additional support to the companies in the form of economic feasibility studies. After one year, they have an agreement with the Malaga-based Andalusia Technology Park (PTA) that the firms can move to the incubator in the Park. The university also has two persons in the research office working with the various research groups trying to determine what kind of results can best be diffused to private companies. They are mainly focused on those groups that do not have a tradition of successfully transferring technology to private sector firms. The objective of this focus is to demonstrate to new research groups within the university the feasibility of engaging in technology transfer activities. Patenting tends to get more attention than spin-offs within the university because licensing a patent is easier to do and a license generates faster returns to the university than the lengthy process involved in establishing a technology-based business. Thus, the university focuses on promoting patents as a way to support external start-ups through technology licensing.

The university also organises various seminars and meetings between private companies and its research groups. They try to organise thematic meetings to help the match between academics and entrepreneurs. In addition, they have posted online the themes and interests of their research groups with contact information so that they can be contacted by interested business people. The objective of this activity is to convince the private companies that increased contact with the universities is valuable for them, but this is a particular challenge with the SMEs that predominate in the Andalusia economy. They assess the needs of companies and then try to match their needs with the existing skills available within in the university.

The university enjoys a good working relationship with RETA and it draws upon this relationship to build its contacts with private companies. The relationship is based on the extensive knowledge that RETA has of firms on the ground in different parts of the Andalusia economy and RETA's ability 
to send companies to the University for Assistance. RETA often has detailed knowledge of the individual needs or requirements of particular companies which they provide to the university. The university, in turn, tries to identify the appropriate research groups that have the specific skills that can help solve the technical problems faced by the companies. Therefore, RETA acts as an intermediary between the university and the companies and $80 \%$ of the contacts generated by RETA have resulted in successful outcomes from the university's perspective.

One of the main fields in which the university invests more intensively is information and communications technology through its two academic centres which have strong research capabilities in telematics and information and communications technology. They have very good performance indicators at the national level in this research area and the ICT research groups within the university generate $44 \%$ of its overall income from research contracts. Indeed, the University of Malaga ia ranked $8^{\text {th }}$ in the national rankings for ICT departments.

Overall $50 \%$ of the university's research funding comes from national programs, $30 \%$ from regional programs, $10 \%$ from EU programs and $10 \%$ from technology transfer. From the perspective of the university, the Andalusia regional government is doing a good job of providing support for R\&D\&I, but there is still a significant gap between Andalusia and the more advanced regions, such as Catalonia and the Basque Country. For instance, in Catalonia there are more university institutes that participate directly with private companies. With respect to technology transfer organisations within the regional innovation system, the university representatives felt there has been a multiplication of them in recent years, with the result that there are often parallel institutions with overlapping mandates that could be consolidated into fewer structures. The university scientists find this support framework very confusing because they are asked to participate in a lot of different rounds of meetings with these various agencies. RETA is viewed as a useful organisation when it is collaborating with the universities, but less so when it is not. This gives rise to the sentiment that the regional government should simplify the innovation system, because too many organisations are replicating the same functions and competing in the same space. The underlying fear is that the regional government has invested a lot of money in creating parallel structures that may disappear in three years when the EU funding runs out.

With respect to the question of how the university views the "demand pull" approach to technology transfer, the representatives did not seem to place a great deal of emphasis on coordinating technology consulting services for private firms. However, there will be facilities for firms to locate their research efforts on the new campus that will be jointly run with the PTA, plus there are already two buildings in the PTA where companies can locate 
their research efforts. This will provide the location for some institutes where they can co-locate researchers and companies. They also have some programs that provide academic credits to students for working on company research projects. The universities in some respect have much more research and technology capabilities than the local companies need, in other words they are not well adapted to actually meet the innovation needs of the local companies. This suggests the need to rethink the way in which existing university capabilities can be deployed more effectively to meet the needs of local companies and the role that RETA might potentially play in that process.

\section{Technology transfer at the University of Seville}

The second meeting was at the University of Seville with representatives of Citius and the OTRI. Since 2004, the University has had a Vice-Chancellor's Office for Technological Transfer separate from the Office of Research. This office is responsible for overseeing the University's OTRI, as well as providing support services to facilitate work experience for its students in enterprises and the Foundation. There are 14 different research offices which report to the ViceChancellor's office. They offer assistance in the use of advanced equipment for the various research groups in the university plus the support of qualified technicians, $35 \%$ of whom have Ph.D.s and $65 \%$ have Bachelor degrees. Citius, the technology and innovation centre at the university is a 5000 square metre building with a wide range of facilities that include a scanning electron microscope with the highest resolution in Spain, as well as nuclear magnetic resonance equipment. The centre also has radio isotopes used in medical research as well as training technicians for later work in hospitals. Citius has a number of joint agreements with large companies who share joint research facilities in the building. For example, Endesa (the power company) has an agreement with the university under which it rents space, but also has to spend a certain amount of money every year in research with the university which creates synergies between Endesa and the research groups. They have projects underway related to the study of oil in transformers, as well as projects related to bioremediation of toxic substances in transformers and are developing bio-organisms which eliminate the toxic substances. They are also studying how the power network ages and how to predict which elements of the network are going to need to be replaced. There is an important biotech company called Abengoa Bioenergy, which has its R\&D department located in the Citius building.

Citius also provides small space to spin-off companies under a three year agreement for which allows the companies use of the space in the university. Three companies that were mentioned were Ingeniatrics which has been there for three and a half years and are now moving to a warehouse; Biomorphic which develops advanced ceramics for high temperature applications; and Resbioagro, which develops microorganism for agricultural applications. The 
centre also signs joint agreements with private companies. They have seven agreements from last year and about thirty in total. They give companies a special price for using the research equipment in the university. The research centre is self-funding with a budget of EUR 1 million, $50 \%$ of which comes from fees charged to research groups and companies for use of the facilities and the equipment. There are 240 research groups that use facilities and 80 external companies that use their services.

The Office for Technology Transfer has twelve people on staff with strong technical qualifications. The office has three divisions, one for technology commercialisation, one to support research projects and the application process and one for entrepreneurship in the University of Seville. The office has obtained 24 patents in the past year and has license agreements with companies in the industrial sector. In the past year the value of private research contracts awarded to researchers and firms was EUR 28 million for the University of Seville, which accounts for approximately half of the total contract funding for the universities in Andalusia. They have also undertaken all the management of projects related to Framework Funding from the EU. The third division in the Office of Technology Transfer provides support to spin-off companies of which there a total of 28, eight in the past year (2009). Throughout the process of spinning off companies, the Office collaborates with the Regional Development Agency, IDEA. Funding for the OTRI comes half from the University of Seville, $40 \%$ from the regional government, and $10 \%$ from the national government. They are now developing a new building to be located in the Cartuja93 Technology Park that will be focused on research projects and provide flexible infrastructure space for the most important projects of the University of Seville.

One problem that was identified by the university representatives is that they lack a cadre of technically trained people who can provide technical support to research teams and firms. The university is well endowed with professors and administrators, but they also perceive the need for a category of people who do not do research, but who provide technical assistance to the research teams. The meeting with Citius and the OTRI also highlighted the general problem with the issue of the national regulations governing university employment which had been raised previously. Professors cannot leave the university and go to work for a start up company with any assurance that they will be able to return from that employment to their university position.

A related problem that was identified concerns the issue of intellectual property rights (IPR). The university has found that companies want to retain all the rights to intellectual property when they sign a contract with a university research team, and the university researchers are usually keen to sign the agreement no matter what the conditions are. As a consequence, this means that the university will end up losing the benefit of years of research. 
From the administrators' perspective, this implies the need for a more balanced approach to sharing the benefits that will potentially flow from the IPR derived from university research. However, control over IPR is often found to be one of the most difficult issues to negotiate in joint universityindustry research initiatives and there is no universally agreed solution to this problem. Furthermore, the university representatives suggested the need to redesign career incentives, because a career reward system based primarily on publications does not provide adequate recognition to researchers who are also interested in research commercialisation and the transfer of knowledge. However, research into this subject conducted in the U.S. indicates that the internal incentive system within university departments tend to be strongly shaped by the leadership of those departments. Departments with chairs who have a strong track record of licensing and commercializing their research results tend to set a pattern for other members of the department. Similarly, there is a strong degree of emulating the behaviour of peers in terms of the propensity to disclose research results: if individual members of a department observe others at their academic rank engaging in commercialisation and licensing activities, then they are more likely to participate in technology transfer (Bercovitz and Feldman, 2008).

With respect to the question of technology transfer to SMEs the university representatives suggested that the OTRI is not well prepared to provide technical assistance to firms. It does not have a big enough staff to deal with this. The real problem they face is with respect to the size of university, which has 4000 researchers and approximately 70000 students. The OTRI has just twelve people. They suggested that there is a need for a separate office in each of the different sub-units of the university, or at least in each of the applied science departments. The small size of the OTRI creates additional problems for the university in working with SMEs because the relatively small team of technology transfer agents has difficulty analyzing the commercialisation potential arising from different fields of research. The technology transfer agents are occupied with administrative procedures and dealing with the legal framework and do not have time to be proactive and look out for small firms that may need university support to introduce incremental improvements in their products or processes. This highlights a critical issue in the university's relations with the SMEs that characterise the regional economy. The staff limitations of the technology transfer offices make it difficult for universities to work with small firms and, as a consequence, they focus their efforts on working with the firms that engage in R\&D. There are effective models available in other countries that suggest alternative mechanisms.

With respect to RETA and the other coordinating organisations in the R\&D\&I system, the problem is that they establish initial contacts between firms and the university, but they do not do much follow-up. This suggests that there exists a critical opportunity for RETA to use its intermediary 
position between the small coterie of firms that have been identified as innovative and the universities to assist the firms in finding the researchers with the appropriate knowledge and skills, thereby assisting the firms in solving technical problems that may limit or constrain their innovative potential.

\section{University-industry linkages: a more varied perspective}

While the emphasis in both the regional government's strategic plans and in the universities' own efforts to promote regional development and innovation seems to focus on technology transfer, commercialisation and the spinoff of EBTs, two recent surveys by researchers at the Institute for Advanced Social Studies, part of the CSIC, provide a more nuanced and varied picture of the relations between university researchers and private firms, especially SMEs in the region. The studies suggest that the primary focus on intellectual property mechanisms is misplaced, as they tend to be concentrated in specific scientific fields and are of relevance only to a small proportion of the research community. On balance, intellectual property activities seem to be more predominant in the analytical fields of scientific investigation discussed above and are of greater importance for firms that engage in the STI form of innovation. Even within these fields, intellectual property related activities constitute, at best, a small part of a more complex and varied set of relationships that exist between the research community and private sector firms. Only a small part of these relationships is captured in the formal data gathered by the university technology transfer offices. The findings of this research are highly consistent with other studies in a different context such as MIT and the Boston area (Agrawal and Henderson, 2002).

The researchers surveyed a total of 765 research teams at Andalusia universities in 2008 based on the official registry of researchers in the public sector that is used by the regional government to allocate research funding. The majority of these research teams $(89 \%)$ were based at universities, reflecting the predominant role they play in the regional R\&D\&I system. The survey covered a long list of knowledge transfer activities which were subsequently coded into four main categories based on the survey results: (1) $R \& D$ activities and formal consulting; (2) training and the transfer of personnel; (3) commercialisation activities related to intellectual property rights; and (4) other contacts. More than half of the research teams surveyed $(55.5 \%)$ replied that they had participated in some form of collaborative activities with private firms over the period from 2000 to 2007. The results revealed that a high proportion of the research teams provide expert consulting to private firms ( 38 percent) and carry out research projects commissioned by firms (34.8 percent). Secondly, there was a considerable amount of activity related to the training of human resources, both in terms of the specific training of personnel provided by the researchers for firms and internships of 
university researchers in private firms, as well as the exchange of scientific personnel between research teams and firms. Activities directly related to the exploitation of intellectual property rights resulting from university research occurred in many fewer instances, with only $10 \%$ of the teams being involved in patenting and only $6 \%$ involved in the creation of spin-offs or start-up firms. The researchers note the critical policy implications that emerge from the study. "If policies aimed at fostering interactions concentrate primarily on a single, collaborative activity, they are not taking into account a number of important types of relationships with industry that are developed in most university systems." The excessive focus on intellectual property rights provides a disincentive for the many university researchers who participate in the multiple other forms of university-industry collaboration. They also note that policy-makers who rely on the formal data collected by university technology transfer offices are privy to at best the "tip of the iceberg" in terms of the true dimensions of university-industry collaboration that exist (Ramos-Vielba et al., 2009, p. 17).

In a related study, the same group of CSIC researchers surveyed 737 Andalusia innovative companies, covering a broad variety of industrial sectors and innovation profiles, taken from the directory of firms compiled by RETA as part of their innovation assessment. The directory includes a list of 1898 firms, including firms that received some type of financial support for innovation during the period from 2000 to 2006, as well as others added by RETA which were identified as being prone to undertaking innovative activities. The firms were asked about the nature of their university-industry connections. The researchers discovered that $57 \%$ of the firms in the sample did not engage in any type of collaboration with universities. The firms in this group tended to be smaller, independently owned and more locally oriented. They were also less innovative, had few employees with higher education degrees and few of them had R\&D departments. Among the remaining 305 firms that collaborated with universities, the most frequent type of collaboration involved informal relationship followed by the training of university personnel inside the firm. Among the other firms, 15 to $25 \%$ engaged in some form of consultancy relationship with university staff, 5 to $15 \%$ of the firms had contract research projects with the universities and less than $5 \%$ of the firms had participated in the creation of spin-off or start-up firms, the sale or transfer of patents or joint ventures. It should be recalled that this sample of firms involves the second tier of innovative firms in the region and not the top tier of the 300 to 500 most R\&D-intensive firms. However, this sample is highly significant for any discussion of RETA's role in enhancing connections between the universities and the next tier of innovative firms in the region and is consistent with the recent focusing of RETA's mandate on this tier of innovative firms in the region. 
Another interesting finding was the role of informal contacts and relationships between universities and companies and how "contacts that occur in different kinds of events are the breeding ground for future interchanges". The survey suggested that while R\&D activities might be easily transferred in regional innovation systems with high-technology business sectors, this is not necessarily the case for regions dominated by low-technology businesses. In other words, relationships between universities and companies are not limited to R\&D transfer, but they depend on the needs and characteristics of the companies in the part of the regional economy where the universities are located. This supports the idea that knowledge creation and application - and therefore innovation - are socially embedded processes.

The authors also suggest that it is important to recognise that $R \& D$ related activities do not play a major role in most of the firms that are designated as "innovative" within the regional economy. It is important for universities and regional coordinating bodies to recognise that R\&D activities, especially the commercialisation and exploitation of intellectual property derived from university research are just a portion of the firm's overall interactions with the higher education system and that an interest in this aspect only emerges when firms have an absorptive capacity that has been built up through a wide range of previous interactions with universities.

The policy implications of this research suggest the need for greater support on the part of the higher education system for a less R\&D-intensive form of interaction between the universities and the private sector that the latter is capable of managing. This would require the universities to provide greater support for these firms in the form of technical advice and problem solving in a wide range of activities that are consistent with the DUI form of innovation. It could also be facilitated by more focused forms of cooperative education programs which could ensure that the students being trained in the universities are familiar with the kinds of technical problems that these firms

\section{Table 3.1. Interactions with universities of Andalusian innovative firms}

(Percentage of "yes" answer to each type of interaction)

\begin{tabular}{lr|lr|lr}
\hline Consultancy work & 21.8 & Patent exploitation & 4.6 & Joint ventures with Universities & 3.7 \\
Commissioning of R\&D projects & 14.0 & Training of Uni. Postgraduates & 27.5 & $\begin{array}{l}\text { Participation in spin-offs/ } \\
\text { and internships at firms }\end{array}$ & 3.9 \\
to Universities & 22.1 & Exchange of personnel & 7.1 & Informal networks & 32.2 \\
Joint R\&D projects & 8.1 & Training of firm workers by the & 15.2 & $\begin{array}{l}\text { Other types of collaborative } \\
\text { activities }\end{array}$ & 1.9 \\
Use or renting of facilities & & Universities & &
\end{tabular}

Source: Fernandez-Esquinas et al., 2009. 
must overcome. It is through these lower orders of interaction between public research organisations and private firms that the absorptive capacity of local firms will be developed. And the latter is needed for firms to engage in more $\mathrm{R} \& \mathrm{D}$ intensive forms of interaction leading to the fuller exploitation of intellectual property (Fernandez-Esquinas, Ramos-Vielba, Jimenez-Buedo, et al., 2009).

To reiterate, the key challenge is how to tighten the linkages in the system between the individual agencies that comprise this part of the innovation system and how to improve the linkages between universities and innovative firms. Andalusia needs to move beyond the narrow number of R\&D performing firms to bring in a broader range of the currently innovative firms and the greater number of potentially innovative ones. Given that the majority of presentations to the Study Mission were concerned primarily with the STI mode of innovation, the distinction between the STI and DUI modes of innovation serves to broaden the conception of the different roles that the universities and research sector can play in the regional innovation system.

\section{The Role of RETA}

One of the main roles of RETA as conceived initially in 2005 was to serve as a bridge between the technology parks and the $99 \%$ of Andalusian firms which are SMEs and are situated far from the parks. Its originating motivation was to bring the ethos and the culture of the technology parks to the majority of small companies scattered throughout the region, thus turning the entire region into one big technology park. RETA is thus conceived of as a networked model with the dual responsibilities of: (1) integrating the various elements of the Andalusian $\mathrm{R}+\mathrm{D}+\mathrm{I}$ system and serving as a coordinating mechanism between the small firms that comprise the backbone of the regional economy and the other organisations which play an innovation support role; and (2) to facilitate the dissemination of research expertise and knowledge relevant to innovation to the commercial sector broadly. Until recently, RETA has operated through a network of 67 associate members, including the science and technology parks, technological centres and public universities and worked through a network 85 innovation agents situated in the parks, technology centres, main industrial estates, and peripheral areas. The reorganisation of RETA's mandate, subsequent to the visit of the OECD Study Mission, has refined this role to a considerable degree.

These observations derived from the OECD-LEED Study Mission to Andalusia are consistent with other recent evaluations of the role of the higher education institutions in the region. With respect to the various intermediary organisations that comprise the institutional infrastructure of the regional R\&D\&I system, the universities displayed a generally positive attitude towards the contribution of CITAndalucía, which is not surprising given that its primary 
mandate is to help university research groups attract EU funding for their institutions. Some of the universities were more critical of the contribution that RETA makes to promoting linkages between researchers and SMEs in the region. There was a perception that the absence of a formal mechanism for managing RETA's relations with the OTRIs in order to establish connections between university researchers and private firms limits RETA's effectiveness in the eyes of the research community (Laurent, et al. 2010, 34-35). While this perception may reflect a clash between the different institutional structures and cultures of the coordinating agency and the universities, it suggests there is considerable room for RETA to revaluate the way in which it currently manages its relationship with the region's research organisations.

The task that had been assigned to RETA, given the resources at its disposal, was daunting to say the least. The regional government's strategic plans, as embodied in the PIMA and PAIDI rely on the coordinating and support organisations, such as RETA, to maintain links between the research organisations, particularly the universities, and local businesses within the region. However, as was observed several times during our site visits to the universities, this system operates imperfectly at best. The challenge that RETA faces is that only a very small portion (less than 5\%) of the second tier innovative firms that it services are in a position to engage with the universities in collaborative R\&D undertakings or attempts to license and commercialise the outputs of university research. Its role would be more manageable if it were limited to working with the 300 more innovative companies that have been identified and help them upgrade their innovative capabilities. This would more likely follow the DUI mode of innovation, rather than the STI mode. This would allow RETA to concentrate its efforts and resources in working with the subset of companies studied by CSIC and who have the potential to engage more fully in these activities. It would appear that this more focused role is consistent with the revision of its mandate that was introduced in the summer of 2010.

However, in order for RETA to perform this more focused role, then it must begin to think of how to leverage its current assets and its strategic position within the regional R\&D\&I system to achieve these goals. Based on the information that was provided to the Study Mission in our meetings at the two universities, that current role seems to be limited at best, especially in comparison to their perception of the role played by other organisations in the region. The recent changes in the mandate of RETA may help to reduce the degree to which it is seen as a competitor by some of the others organisation in the region, such as CTA, the Employers Association and even the universities, and provide complementary services that meet the needs of the tier of innovative SMEs it is mandated to serve. Doing so would allow it to be viewed as a valued partner by the public universities through the creation of new mechanisms for linking up the knowledge capabilities of the research groups with the 
innovative needs of the SMEs. The key challenge is how to expand its ability to build linkages in the innovation system, especially by focusing on those firms and sectors that are more likely to use a DUI mode of innovation. We will explore the alternative ways to create these linkages through the policy recommendations laid out in the next section of this chapter.

\section{Policy recommendations}

This section of the chapter outlines three key recommendations to help RETA build more effective linkages with other key players in the regional R\&D\&I system and to help accomplish the key objectives set out in its 2010 strategy.

\section{Create a database of faculty's skills and match it with the innovative needs of local firms}

The detailed surveys of both university research teams and innovative firms conducted by the team at IESA-CSIC reveal that there are already a substantial number of university researchers who engage in a wide range of informal contacts with regional firms in a variety of activities, including consultancy. We know from the broader literature that consultancy with university faculty often serves a variety of purposes from the firm's perspective. It is a relatively low cost and efficient way in which to gain needed assistance in solving technical problems with respect to both product and process innovation. It also serves as a means by which private firms test the compatibility of university faculty in terms of potentially engaging with them in contract or collaborative research. Where the consultancy arrangement works out to the firm's satisfaction, studies indicate that they often move on to the next level of involvement with the university researcher or research team in terms of engaging in a formal contract for research or developing a collaborative research project. Our study team visits to the universities revealed that the universities themselves are much happier when RETA works with them to bring individual firms to the research office or OTRI to find suitable faculty collaborators. RETA and the RED-OTRI need to work together to develop a mechanism for linking firms in need of technical assistance with university faculty with the requisite technical or business skills to provide that assistance. One mechanism to accomplish this might take the form of creating an integrated database of faculty research and consulting skills at the nine research universities in the region. The IESA-CSIC surveys might even provide the preliminary basis for constructing such a database if the restriction of confidentiality could be satisfied. RED-OTRI could use the results of the survey to begin to identify the faculty members on the various research teams at the individual universities with skill sets in demand by the second 
tier of innovative companies that RETA works with. This could be rolled out on a university by university basis beginning with one or two, where both organisations feel there is the greatest potential for collaboration. Once they have begun to use the database to link researchers up with firms in need of their expertise, RETA and RED-OTRI could extend the model to the other universities in the region. While this may take some time to fully implement, it is expected that early successes at one or two universities in the region would have a positive demonstration effect that would make the others want to participate. A successful endeavour along these lines can help to develop the interpersonal and social networks among private firms and university researchers that are viewed as a central component of third generation innovation models.

\section{Promote cooperative education programmes}

The second recommendation concerns ways to expand the current number of trainees in the university system by introducing some form of cooperative educational program at the universities. The Study Mission heard that there currently exist a number of different programs in the region to provide training spaces for university students in private firms. This was made clear in both visits to the universities, as well as in the surveys conducted by the IESA-CSIC research teams. While the exact scope of these programs is not clear, there seems to be considerable scope for expanding the range of these programs. It should be noted that a formal cooperative education program goes beyond merely placing student trainees with firms for a limited period. A cooperative education program usually involves engaging university students in alternating work study terms throughout the course of their undergraduate or first degrees. Where these programs have been used extensively, such as at the University of Waterloo in Ontario, there is solid research evidence which indicates that that the coop students themselves provide a highly effective conduit for transferring research and specialised knowledge into the private firms and also for bringing the "real world" perspective of the firms back from their work terms into the university classroom. This example is discussed in further detail in one of the learning models. The introduction of a full-fledged co-op program at several of the regional universities would require some additional public support, but it could make use of RETA's contacts with the group of innovative firms in the region as the basis for finding job placements for university students in the small and medium-sized enterprises that RETA services. The principle obstacle to introducing and expanding university coop programs is the high cost incurred by the university administrations in locating work placements for their students. In successful coop programs, this is usually accomplished through the provision of several dedicated university personnel to the task of finding these placements in the firms. The high cost of this task could 
be overcome to some degree by using RETA's existing network of contacts with innovative firms in the region to locate the placements for the university students. It would require RETA to work closely with both the firms located in the technology parks as well as firms distributed more broadly throughout the region to identify the firms that would be interested in providing work placements for students in a cooperative education program. This could accomplish several purposes at once. It could improve the quality of human capital working in the firms by providing them with technically trained university students; it could provide students with more real life work experience as part of their formal education; and it could use the students as a conduit for feeding problems and concerns of small and medium-sized enterprises back into the teaching activities of the university faculty. There is also some evidence from the North American experience that coop students can create a demand-pull mechanism to pull technical knowledge out of universities to provide assistance to firms (Bramwell and Wolfe, 2008).

\section{Consider the creation of a "virtual technology park"}

The third recommendation involves alternative ways for RETA to work more closely with the tier of innovative firms located in the technology parks as well as those located outside in order to develop a denser network of social relationships between firms and research teams. Two ways to achieve this are to expand the presence of incubators in the technology parks as a way of providing more space for university spin-offs and entrepreneurial start-up firms, or to physically locate the parks on a university campus, as is the case with the new PTA-University of Malaga Campus. However, the impact of the current crisis in the region and the eventual reduction of ERDF funds may constrain the resources available for the construction of physical infrastructure. In this case, the original conception of RETA as building a network of "techno-cells" that bring the parks to the companies may take on even greater importance. This may require that RETA adopt a more focused approach where it concentrates on strengthening the connections with one or two of the key universities and building a denser set of relationships with both the research community and a subset of the innovative firms it is working with. This recommendation is closely linked to the first two, as RETA could use the process of building both the database of expert skills in the universities and the creation of a focused cooperative education program with some of the universities and innovative companies as a means to strengthen the social networks between firms and universities. The objective of this third recommendation would be the creation of a "virtual technology park" for some of the innovative firms dispersed throughout the region which would bring the benefits of physical proximity to the firms without the need for co-locating in the technology parks. This approach has the benefit of allowing RETA to concentrate its resources more effective in a limited area of the region 
and demonstrate the effect of its approach, using some of the techniques suggested in the first two recommendations. Success achieved on a more limited geographic scale, with one or two universities and one or two parks, would allow RETA to "scale up" the model by extending it to other parks and universities in the region. A key assumption underlying all three recommendations is that there are powerful demonstration effects associated with the successful implementation of any one of these initiatives. Early success in one or two cases will create a demand for emulating the approach in other firms and universities across the region.

\section{Learning models}

This part of the chapter presents evidence from three learning modules, largely from North America, that provides further support for the policy recommendations set out above.

\section{The Industrial Research Assistance Program/National Research Council}

\section{Description of the approach}

The first learning model explores the relevance of Canada's Industrial Research Assistance Program (IRAP). The program is highly relevant as it bears a strong affinity to both the organisational structure and policy objectives of RETA. Widely acclaimed as one of the most effective innovation support programs in Canada, its mission is to provide technical assistance and advice to a wide range of enterprises across Canada. IRAP provides SMEs with four main services, including technological advice, financial assistance for R\&D activities, networking and partnerships. Its services are delivered by a network of about 260 Industrial Technology Advisors (ITAs), who are housed in universities, community colleges and other technology transfer organisations across the country. In this respect, IRAP performs a networking and coordinating role between firms and other key organisational units in the Canadian innovation system, comparable to that performed by RETA.

\section{Rationale for the intervention}

A general feature of the Canadian economy, especially in the high technology sectors, is the predominance of small and medium-sized enterprises, especially when compared to other leading industrial countries in the OECD. More than three quarters of Canadian firms have less than 10 employees. At the same time, Canada has relatively fewer large R\&D performers than most other OECD countries and the total share of business expenditures on 
R\&D from firms with more than 250 employees is significantly lower than the OECD average. As a corollary, the relative contribution of small and medium-sized enterprises to business expenditures on R\&D in Canada is significantly higher. As a consequence, government programs targeted at promoting entrepreneurship and innovation among Canadian SMEs takes on greater significance than it does in many other OECD countries.

The main national policy in Canada that addresses the innovation activities of SMEs is the Industrial Research Assistance Program, which is run by the National Research Council, home to the largest number of federal government laboratories. IRAP is described as the Government of Canada's premiere innovation and technology assistance program, supporting small- and medium-sized enterprises in communities across the country. The program has been in existence for almost 60 years and delivers comprehensive innovation assistance to technology-based SMEs in almost every industrial sector of importance to Canada's economic development. While housed under the NRC and administered by staff of the NRC, IRAP is in many respects a stand-alone program run by its own Director-General. The Industrial Research Assistance Program provides financial support to qualified small and medium-sized enterprises to help them develop technologies for competitive advantage. NRC-IRAP operates on a shared-risk model, providing cost-shared financial assistance for research and development projects that meet both the firm and project assessment criteria. Financial support may be provided for an eligible R\&D project, supporting up to $100 \%$ of salary costs associated with the project, or up to $75 \%$ of contractor fees.

\section{Reasons for success}

The success of the program is widely attributed to its ability to provide both highly qualified technical advice to SMEs in a timely and relatively non-bureaucratic fashion, as well as to provide them with small grants to subsidise their costs in developing new products and processes or upgrading their technological capabilities. IRAP has been evaluated a number of times and it has consistently been rated as one of the most effective innovation programs delivered by the federal government in Canada. A study by Lipsey and Carlaw in 1998 concluded that IRAP had been highly effective in achieving its goals and that the assistance it provided to SMEs in Canada had been a major factor in technology adoption and diffusion among those firms and in increasing their innovative capabilities. A more recent study by Niosi (2008), comparing the effectiveness of IRAP with venture capital funding, found that the receipt of IRAP funding was more often correlated with an increase in the rate of the firm's growth than the receipt of venture capital funding. $\mathrm{He}$ strongly favoured an increase in the program's overall level of funding. 


\section{Obstacles and responses}

The program has historically been budgeted at CND 150 million per annum, but in recent years demand for the services provided by IRAP's national network of ITAs and the subsidies they can provide has outstripped the funds available to the program. The fact that the program budget has frequently been oversubscribed by the middle of the fiscal years has been one of the main impediments to its further success. As a result of this, the federal government announced a substantial increase in funding for the program in the 2009 budget, providing it with an additional CND 100 million a year for the next 2 years to allow it to temporarily expand its initiatives for SMEs.

\section{Relevance to Andalusia}

The relevance of the IRAP program for Andalusia is the strong similarity between the role of the ITAs in Canada and RETA's Innovation Agents. One important difference is that many of the ITAs have worked in industry themselves, some have taught at universities and community colleges, and many of them have worked for IRAP for a considerable period of time. This gives them a deep knowledge of their industrial sectors and a wealth of practical experience to draw upon that the innovation agents may not have. It is also clear that IRAP enjoys a much higher level of funding than is the case with RETA, although it faces a similar challenge in trying to meet a level of demand that continuously outstrips the resources it has available. Nonetheless, its consistent success and the high level of regard in which it is held have some important lessons for any organisation in the regional innovation system interested in revamping the profile of the innovation agents.

\section{For further information}

www.nrc-cnrc.gc.caleng/ibp/irap.html

\section{The Co-operative Education Program at the University of Waterloo}

\section{Description of the approach}

The second learning model provides more details about the University of Waterloo's cooperative education program and particularly, the crucial role that it plays in the local innovation system. This case also suggests a justification of the key contribution that RETA could make to helping broaden the role of trainees in the Andalusia innovation system. The University of Waterloo currently has the largest cooperative education program in the world, with over 11000 students (60\% of the student body) and 3000 employers, 281 of them local, involved in the program each year. Coop 
program offerings are extensive and are available in all faculties and departments, and in over 100 different programs. The Centre for the Advancement of Coop Education (WatCACE) was established in 2002 to provide a research capacity to identify and disseminate best practices in co-op education. Many of the larger Waterloo firms, as well as global ones, have deep and enduring links with the co-op program. Mike Lazaridis, the co-CEO of Research in Motion, is an active and vocal proponent of technology transfer through the Waterloo co-op program. At Sybase, an enterprise software company that spun-off from the original WATCOM Corporation, with over 250 employees in its Waterloo campus alone, $15 \%$ of its current employees are Waterloo co-op students, and more than half of their Waterloo staff consists of former co-op students.

\section{Rationale for the intervention}

The Waterloo Region in Ontario, located about $100 \mathrm{~km}$ west of Toronto, enjoys the strong factor advantage of a rich local labour pool largely as a result of a strategic decision made at the institution's inception. The founding document for the new university in the $1950 \mathrm{~s}$, referred to as the Waterloo Plan, called for a new type of education to be offered on a cooperative basis with industry. The initial rationale for the program was twofold: first, to create a more practical approach to post-secondary education, especially in the sciences and engineering by giving the students hands-on experience working in firms to complement their classroom time; and second, to maximise the usage of what was initially a very constrained physical plant by ensuring that classrooms were being fully used through all three semesters of the year. The rotation of students to industry and back to the classroom helped solidify tight relations with local industry.

\section{Reasons for success}

The reflexive relationship between the university and local industry allows the curriculum to keep up with the ever-changing technological frontiers of industry while industry support of the program funds the acquisition of technology to enhance classroom learning. As a result Waterloo became one of the first universities in Canada to enable students to actively explore and make use of innovations in the relatively new field of computing science in the 1960s and 1970s. The exposure that students had to the early days of computer technology laid the foundations for a technological leap that shaped the industrial development of the region from the 1970s onward. Of particular significance, is the finding that the university performs a critical intermediary function in facilitating the transfer of knowledge between students and local and non-local industry through the Co-Operative Education Program (Nelles, Bramwell and Wolfe, 2005). 
A number of key benefits of the co-op program were identified in research conducted on the role of the University of Waterloo in the regional economy. First and foremost, it acts as a steady source of new hires, because firms know that the students have work experience, and they get an opportunity to evaluate their performance in the workplace before hiring them. The Co-op Program is attributed with "putting knowledge on the streets", and recent graduates provide "fresh eyes': "new ideas, new minds, younger talent in the company". Second, co-op students act as an important transfer mechanism for tacit knowledge and know-how; they also act as a critical source of knowledge circulation within the local high-technology cluster, effectively transferring knowledge between different firms as they move from placement to placement over the course of their integrated work-study program. Not only are graduates well trained within the university, they also come with practical experience gained through co-op placements, both in local firms and in firms all over North America. Waterloo co-op students have an international reputation for being of high quality, and as a result, local firms have to compete with global ones to attract the best students, though they retain the benefit of location. For instance, in a recent speech at the university during his Microsoft 2005 Tour, Bill Gates referred to Waterloo as "a special relationship for us. Most years, we hire more students out of Waterloo than any other university in the world."

Beyond these highly visible and tangible benefits of the Co-op Program is its contribution to the virtuous cycle of entrepreneurialism in the region. Co-op students also act as an important conduit between local firms and the teaching faculty at the university. At the same time, student-driven technology transfer is critical specifically to the commercialisation process. One firms reported that: "students come off co-op terms and co-opt entrepreneurial faculty to develop a company ... [They] play a big role in spin-offs and technology transfer." This awareness of the crucial link between commercialisation and entrepreneurialism is also underscored and supported by the Enterprise Co-op Program, which enables students to start their own venture in lieu of doing a co-op placement with an established firm, and focuses on creating a local network of contacts and mentors to support it (Bramwell and Wolfe, 2008).

\section{Obstacles and responses}

The principal obstacle to the success of the co-op program, and the key reason that many other North American universities have not implemented it to the same degree, is the high cost of finding and maintaining the placement positions for the student body. The university invests a considerable amount of its own resources in financing and managing the program. It has the advantage that these costs have been built into the universities budget 
virtually since its inception. It also now benefits from the high reputation that both the program and the university's students enjoy, which makes it easier to find firms willing to take the students on work placement.

\section{Relevance to Andalusia}

The key lesson to be drawn from this experience is that the patient investment of resources in a program such as this can pay incredible dividends to the local economy over a long period of time. It has proved invaluable in both creating extremely tight linkages between the university and the dense network of technology-based firms in the local economy, as well as serving to enhance the region's international reputation by attracting global firms, such as Microsoft and Google, to both recruit from the region as well as establish research branches in Waterloo region. The relevance for RETA is that it already enjoys a certain advantage through its network of contacts with innovative firms in Andalusia. RETA could leverage this existing relationship with the firms to provide a valuable service for the public universities interested in expanding either work-related training programs or introducing a full coop education initiative in finding the work placements for students.

\section{For further information}

www.cecs.uwaterloo.calabout

\section{Future trends in science and technology parks}

\section{Description of the approach}

The third learning model corresponds to the third policy recommendation in that it draws upon the evolving trend of science and technology parks towards a more virtual format, also referred to as regional knowledge ecosytems. In this respect, the learning model is more prospective in pointing to work that has recently been carried out on the future evolution of technology parks. However, it is highly relevant to the current situation which RETA faces in terms of the need to intensify the social networks and linkages between innovative firms in the region and the existing technology parks without the option of physical co-location.

Two recent reports on evolving trends in research parks provide interesting parallels with the RETA model. Battelle Technology Partnership Practice, in cooperation with the Association of University Research Parks, undertook an extensive review of the characteristics and trends in research parks over the last 50 years. The report notes that today's research parks differ significantly from their predecessors, which were primarily viewed as 
standalone real-estate development projects. Research parks evolved in the 1980 and 1990s to include anchor R\&D facilities aligned with the particular industry or niche focus of the parks. Innovation centres and technology incubators became more common, as did support for entrepreneurs and start-up companies.

Within the last five years, research parks have evolved to address the changing nature of innovation and address the fact that science is becoming a more inter-disciplinary, multi-institutional and inter-global process. The Battelle report notes that the current model for research parks is changing with the parks placing greater emphasis on supporting incubation and entrepreneurship to grow their future tenant base; strategically planned mixeduse campus expansion is emerging as a key trend that includes space for academic and industrial use which is designed to create an innovative environment for frequent exchanges between academic researchers and industry counterparts; and international partnerships are becoming more important as research parks seek to attract more international tenants and have more of a global focus in the future (Battelle Technology Partnership Practice, 2007). The classic example of the planned mix use campus expansion is the Centennial Campus of North Carolina State University where the facilities for incubation and private firm R\&D activities were designed as an integral part of the university's new campus (Geiger, 2004).

\section{Rationale for the intervention}

A second report, prepared by the Institute for the Future, suggests that the model of self-contained research parks that has prevailed for the past fifty years is currently under challenge from a series of shifts in the global economy, as well as changing understanding of the nature of the innovation process. The report proposes three alternative scenarios for possible trends in technology-based economic development and the role of science and technology parks. One scenario suggests that research parks will evolve as an upgraded version of their predecessors: faster, more efficient and with more features. Under this scenario, parks will bring conventional tenants together with new kinds of collaborative networks and lever the intellectual resources of universities more effectively than today. The second scenario puts forward a model where research occurs in "clouds" that virtually link together smaller research facilities that are distributed, agile and lightweight. This scenario shifts away from a research campus model toward an innovation zone model. The model combines the scale efficiencies of traditional research parks with the diversity and dynamism of small, social collaborate research places. This scenario bears a certain affinity to the third generation innovation models discussed earlier in this chapter. The third scenario sees the decline of the conventional research park model as virtual R\&D networks make gains due 
to the pending energy crisis, allowing companies to maintain innovative pipelines while gaining greater flexibility and lower fixed costs (Townsend, Pang, and Weddle, 2009).

\section{Reasons for success}

As is the case with all scenario planning it is impossible to predict which scenario will prevail, and both recent reports bring some evidence to believe that a hybrid combination of all the three models is the most likely outcome. What will determine the success of the likely outcome is the ability to deliver the benefits that have been widely associated with physical proximity of research-intensive firms and universities through co-location in a traditional technology park through a more distributed and virtual form of network. While distance has traditionally been viewed as an important physical barrier, the increasing use of telecommunications technology and the creation of denser social networks through intermediary agents, such as RETA, provide a solid basis that the hybrid forms of physical and virtual parks will have a strong basis for success.

\section{Obstacles and responses}

The critical challenge faced in using advanced technology to create relationships and building virtual networks is the need to establish trust relations as the fundamental criteria for recreating the conditions that are derived from direct physical contact. This usually succeeds where the firms and research institutes involved begin to build their relationship through some form of direct contact which establishes the initial conditions for building trust. Once these conditions have been established, it then allows the parties involved to continue to develop the relationship on a virtual basis. This is clearly the case that is envisioned in the second and third scenarios outlined above.

\section{Relevance to Andalusia}

The scenario that is most relevant for RETA is the second model outlined above, which bears a strong affinity to the original conception of RETA as a mechanism for bringing the intense form of social and technological interaction facilitated by physical co-location within the technology park to the many firms who could not be located within the park. The most like scenario for Andalusia will involve some combination of the second and third scenarios outlined for the future evolution of technology parks. The end of ERDF funding after 2013 will impose constraints on the ability of the regional government to continue to build the physical infrastructure of the parks and the technology centres. In this context, the virtual model that RETA has embodied from the outset, enhanced by the implementation of the first two 
recommendations in this chapter, will take on even greater importance in helping move the R\&D\&I system in Andalusia towards a third generation innovation model.

\section{Note}

1. The PAIDI identifies a long list of priority research areas for the region, including among others: aeronautics, space, biotechnology and bioengineering, agroindustrial and food, health, tourism, production technologies, nanotechnology and advanced materials and information and communication technologies. 


\section{References}

Asheim, Bjorn T., and Meric S. Gertler. 2005. "Regional Innovation Systems." In The Oxford Handbook of Innovation, eds Jan Fagerberg, David C. Mowery, and Richard R. Nelson. Oxford: Oxford University Press.

Barca, Fabrizio. 2009. An Agenda for Reformed Cohesion Policy: A PlaceBased Approach to Meeting European Union Challenges and Expectations. Independent Report prepared at the request of Danuta Hubner, Commissioner for Regional Policy. Brussels: European Commission.

Bathelt, Harald, Anders Malmberg, and Peter Maskell. 2004. "Clusters and Knowledge: Local Buzz, Global Pipelines and the Process of Knowledge Creation." Progress in Human Geography 28(1): 31-56.

Battelle Technology Partnership Practice. 2007. Characteristics and Trends in North American Research Parks: 21st Century Directions. Developed in cooperation with Association of University Research Parks. Columbus, OH: Battelle Memorial Institute.

Bercovitz, Janet and Maryann Feldman, 2008. "Academic Entrepreneurs: Organizational Change at the Individual Level," Organization Science 19 (1, January-February): 69-89.

Bramwell, Allison, and David A. Wolfe. 2008. "Universities and Regional Economic Development: The Entrepreneurial University of Waterloo." Research Policy 37 (September):1175-87.

Fernandez de Lucio, Ignacio, Fancisco Mas-Verdu, and Enrigque Tortosa. 2010. "Regional Innovation Policies: The Persistence of the Linear Model in Spain." The Service Industries Journal 30(5, May): 749-62.

Fernandez-Esquinas, Manuel, Irene Ramos-Vielba, Maria Jimenez-Buedo, and Elena Espinosa-de-los-Monteros. 2009. "Unfolding the Complexity of Interactions Between Industry and University." IESA-CSIC Paper. Cordoba.

Geiger, Roger L. 2004. Knowledge and Money: Research Universities and the Paradox of the Marketplace. Stanford: Stanford University Press. 
Gertler, Meric S., and Tara Vinodrai. 2005. "Anchors of Creativity: How Do Public Universities Create Competitive and Cohesive Communities?" In Taking Public Universities Seriously. eds Frank Iacobucci and Carolyn Tuohy. Toronto: University of Toronto Press.

Gomez, Antonio-Martin Porras. 2007. "Internationalization and Innovation Policies in Andalusia: Which Prospects in the Mediterranean." Fondacion Tres Culturas del Mediterraneo.

Granados-Cabezas, Vicente. 2010. Innovation and the Internationalization of the Local Economies: Andalusia, Spain. Diagnostic Report Prepared for the OECD-LEED Study Mission to Andalusia. Malaga.

Grossman, Jerome H., Proctor P. Reid, and Robert P. Morgan. 2001. "Contributions of Academic Research to Industrial Performance in Five Industry Sectors." Journal of Technology Transfer 26(1-2, 0143-52).

Jensen, M.B., B. Johnson, E. Lorenz, and B.-Å Lundvall. 2004. "Absorptive Capacity, Forms of Knowledge and Economic Development." Paper presented at the. Second Globelics Conference. Beijing, 16-20 October.

Junta de Andalucia. 2006. Innovation and Modernisation Plan for Andalusia. Seville: Regional Ministry for Enterprise, Science and Innovation.

Koschatzky, Knut, and Thomas Stahlecker. 2010. "A New Challenge for Regional Policy-Making in Europe? Chances and Risks of the Merger Between Cohesion and Innovation Policy." Euro 18(1, vol.18, no.1,).

Laestadius, S. 1998. "Technology Level, Knowledge Formation and Industrial Competence in Paper Manufacturing." In Microfoundations of Economic Growth: A Schumpeterian Perspective, eds Gunnar Eliasson et al. Ann Arbor: University of Michigan Press.

Landabaso, Mikel, Antoni Kuklinski, and Carlos Roman, eds. 2007. Europe Reflections on Social Capital, Innovation and Regional Development. Nowy Sacz: Wyzsza Szkola Biznesu-National-Louis University.

Laurent, Julia, Inmaculada Perianez Forte, and Eulalia W. Petit de Gabriel. 2010. Andalusia, Spain: Self-Evaluation Report. OECD Reviews of Higher Education in City and Regional Development. Seville: General Secretariat for Universities, Research and Technology, Regional Ministry for Innovation, Science and Enterprise, Junta de Andalusia.

Lundvall, Bengt-Åke. 2006. "One Knowledge Base or Many Knowledge Pools?" DRUID Working Paper No. 06-08. Aalborg and Copenhagen. Www.druid.dk.

Manzella, Gian Paolo, and Carlos Mendez. 2009. The Turning Points of EU Cohesion Policy. Background Working Paper prepared for the Report on An 
Agenda for a Reformed Cohesion Policy (Barca Report). Brussels: European Commission.

Mowery, David C., Richard R. Nelson, Bhaven N. Sampat, and Arvids A. Zeidonis. 2004. Ivory Tower and Industrial Innovation: University-Industry Technology Transfer Before and After the Bayh-Dole Act. Stanford, CA: Stanford Business Books.

National Academy of Engineering. 2003. The Impact of Academic Research on Industrial Performance. Washington, DC: The National Academies Press.

Nelles, Jen, Allison Bramwell, and David A. Wolfe. 2005. "History, Culture and Path Dependency: Origins of the Waterloo ICT Cluster." In Global Networks and Local Linkages: The Paradox of Cluster Development in an Open Economy, eds David A. Wolfe and Matthew Lucas. Montreal and Kingston: McGill-Queen's University Press for the School of Policy Studies, Queen's University.

Niosi, Jorge. 2008. IRPP Choices 14(4, October)Connecting the Dots Between University Research and Industrial Innovation. IRPP Choices. Montreal: Institute for Research on Public Policy.

OECD, Science Technology Industry. 1999. University Research in Transition. Paris: Organisation for Economic Co-operation and Development.

Paytas, Jerry, Robert Gradeck, and Lena Andrews. 2004. Universities and the Development of Industry Clusters. Pittsburgh and Washington, DC: Center for Economic Development, Carnegie Mellon University and Economic Development Administration, U.S. Department of Commerce.

Ramos-Vielba, Irene, and Manuel Fernandez-Esquinas. 2009. "Beneath the Tip of the Iceberg: The Multiple Forms of University-Industry Collaborative Linkages." IESA-CSIC Paper. Cordoba.

Sanz-Menendez, Luis, and Laura Crus-Castro. 2005. "Explaining the Science and Technology Policies of Regional Governments." Unidad de Politicas Comparadas, Working Paper 05-10, Consejo Superior de Investigaciones Cientificas (CSIC).

Stokes, Donald E. 1997. Pasteur's Quadrant: Basic Science and Technological Innovation. Washington, DC: Brookings Institution Press.

Teubal, Morris, Dominique Foray, Moshe Justman, and Ehud Zuscovitch, eds. 1996. Technological Infrastructure Policy: An International Perspective. Dordrecht: Kluwer Academic Publishers.

Townsend, Anthony, Alex Soojung-Kim Pang, and Rick Weddle. 2009. Future Knowledge Ecosystems: The Next Twenty Years of Technology-Led Economic Developmen. Palo Alto: Institute for the Future. 
Wolfe, David A., and Matthew M. Lucas. 2001. "Investing Knowledge in Universities: Rethinking the Firm's Role in Knowledge Transfer." In Knowledge Management in the Innovation Process: Business Practices and Technology Adoption, eds John de la Mothe and Dominique Foray. Amsterdam: Kluwer Academic Publishers. 


\section{Chapter 4}

\section{Entrepreneurship and start-ups}

\section{Introduction}

This chapter focuses on two inter-related issues: entrepreneurship and start-ups. It starts with a general policy analysis of the importance of entrepreneurship at national and regional levels. The next section focuses directly on the current situation in the Andalusia region, concentrating on the stiff challenges that it is currently facing, as well as the opportunities that can be utilised more effectively. The third section highlights a series of policy recommendations. The chapter concludes with a set of international "learning models" which are designed to illustrate what is being done in other regions to face-up to the entrepreneurship and start-up challenges, as a means of reinforcing the preceding policy recommendations.

\section{Policy issues}

Developing a culture of entrepreneurship, including start-ups, continues to be the focus of policy debate. This section concentrates on the reasons why a culture of entrepreneurship combined with the development of new enterprises are important. The section goes on to address the importance of EU structural funds in stimulating entrepreneurial development in lagging regions experiencing economic decline.

\section{Entrepreneurship policy}

It is widely acknowledged that entrepreneurship plays a key role in relation to economic development and that entrepreneurs are key agents of change in market economies. It has also become apparent that what constitutes entrepreneurship is not easily pinned-down: it is evident in both small and medium-sized enterprises (SMEs), as well as large ones; in the formal 
and informal economy; in legal and illegal activities; in innovative and traditional firms; in high and low-risk ventures; and in pretty much all sectors and sub-sectors of the economy (OECD, 2001, p.35). If Governments were increasingly emphasising the importance of the development of a "culture of entrepreneurship", the challenges presented by the current economic and financial crises are likely to reinforce this trend.

The European Commission's (EC) main policy document, the Entrepreneurship in Europe Green Book (2003) associates entrepreneurship with certain types of behaviour, such as a willingness to engage in risk-taking, desire to achieve independence, and self-fulfilment of the entrepreneur. At the level of local, regional, national and super-national economies, the EC highlights the importance of entrepreneurship in terms of its contribution to job creation and growth, competitiveness, unlocking individual potential and wider benefits to society as a whole.

Not surprisingly, given the above policy conclusions, the EC has committed itself to stimulating entrepreneurship across all EU nations and regions: entrepreneurship is considered to be a major driver of innovation, competitiveness and growth. Consequently, entrepreneurship is promoted and supported by the EC via a plethora of strategies, policies, programmes and funding regimes, not the least of which are the structural and cohesion funds, which focus on improving the entrepreneurial environment for start-ups and SMEs.

Because a broad policy agenda can be addressed through an emphasis on entrepreneurship, national, regional and local policy-makers increasingly recognise that the task of stimulating a culture of entrepreneurship is a politicallydriven one. At the same time, there is general acknowledgment that there are no ready-made models for this. Each nation, region and city must experiment in order to identify the right formula to reap the benefits of stimulating a culture of entrepreneurship in their locality. However, the key elements are likely to include its particular historical, cultural, social, economic and political heritage (OECD, 2009).

\section{EU Strategies affecting entrepreneurship and regions}

The EU meeting in Lisbon (2000) to respond to the challenges of globalisation and technologic revolution, set itself the ambitious goal of making the EU "the most competitive and dynamic knowledge-based economy in the world, capable of sustainable growth with more and better jobs and greater social cohesion" by the year 2010. Structural reforms were launched in the fields of employment, innovation, economy, social cohesion, and environment. However, by 2005 it was apparent that the goal was overly ambitious. This resulted in a revised Lisbon Strategy focusing on two tasks: stimulating lasting growth and creating more and better jobs. The renewed Lisbon Agenda 
also stressed the need for less prosperous regions, such as Andalusia as other Objective-1 regions, to catch-up with the more prosperous ones. The goals required investment in research, education, transportation, renewable energies, and employability.

The renewed Lisbon Strategy was based on a set of 10 interventions:

Europe becomes a more attractive place to invest and work:

1. Extend and deepen the internal market;

2. Improve European and national regulation;

3. Ensure open and competitive markets;

4. Expand and improve European infrastructure.

Knowledge and innovation are key to European growth:

5. Increase and improve investment in $\mathrm{R} \& \mathrm{D}$;

6. Facilitate innovation, the uptake of ICT and the sustainable use of resources;

7. Contribute to a strong European industrial base.

Policies that allow business to create more and better jobs:

8. Attract more people into employment and modernise social protection systems;

9. Improve the adaptability of workers and enterprises, and the flexibility of labour markets;

10. Invest more in human capital through better education and skills.

The recent global crisis has however called for another major rethink of the Lisbon Strategy. The result was Europe 2020, a 10-year strategy designed to revive the European economy through "smart, sustainable and inclusive growth," with greater coordination of national and European policy. Five targets were set to boost growth and employment (EU, 2010):

- Raise the employment rate of the population aged 20-64 from $69 \%$ to at least $75 \%$;

- Invest 3\% of GDP in R\&D by improving the conditions for R\&D investment by private sector;

- Drop greenhouse gas emissions by at least $20 \%$ compared to the 1990 levels or by $30 \%$ if the conditions are right, increase the share of renewable energy in final energy consumption to $20 \%$, and achieve a $20 \%$ rise in energy efficiency; 
- Lower the share of early-school leavers to $10 \%$ from the current $15 \%$, and augment the share of the population aged 30-34 having completed tertiary education from $31 \%$ to at least $40 \%$;

- Reduce the number of Europeans living below national poverty lines by $25 \%$, lifting 20 million people out of poverty.

Increased levels of innovation and competitiveness underlie the new Europe 2020 initiative, which in turn, requires greater levels of entrepreneurship, improved business environments, and development of a strong and sustainable economic base. This policy agenda applies to nations as well as regions.

\section{Regional Development in Andalusia}

Turning the attention specifically to Andalusia, its regional development approach is mainly driven by the Innovation and Modernisation Plan for Andalusia (PIMA). The principal aim is to ensure that Andalusia becomes one the most advanced regions in Europe based on innovation. The PIMA focus on innovation includes an entrepreneurship and start-up element: "For Andalusia, encouragement of an entrepreneurial culture, spirit and activity is a basic strategy for its business development (...) an entrepreneurial spirit is the main driving force behind innovation, competitiveness and economic growth. There is a relationship between the entrepreneurial spirit and economic results in terms of growth, consolidation of the business framework, innovation, job creation, technological changes and increase in productivity. Within this policy, it is just as important to promote entrepreneurial culture and spirit as to support business-minded people who have already decided to start up a new enterprise" (Andalusia Region, 2006, p.57).

Connected with the preceding discussion on the EU, the Andalusia Operational Programme 2007-2013 embraces the renewed Lisbon agenda-Europe 2020. Not coincidentally, since the EU is its main funder, the priorities of the Andalusia Operational Programme reflect those of the wider European agenda (Andalusia Region, 2007a):

- Priority 1: Knowledge economy (4.6\% of total expenditure): promote research, technological development, innovation and the information society.

- Priority 2: Entrepreneurial development and innovation (19\% of total expenditure).

- Stimulate innovative entrepreneurial initiatives with particular emphasis on local and urban trade initiatives; 
- Update and encourage competitiveness within the productive fabric by giving priority to innovative projects that provide added value;

- Spread the use of environmentally-friendly production processes and support firms in Andalusia committed to the growth and globalisation of the regional economy.

- Priority 3: Environment, natural surroundings, water resources and risk prevention ( $29.7 \%$ of total expenditure).

- Priority 4: Transport and energy (31\% of total expenditure).

- Priority 5: Sustainable local and urban development (10.1\% of total expenditure).

- Priority 6: Social infrastructure (5\% of total expenditure).

- Priority 7: Technical assistance (0.6\%).

The Andalusia Operational Programme has a budget of around EUR 10 billion from the EU, representing 19.4\% of the EC's contribution for the benefit of Spain under the 2007-2013 cohesion policy; the national contribution amounts to a further EUR 3 billion. This represents a very significant amount of funding for its activities, including entrepreneurship and startups. At this point it is important to note that Andalusia is expected to lose its Objective 1 status in the next EU funding round; this will have consequences for its future level of EU subsidy. The significant levels of resources, therefore, represent a unique window of opportunity to get the regional economy in shape for the future.

\section{Assessment of the region}

This section examines the nature of entrepreneurship in the Andalusia region, such as the number of births and deaths of firms, as well as other factors such as the density of enterprises. This is followed by a brief analysis of the key institutions responsible for stimulating entrepreneurship and startups. It terminates with an analysis of the key challenges and opportunities facing the region.

\section{Entrepreneurial profile}

There are a number of aspects of the Andalusian economy that are relevant from the viewpoint of entrepreneurship and start-ups. Firstly, Andalusia has traditionally been an underdeveloped region of Spain, although in recent decades there has been a remarkable catch-up effect, driven primarily by 
the performance of the construction and tourism sectors. Secondly, by 2008, Spanish GDP per capita exceeded that of the EU average (103) and Andalusia exceeded $80 \%$ of the same average (this being partly accounted for by accession of new EU member states from Central and Eastern Europe, which had pushed down the average). Thirdly, in contrast with many other parts of Spain, there has been a reduction in university attendance: from $14.7 \%$ in $1997-8$ to $12.2 \%$ in $2007-8$. Fourthly, Andalusia has been hit hard by the financial crisis and economic recession: GDP has declined, the construction and real estate sectors have melt down, and household consumption has dried up.

The crisis has taken a toll on local employment. The unemployment rate has risen steeply to $27.2 \%$ compared with $20 \%$ in Spain as a whole. The very high unemployment rate, one of the highest in Spain, hides significant regional variations. In the province of Malaga, for example, over 233000 are out of work, which pushes the unemployment rate to over 30\% (the second highest in Spain). However, Cadiz tops the list, with an unemployment rate of $31.9 \%$ according the National Institute of Statistics (April 2010). In the other provinces, the unemployment rate has risen to $27.7 \%$ in Almeria, $26.8 \%$ in Granada, $26.7 \%$ in Huelva, $25.8 \%$ in Seville, $23.5 \%$ in Cordoba, and 20\% in Jaen. The youth unemployment rate is much higher: while it is $43 \%$ in Spain, estimates indicate that $39 \%$ of the registered youth unemployed are located in Andalusia. More than 200000 are registered unemployed but it is estimated that only $46 \%$ of Andalusia's under- 25 population who are out of work are actually receiving benefits. The low level of benefit take-up is due to the Spanish benefits rules, which require employees to have completed a year of full employment before qualify. Many under-25s are unable to demonstrate 12

Figure 4.1. Number of enterprises in Andalusia, 1999-2008

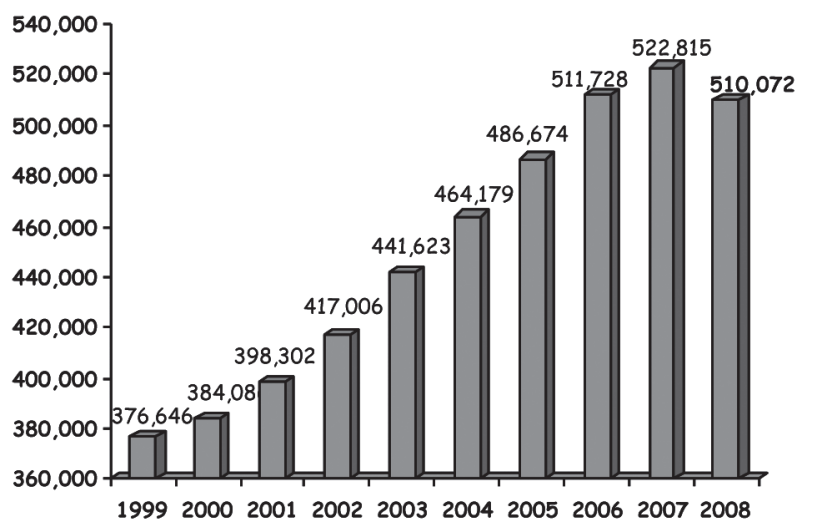

Source: Directorio Central de Empresas, INE. 
months" worth of unbroken employment (The Leader, Andalusia Suffering Most from Unemployment, 21.11.2009). The above synopsis indicates that the rapid economic growth and other gains experienced in recent decades, which have resulted in the region approaching national averages, have been partly diluted by a decline disproportionate compared with other regions.

Turning to the business demographics of the region, Figure 4.1 shows that the number of enterprises has risen year-on-year since 1999, peaking at 522815 in 2007. However, the global recession has caught-up with the region, resulting in a decline to 510072 enterprises in 2008, a process which almost certainly continued in the subsequent two years, mirroring country-wide trends. In 2008 Andalusia had $15.2 \%$ of all national enterprises, a reduction of $2.4 \%$ on the previous year.

The density of firms in the Andalusia region has increased dramatically since 1999, from 51.3\% (versus 64.1 in Spain) to 63.7\% in 2007 (versus 74.1 in Spain). However, the density declined during 2007/2008 to 61.4 (compared with 71.8 in Spain). Nevertheless, Table 4.1 shows a massive catch-up effect vis-à-vis the rest of Spain.

Table 4.1. Firm density by province, 1999-2008

\begin{tabular}{lccccc}
\hline & 1999 & 2007 & 2008 & $\begin{array}{c}\text { Difference } \\
07 / 08\end{array}$ & $\begin{array}{c}\text { Difference } \\
\end{array}$ \\
& & & & $69 / 08$ \\
\hline Almeria & 57.72 & 67.60 & 63.56 & $-5.97 \%$ & $10.11 \%$ \\
Cadiz & 40.78 & 52.85 & 51.05 & $-3.42 \%$ & $25.16 \%$ \\
Cordoba & 52.46 & 62.66 & 60.92 & $-2.78 \%$ & $16.12 \%$ \\
Granada & 55.76 & 69.09 & 66.14 & $-4.28 \%$ & $18.61 \%$ \\
Huelva & 45.47 & 54.07 & 52.17 & $-3.52 \%$ & $14.72 \%$ \\
Jaen & 47.74 & 55.99 & 54.58 & $-2.51 \%$ & $14.32 \%$ \\
Malaga & 59.49 & 74.64 & 71.16 & $-4.66 \%$ & $19.61 \%$ \\
Seville & 50.49 & 63.63 & 62.13 & $-2.36 \%$ & $23.05 \%$ \\
Andalusia & 51.31 & 63.74 & 61.43 & $-3.62 \%$ & $19.72 \%$ \\
Spain & 64.08 & 74.14 & 71.79 & $-3.17 \%$ & $12.02 \%$ \\
\hline
\end{tabular}

Source: Directorio Central de Empresas, INE. 
That said, a large number of the new enterprises created in the region were connected with the construction sector, which experienced a massive expansion from 2001 to 2007; the period since has experienced a vertiginous decline $(9.3 \%$ to $12.4 \%$, back down to $10.7 \%$ in 2008 and experiencing a steep deep in the time since). During 2001-2008, industry and commerce have experienced declines in importance in Andalusia compared with construction (slight increase) and other services (major increase).

Table 4.2. Firm distribution by sector in Andalusia, 2001-2008

\begin{tabular}{|c|c|c|c|c|c|c|c|}
\hline & \multicolumn{7}{|c|}{ Andalusia } \\
\hline & \multicolumn{2}{|c|}{2001} & \multicolumn{2}{|c|}{2007} & \multicolumn{3}{|c|}{2008} \\
\hline & Number & $(\%)$ & Number & $(\%)$ & Number & $(\%)$ & $\begin{array}{c}\text { Variation } \\
2006 / 07 \\
(\%)\end{array}$ \\
\hline Industry & 31569 & 7.93 & 34208 & 6.54 & 33633 & 6.59 & -1.68 \\
\hline Construction & 37247 & 9.35 & 65078 & 12.45 & 54918 & 10.77 & -15.61 \\
\hline Commerce & 136251 & 34.21 & 148021 & 28.31 & 145845 & 28.59 & -1.47 \\
\hline Other services & 193235 & 48.51 & 275508 & 52.70 & 275676 & 54.05 & 0.06 \\
\hline Total & 398302 & 100.00 & 522815 & 100.00 & 510072 & 100.00 & -2.44 \\
\hline
\end{tabular}

Source: Directorio Central de Empresas, INE.

From an entrepreneurial perspective, one of the most important indicators is the economic churn rate, namely the entry and exit of firms. The number of new enterprises (birth rate) stated declining in 2006/7, a process which accelerated dramatically in Spain (-27.46\%) in 2007/8; the decline was even more intense in the Andalusia region (-32.07\%). Discussions during the OECD Mission (April 2010) suggest that the process has continued in the time since, though not necessarily at the same rate.

Table 4.3. Firm Dynamism in Andalusia and Spain, 2005-2008

\begin{tabular}{lcrcccc}
\hline & \multicolumn{2}{c}{$2005 / 2006$} & \multicolumn{2}{c}{$2006 / 2007$} & \multicolumn{2}{c}{$2007 / 2008$} \\
\hline & Andalusia & Spain & Andalusia & Spain & Andalusia & Spain \\
\hline Births & 3.64 & 7.18 & -4.11 & -4.16 & -32.07 & -27.46 \\
Deaths & 15.10 & 13.58 & 66.14 & 63.01 & -9.14 & -10.11 \\
Firm Dynamism & 2.83 & 6.70 & -9.67 & -9.56 & -35.42 & -29.97 \\
(Births-Deaths) & & & & & & \\
Churn rate & 11.06 & 5.97 & 73.26 & 70.09 & 33.76 & 23.91 \\
\hline
\end{tabular}

Source: Estadisticas de Sociedades Mercantiles, INE. 
Andalusia's entrepreneurship level was assessed by the Global Entrepreneurship Monitor (GEM) in 2006. The GEM highlights some of the most pertinent entrepreneurship features of the region:

- Highest scoring aspects: access to physical infrastructure, promotion of growth, government programmes, and commercial/services infrastructure.

- Lowest scoring aspects: absence of entrepreneurship in universities and in primary and secondary education, technology transfer, and the role of the universities.

- Key obstacles for start-ups: social and cultural issues, lack of financial support, and limited enterprising capacity.

- Advantages for start-ups: government programmes and policy, the economical climate (at the time), and financial support.

A key issue addressed in the GEM is the entrepreneurship potential or, more specifically, whether the adult population plans to establish a firm in the next 3 years. Whereas the Spanish average is $6.4 \%$, it is $5.4 \%$ in Andalusia; this compares with $10.2 \%$ in Murcia, the leading Spanish region. On this basis, Andalusia is ranked $14^{\text {th }}$ (out of 17 regions) by the GEM. This appears to bear out a perception that the inhabitants of Andalusia are not the most entrepreneurial. According to anecdotal evidence, the impression is that young Andalusians continue to prefer the relative labour market security of the public sector. Nevertheless, the GEM indicated that some 270000 Andalusian people plan to become entrepreneurs in due course; the main reason being a desire to gain economic independence (53\%). The entrepreneurs in Andalusia tend to be male and aged 32-43, somewhat younger than in the rest of Spain. However, their level of education is relatively low and their income levels fall in the range EUR $1200-1800$ per month.

To conclude, the preceding analysis indicates that the region has made significant economic progress in recent decades, which has resulted in a degree of catching-up with Spain's average. Andalusia has gone from being a net exporter of people to being a net importer; the level of GDP has increased; and the number of enterprises and employment has also gone up. At the same time, the analysis illustrates that the region has been hit severely by the crisis, whose impact is deeper than elsewhere in Spain and which is set to continue for the medium term. Many of the new firms established in the region and which have driven its recent growth spurt, for example in the construction sector, are currently experiencing severe retrenchment. Startups, stock of enterprises and unemployment, notably youth unemployment, are being severely impacted. Moreover, the region has a relatively limited entrepreneurial where people enter public sector employment as their preference. That said, there is a certain degree of willingness to engage in future 
entrepreneurial activity and the current economic circumstances may stimulate this interest. The rapid increase in unemployment rates to $27.2 \%$ is a major concern; this necessitates a strong emphasis on economic development, including self-employment and start-ups, but this is likely to be hampered, to some extent, by the relatively low levels of human capital in the region. The analysis suggests that there is an urgent need to further diversify the regional economy; given the education levels and other limitations, there is a need for broader support to entrepreneurship and job creation.

\section{Institutions and policies for entrepreneurship}

Prior to assessing the challenges and opportunities facing Andalusia, it is helpful to recall the main actors in the entrepreneurship support framework in the region.

\section{Ministry of Economy, Innovation and Science}

The regional Ministry of Innovation, Science and Enterprise merged in 2010 with the Regional Ministry of Economy, to result in the Ministry of Economy, Innovation and Science (MEIS). The MEIS is a powerful institution with a commensurate annual budget of some EUR 3 billion. Its activities determine the contours of the entrepreneurial and start-up landscape in Andalusia.

The Secretary General for Innovation is the main policymaker for numerous issues subsumed within the innovation banner. The new Ministry is, in itself, a response to the massive economic challenges facing the Andalusia region as regional politicians sought to integrate the key economic levers in one institution. The Andalusia regional government, within the catch-all focus on innovation, does seek to promote entrepreneurship and start-ups in its development model. This political commitment springs from awareness that a culture of entrepreneurship is the driving force for innovation, competitiveness and economic growth in all regions, including Andalusia.

The region has deployed numerous public instruments and resources to boost the competitiveness and innovative capacity of enterprises. This has resulted in the creation of one of the largest networks supporting economic development through innovation in Europe, underpinned by very substantial EU and national subsidies. Given this dense and extensive network of institutions, the regional government recognises that a central challenge is to: "professionalise the management of varying instruments in the network, coordinate them and convert them into the most motivated innovation system in Spain.” (MEIS Secretariat for Innovation's presentation, April 2010) 
Therefore, in response to the above challenge, the region is crafting a new Strategy for 2010-2012 featuring three main policy dimensions:

- Creation of an Entrepreneurial Ecosystem:

- Consolidation, coordination and professionalisation of the entrepreneurial network so as to transform it into the best system in Spain;

- Specialisation of the 10 Andalusia public universities to transform them into driving forces enriching businesses in the region;

- Attraction of multinational firms in strategic regional sectors;

- Attraction of the best technology-based firms to the regional business incubators.

- Multiplication of Renewable Resources:

- Select and train 5000 youth based on effort, ambition and merit;

- Send 500 youth to the best universities in the world;

- Train and counsel 5000 SMEs to add innovation to products and services;

- Commit resources, instruments and public programmes on clean technologies and renewable energy so that the region becomes a world leader.

- Positioning of Andalusia as a world class region through focus and specialisation:

- Identify, advise, and finance 100 high-growth companies to help them become global leaders in their industries;

- Create six innovation hubs around six high growth industries in which Andalusia has clear competitive advantages;

- Create a world class innovation and entrepreneurship centre as a cross-industry catalyst to accelerate the innovation rate and the creation of high-tech start-ups in the region.

The revised strategy ensures that innovation remains the top policy priority for MEIS and thus for the region. The main institution responsible for the implementation of the approach with regard to entrepreneurship is the ANDALUCIA EMPRENDE Foundation, which is discussed below. 


\section{ANDALUCIA EMPRENDE}

Since 1999 ANDALUCIA EMPRENDE has been responsible for creating and consolidating enterprises and promoting entrepreneurship throughout the region. It has two main goals:

- Promote a culture of entrepreneurial activity through awarenessraising, a focus on young people and women, and on sectors such as cultural and creative industries.

- Create and consolidate enterprises and employment through advice and support to firms, business training, and accommodation at the pre-incubation and incubation stages.

More specific objectives are to: improve the image of entrepreneurs; enhance the entrepreneurial skills of the Andalusia society; facilitate access by enterprises to public funds; improve the qualifications and professional development of young Andalusians at different educational levels and strengthen work placement in companies; participate in development co-operation with other countries; co-operate with other institutions at local, provincial, regional and national level in the design and implementation of entrepreneurshiprelated projects. To accomplish its extensive remit, EMPRENDE has a network of: 8 offices located in each of the provincial capitals of the region; 37 Centres for Entrepreneurial Development; 215 Entrepreneurial Support Centres (CADE); 280 business premises and 272 industrial premises (for preincubation lasting at least 6 months).

ANDALUCIA EMPRENDE has a very extensive territorial network of support for entrepreneurs, covering the entire region. CADE alone includes approximately 1000 specialists, providing services to entrepreneurs in the creation and management of companies, including information, training, technical advice, access to finance and business accommodation in buildings and offices. In 2009, based on the meeting held by the study team with representatives of the Foundation, EMPRENDE achieved the following results:

- Establish businesses: support and advice led to the creation of 7772 firms $(85 \%$ in services, $6.9 \%$ in construction, $4.4 \%$ in industry and $1.3 \%$ in agriculture).

- Generate jobs: through the above companies, 9447 jobs were created.

- Generate investment: through the above companies, EUR 168 million were engendered.

- Provide incubator accommodation: for 500 firms.

- Provide services: to nearly 12400 entrepreneurs that applied for start-ups funds. 
- Support the creation of business plans: approximately 2500 of such them were supported.

- Deliver basic business management: 4435 hours of training delivered.

This chapter does not assess the impact that can be directly or indirectly attributed to EMPRENDE, but the figures above represent a significant range of business support offered.

\section{The role of spin-offs and relevant policies}

Previously discussion has illustrated the broad range of policies and instruments in relation to start-up support, some of which focuses on significant levels of assistance through pre-incubation, incubation and postincubation, an issue that we return to later in this chapter.

The chapter on "research organisation" of this report discusses the issue of R\&D and and innovation system in Andalusia more at length. As far as university spin-offs are concerned, based on the results of the study visit, Andalusia emerges the leading Spanish region in quantitative terms (number of university spin-offs generated). However, in qualitative terms (such as growth, employment, turnover, etc.) the approach could be improved. Major constraints include legal barriers and a lack of incentives for academics to engage in entrepreneurial activity. For example, they are only allowed a maximum of $10 \%$ participation in spin-offs and the academic burdens is not reduced to reflect entrepreneurial engagement. Therefore, although research funding may be partly conditional on the number of spin-offs generated, the overall incentives to invest the necessary time and effort into converting the resulting spin-offs into commercial successes remain low.

Another form of spin-off is the corporate spin-off, which is a process whereby a part/unit/division of an existing company splits into two, usually a bigger one (the parent company) and a smaller one (the spin-off). The people, assets and intangibles transferred from the parent company constitute a key element of the spin-off's core-business, and the corporate spin-off process results in significant changes in ownership, responsibility and liability. Local interviews suggest that corporate spin-offs are occurring in the region, as shown by AT4-Wireless and other innovative firms. Curiously, for a region which has an extensive range of policies and tools to support entrepreneurship, there does not appear to be initiatives to support spin-offs of a commercial nature.

\section{Entrepreneurship support: two main issues}

Two main points are worth reiterating to conclude this section: 
- Firstly, Andalusia does recognise the importance of entrepreneurship and start-ups. However, there is a strong emphasis on research and development and innovation (R\&D\&I), which amounts to a technological biased view of entrepreneurship. The problems connected with current recession, not least the steep rise in general and youth unemployment, suggest a need for a wider focus on entrepreneurship, including education, vocational educational training, self-employment, assistance to all forms of start-ups, not only those connected with R\&D\&I.

- Secondly, there is a clear divide between policy-making (the responsibility of the new Ministry of Economy, Innovation and Science) and implementation. While the main actor with regard to the implementation of entrepreneurship programmes is certainly ANDALUCIA EMPRENDE, there are some overlaps with other institutions, this being a common feature of the regional support framework for entrepreneurship and SME development. The significant levels of resources currently available appear to have spawned a multiplicity of institutions and networks to support enterprise development. From a public policy perspective most issues seem to be covered with the possible exception of a few, such as corporate spin-offs.

\section{A SWOT analysis of the region}

This section summarises the main strengths, weaknesses, challenges, and opportunities facing Andalusia with regard to entrepreneurship and start-ups. The analysis conducted so far has already implicitly dwelled on the main strengths and weaknesses, so the focus is here especially on future challenges and opportunities.

\section{Strengths and weaknesses}

One of the region's most significant strengths is the level of EU, national and regional funds. Such funding initially prioritised infrastructure but the current programming period focuses on softer aspects such as institutions, capacities, know-how, etc. A current key strength can become a weakness if the region proves to be overly dependent on such funding. The next EU programming period will certainly result in a transition to lower levels of structural funds; at the same time, the current sovereign debt crisis is already leading to retrenchment in public expenditure in Spain, with consequences for the Andalusia region.

The institutional environment in the region is incredibly dense: an extensive network of institutions, policies, programmes and projects now exists, which is a source of great regional strength. These institutional networks 
criss-cross the territory and there are few discernable gaps. At the same time, the pressure to spend a very large amount of funding on soft measures leads to potential weaknesses in terms of policy effectiveness. While the gaps are hard to discern, the potential and actual overlaps in provision are easier to identify. These can result in confusion for the business sector (multiplicity of organisations, programmes, etc.), potential crowding out of the private sector (delivery of activities which would normally be provided by the private sector, price distortion due to free delivery of services, etc.) and inefficiency (resources not necessarily deployed in a manner which maximises impact). In this context, the regional government should periodically assess the extent to which its entrepreneurship support activities are achieving the desired policy objectives; this would enhance the targeting of activities and resources.

\section{Challenges}

Firstly, the region must cope with the very high levels of unemployment (average of 27.2\%, peaking at almost 32\% in Cadiz in April 2010), particularly youth unemployment, which has risen steeply in recent years. This is a trend that is not expected to be reversed in the short term. The sheer levels of unemployment require the region to support all forms of entrepreneurship and start-ups in all sectors of activity (not simply those closely connected with R\&D\&I) and by all social groups, if it is to utilise the growing pool of idle human capital in the medium to long term.

Secondly, the level of local human capital, whether or not in employment, needs to be upgraded. Despite the recent catch-up effect driven by higher levels of business activity (e.g. construction and tourism sectors) and GDP per capita (now $80 \%$ of the EU average), the region has experienced a reduction in university attendance, declining from $14.7 \%$ in $1997 / 8$ to $12.2 \%$ in $2007 / 8$. Human capital needs upgrading so as to compete with the rest of Spain, the $\mathrm{EU}$ and further afield, which is a long term process.

Thirdly, the current regional policies can only be understood in the context of the EU structural funding framework. The EU funds for Andalusia for the period 2007-2013 alone amounts to EUR 14 billion (excluding various national and regional contributions and programmes). This massive amount of support is actually a reduction compared with the preceding programming period, which focussed primarily on investment in infrastructure. The focus of the current programme is on soft measures such as capacity and institution building, leading to greater innovation and competitiveness. These objectives are much harder to absorb funds than infrastructure investment. However, the necessity to put to good use the large flows of funding has contributed to sprawling and potentially overlapping institutions, programmes and projects. This has resulted in significant levels of public support going to the private sector. The consequence of this level of public subsidy is that much of the 
regional economy, including entrepreneurs and enterprises being supported, are protected to some degree from general competition.

Fourthly, although the local economy may be cushioned by EU and national subsidies, it has certainly not been spared from the economic crisis. The construction and real estate sectors have been severely affected, and so as has agriculture and, to a lesser extent, tourism. The consequence is high levels of youth unemployment, a slow-down in the number of migrants, emigration by EU ex-pats, etc. A connected issue is the levels of demand for goods and services. The regional economy in not strongly export-oriented, companies refrain from placing orders, and the general public is nervous about possible lay-offs and responds by increasing savings at the expense of consumption. In this context, demand for local products and services is affected. In addition, the level of Spain's public indebtedness has already resulted in austerity packages that have an impact on aggregate demand.

Finally, with the eastward enlargement of the EU, the region is likely to lose its Objective 1 status and, in consequence, EU structural funds will decline markedly beyond 2014. Given the extent to which the region benefits from financial and non-financial subsidies directly emanating from the EU, it should initiate as soon as possible a process of transitioning to a more marketoriented and sustainable entrepreneurship and SME development policy. It is extremely unlikely that the current extensive and dense institutional network of enterprise support will continue in the new emerging financial environment.

\section{Opportunities}

Firstly there is a low but growing level of entrepreneurial culture in the region. Based on the 2006 Global Entrepreneurship Monitor (GEM) data, the density of enterprises was approaching the national level. The same report also suggested that the population of the region has a fairly high level of interest in entrepreneurial activity. Anecdotal evidence suggests that although young people have traditionally seen the public sector as the natural route to the labour market, the sharp economic downturn in Andalusia may stimulate a greater willingness to embrace self-employment and other forms of entrepreneurship. This is clearly something to build on in the region via a greater focus on developing a culture of entrepreneurship at all levels of the education system: primary, secondary, vocational and tertiary.

Secondly, there is a need to make more effective use of EU and other funds. The regional government recognises the challenges posed by the likely downgrade in status from Objective 1 to Objective 2. This is a problem but it is also an opportunity. It would necessitate more efficient use of resources by minimising institutional overlaps and improving the targeting of support. 
The EU resources will not be withdrawn overnight; transitional arrangements will be introduced to assist the region to adjust to the new financial reality. This presents the region and its enterprises with new opportunities. The commissioning of a detailed study and transition plan to assess the current situation and recommend possible mechanism for adjustment in the medium term could assist the region.

Finally, the growing levels of diversity, including the large influx of migrants can be utilised by the region. The previous growth spurt has sucked-in migrants, both from Europe and from elsewhere (South America and Africa, primarily). Some, such as the expat communities, are relatively well educated; others are not. However, by their very nature, migrants tend to be relatively young, willing to take risks and naturally entrepreneurial in their mindset. The region could consider ways and means of harnessing this economic potential through new forms of policy support not restricted to Spaniards or Andalusians.

\section{Policy recommendations}

This section provides a set of key policy recommendations, based on the preceding discussion, analysis and conclusions. It includes a brief discussion of the role of the relevant institutions in relation to each of the proposed recommendations.

\section{Develop the local entrepreneurial culture}

The Andalusia government does recognise the need to promote entrepreneurship as the basis for the development of the economic model being pursued by the region. This recognition comes from a conviction that entrepreneurial spirit can be a driver for innovation, competitiveness and economic growth. The region also recognises the role of universities in this respect; the Andalusia Innovation and Modernisation Plan (PIMA) and the Research, Development and Innovation Plan of Andalusia (PAIDI) include a set of actions designed to encourage entrepreneurship in universities. The above is a good basis, and yet there is a need to develop a stronger culture of entrepreneurship in a region which has traditionally had limited interest in engaging in business activity. There is a need for greater policy integration, focusing on all educational levels: primary school, secondary school, VET institutions and universities. This should not be restricted to a technologically-oriented view of innovation and entrepreneurship. The high and rising levels of general and youth unemployment necessitate the harnessing of all ideas, talents, sectors, etc. for the future of the region. 
Moreover, the focus on entrepreneurship should not be restricted to future labour market entrants. The region could promote the establishment of dedicated (re)training programmes for existing business people (in employment and/or recently made unemployed), focusing on new business models and approaches, combining elements of local skills and strengths, and generally equipping those already in the labour market with the latest business concepts, tools and techniques. Dedicated (re)training programmes could be established using existing institutions, such as university faculties, research centres, training centres, etc., rather than establishing new ones. Moreover, the large number of people entering the unemployment register will require rapid re-training and start-up support to engage in new forms of activity. All such training must be demand- rather than supply-driven.

Turning to the institutions in Andalusia, a Working Group is in the process of being established by the new Ministry of Economy, Innovation and Science and the Ministry of Education to develop policies and initiatives at primary and secondary school levels. This process should also draw the VET and university systems into the discussion, leading to integrated regional policy and support. The business sector should form part of the Working Group, in defining policies, monitoring and evaluating progress.

ANDALUCIA EMPRENDE seems the agency best suited to implementing an integrated approach to developing a culture of entrepreneurship in the region, including through awareness raising campaign, high profile public events, entrepreneurship competitions, entrepreneurship awards, support (financial and non-financial) for start-ups, etc.

\section{Promote self-employment to tackle unemployment and diversify the economy}

The rising levels of unemployment, the need to diversify the economy (e.g. away from construction, real estate, etc.) combined with the population's latent interest to establish a business (GEM, 2006) call for a greater focus on providing opportunities for people to establish their own businesses though self-employment or creation of firms. Such an approach should not be driven solely by R\&D\&I considerations: a strong focus on "innovation" could restrict the flow of viable business ideas. The current economic situation means that entrepreneurship should be promoted widely.

Most people, including Andalusians, recognise the benefits of being their own boss. Self-employment is typically the simplest and quickest way to start a business. There is generally little bureaucracy involved, start-up capital is low, and record-keeping, accounting and taxation are straightforward. By contrast, setting-up a legal entity is a more demanding affair, involving quite complicated legal, tax, finance and market considerations. 
A number of potential target groups can be identified for such a programme including general registered unemployed, youth unemployed, women, ethnic minorities, ex-patriates, etc. Therefore, the region should consider investing a significant volume of resource, over a period of 5 years, into assisting those who desire to become self-employed or create start-ups. The focus of this activity would include: information provision (registration, tax, accounting, finance, etc.); signposting (linking potential and actual entrepreneurs to their needs); training and capacity building (all aspects of starting a firm); business planning (use of local business advisory service providers); coaching and mentoring (use of local business advisory service providers); access to finance (start-up grants, interest free loans, loan guarantee schemes, etc.).

Turning to institutions in Andalusia, the region should review its policies in relation to the stimulation of self-employment. It is unlikely that new institutions will be required (if anything institutional streamlining is needed). However, there might be a need for some new programmes specifically focusing on this type of entrepreneurship. ANDALUCIA EMPRENDE is well placed to take responsibility for a more targeted programme of support for self-employment. However, this would require an evaluation of its current effectiveness in creating businesses, generating jobs, delivering training and support. This would be necessary prior to gearing-up for a new role: its proposed role would not be simply delivering more of the same. In the context of the unemployed, close links would be established with the national or regional employment office in order to ensure that the social security system is aligned with the new regional priorities designed to facilitate a higher level of entrepreneurial activity.

\section{Set out clear incubation principles and benchmarks}

A significant part of the current support for start-ups in the region relates to business incubation. Many business incubators have been established by the region; universities and municipalities also implement their own business incubator programmes over and above those supported by the region. A notable example is Andalusia Technology Park (PTA), which provides funding, support and information for business creation through a five-stage development model involving:

- Pre-incubation stage: for those with a good business idea from the university or the region.

- Incubator stage: open to the pre-incubated firms, as well as others. It offers lower rents and a support team of 8-10 people over a three-year period of time. 
- Business centres: thereafter the firms may join a business centre. Market rents and less intensive support services are provided but there is no constraint on the length of contract.

- Containers: these are spaces constructed and sold by PTA to incubated firms.

- Buildings: in the final stage of support, firms may either purchase or lease ( 75 years) public buildings.

This approach to incubation almost mimics the "cradle to grave" concept of the welfare state, except for the fact that the focus is private sector firms, not citizens. This incubation system is undoubtedly extremely helpful to the firms that are lucky enough to graduate through the five enterprise development stages. However, there are also clear grounds for concern. Firstly, it distorts the market to the extent to which the selected firms benefit from a seemingly endless array of benefits and subsidies, both financial and nonfinancial in nature, whereas their competitors in the region do not. Secondly, it may not necessarily result in much higher survival rates for the participating firms: $50 \%$ of firms die within 2 years compared with the result of the market (30-50\%) left to its own devices, whereas the European benchmark for incubated businesses is $85 \%$. Thirdly, it may actually hamper rapid growth and development of the very firms being assisted as the high and continuing levels of information, support, training, subsidies, etc. may inhibit their long-term competitiveness, growth and innovation. Fourthly, from a practical perspective, a conveyor belt of support targeting a few selected firms automatically restricts the number of potential start-ups that the region can assist. At a point when the region is under increasing financial pressure and is likely to lose its Objective 1 status, there is an urgent need to review the overall approach to business incubation.

Therefore, the region should reconsider its model of support to start-ups, so as to assist as many firms as possible, whilst avoiding market distortion and generating incentives for supported firms to operate independently as soon as possible. In particular, the region should conduct an independent evaluation of its business incubation model and benchmark it with international best practices. The introduction of a monitoring and evaluation system to assess the impact of this form of support would also be helpful. RETA could be involved and, indeed, take the lead in ensuring that best practice policy principles are applied in technology parks and incubators to ensure that the system is as efficient as possible. 


\section{Introduce forms of support to corporate spinoffs}

The region's spin-off support is currently almost entirely focused on universities, as illustrated in the chapter on research organisations of this report. However, one of the few areas which the Andalusia region and its implementing agents are not yet supporting appears to be corporate spin-offs. The specific nature of corporate spin-offs means that they are an important aspect of the knowledge economy: here, knowledge and experience is combined into new products, services and process. Measures to support corporate spinoffs could have important results: they contribute to the strengthening of regional markets and of their competitiveness; they can generate synergies offering the prospects of strengthening innovation and employment generation; they assist the general process of stimulating entrepreneurial activity and diversifying the regional economy. The regional government should therefore undertake a review of the current levels of corporate spin-offs in the region, including potential and barriers to further development, leading to the design and implementation of specific measures seeking to boost this phenomenon.

In this context, the regional government should work closely with the Andalusia Technological Corporation (CTA). Given its close links with technology parks, RETA could also be actively involved in this policy as far as firms hosted in technology parks are concerned.

\section{Learning models}

This part of the chapter will provide evidence from three learning models from EU countries that can provide further illustration and support for the policy recommendations set out above.

\section{The Entrepreneurship Action Plan for Wales: Developing a culture of entrepreneurship}

\section{Description of the approach}

The Entrepreneurship Action Plan for Wales (EAP) seeks to promote a culture of entrepreneurship in Wales through three key elements: (i) recognising the opportunity: creating a greater awareness of the opportunities and benefits of entrepreneurship in order to encourage more people to start a business or to grow the business they are in, and to develop a greater entrepreneurial culture within our institutions, communities and businesses; (ii) creating enterprises: creating a greater number of sustainable start-up businesses with potential for further growth, particularly by under-represented groups of society such as women, the young, ethnic minorities, etc; 
and (iii) going for growth: increasing the number of businesses in Wales that grow, thereby creating greater wealth, employment and opportunity.

\section{Rationale for the intervention}

Although the Andalusia region has recognised the importance of entrepreneurship and has implemented a range of activities, the approach to developing a culture of entrepreneurship in the region is not as comprehensive, including close involvement of the private sector and extensive awareness raising campaigns, combined with an integrated set of activities involving schools, vocational educational establishment, universities, etc. The Entrepreneurship Action Plan for Wales offers concepts which are suitable for replication by a large region such as Andalusia, subject to the necessary customisation.

\section{Reasons for success}

The creation of a private sector-led steering group is critical. The EAP for Wales's steering group focused on six themes (i) fostering a culture for entrepreneurship (ii) unlocking the potential (iii) enterprising communities (iv) investing in knowledge and experience (v) bridging the funding gap and (vi) reaping the rewards. Another reason for success was the launch as a public consultation document and then submission to the National Assembly for Wales for approval. The strategy of the programme was guided by a private sector-led Entrepreneurship Implementation Panel; the operational part of the project was managed by a special enterprise team established within the Welsh Development Agency. Their main role was to commission work from a range of different organisations to ensure the delivery of the programme. By co-ordinating the role of different organisations and providing the funding for activities, a coherent approach to the development of entrepreneurship across Wales was established. A multi-million Euro programme for funding was made available through European structural funds to ensure the delivery of all aspects of the EAP.

\section{Obstacles faced and responses taken}

Strategies can only work if there is effective implementation by all the organisations responsible for delivering the Entrepreneurship Action Plan. The EAP also requires significant levels of medium term political support, backed-up by financial resources such as through the Structural Funds. There are no "quick fixes" in achieving a gradual change in entrepreneurial culture, as changing the culture is a long-term challenge. Effective delivery and implementation of successful initiatives requires new approaches to education and training, community enterprise, business start-ups, development 
funds and the many other areas for action which this strategy has embraced. Success depends on developing effective innovative partnerships across both the public and private sectors and on targeting resources effectively.

\section{Relevance to Andalusia and considerations for adoption}

Andalusia recognises the importance of developing a stronger enterprise spirit in the region, especially in light of: (i) the very high and increasing levels of general and youth unemployment; (ii) the levels of human capital relatively low compared with elsewhere in Spain; and (iii) the traditional preference for working in the public, rather than in the private sector. The key measures of the success of the Welsh EAP strategy, as shown by the Global Entrepreneurship Monitor for Wales, include a noticeable change in the attitudes of the people in Wales towards entrepreneurship and a public sector that increasingly and explicitly supports entrepreneurship across its activities. Its success has resulted in an increase in new business start-ups. This type of approach would be advantageous in the Andalusia region: entrepreneurship in its widest sense would be supported, rather than being restricted to an R\&D\&I focus.

\section{For further information}

Department of Enterprise Innovation and Networks

Welsh Assembly Government

Plas Glyndwr, Kingsway

Cardiff CF10 3AH

Tel: +44 2920828821

Web site: www.wales.gsi.gov.uk

\section{Start-up subsidies in Germany: Making the transition from unemployment to self-employment}

\section{Description of the approach}

Germany has suffered from persistently high unemployment rate, as well as low self-employment rates. Consequently, a programme known as the "Start-up Subsidy" (SUS - Existenzgründungszuschuss) was introduced in 2003 under which the registered unemployed could choose between the SUS and a second programme, namely the "Bridging Allowance" (BA, Überbrückungsgeld). The two programmes differ in their design most importantly in relation to the amount and duration of the subsidy. Whereas the BA pays recipients the same amount that they would have received in unemployment benefits for a period of six months plus a lump sum to cover social security contribution, the SUS runs for three years, paying a lump sum of EUR 600 per month for the first year, EUR 360 per month for the second, and EUR 240 per month for the third. 


\section{Rationale for the intervention}

Germany had one of the lowest self-employment rates in Europe (fluctuating between $10-11 \%$ ) and yet experienced persistently high levels of unemployment (between 7-9\%). To overcome this constraint, the German government prioritised active labour market policies, including vocational educational training, employment subsidies, job creation schemes and selfemployment schemes targeting the registered unemployed. The policy has been successful in terms of uptake: whereas in $20023.5 \%$ of the unemployed received the subsidy (37 000 start-ups), this increased to 9\% (250 000 start-ups) in 2004 (Baumgartner and Caliendo, 2007). Research leads to the conclusion that both programmes are successful: “. . a the end of our observation period, the unemployment rate of participants in BA [Bridging Allowance] was approximately 17 percentage points lower than that of nonparticipants, and for participants in SUS [Start-up Subsidy], around 18 percentage points lower for women and as much as 29 percentage points lower for men. Additionally, both the probability of being in self-employment and/ or paid employment and the personal income are significantly higher for participants" (Baumgartner and Caliendo, 2007, p.26).

\section{Reasons for success}

Business experts must examine the start-up concept and determine its viability. Such experts could include the Chambers of Industry and Commerce, Chambers of Crafts, Professional Organisations, Expert Associations such as Business Development Service Providers and Financial Institutions. The new entrepreneurs also need to be given support both before the start-up phase (entrepreneurship training, business plan, etc.), as well as after initiation of activities (coaching, mentoring, consultancy, etc.).

\section{Relevance to Andalusia and considerations for adoption}

The high and rising unemployment rate in the Andalusia region, especially as far as youth unemployment is concerned, calls for a much greater emphasis on assisting the unemployed into self-employment through training, start-up grants, etc. The emphasis should be on allowing the potential entrepreneurs to determine the market need and attempt to fill-it, regardless of sector or other policy considerations. That said, the eligibility criteria should ensure that certain activities are avoided (such as property, gambling, etc.). 
For further information

Existenzgründungszuschuss

Bundesagentur für Arbeit

Regensburgerstraße 104

90478 Nürnberg

Germany.

Tel: +491801664466 / 1801555111

Web site: $w w w$.arbeitsagentur.de

\section{Application of Business Incubation using European Best Practice}

\section{Description of the approach}

Unlike the preceding two examples this learning model is not based on a concrete best practice. However, since Andalusia has placed so much effort and investment into establishing incubators already, a relevant issue for the region to consider is a "benchmarking" model that would allow it to assess its performance relative to the European experience. The best example of such benchmarking is the EC-funded report "Benchmarking of Business Incubators" (CSES, 2002).

\section{Rationale for the intervention}

One of the key initiatives that the Andalusia authorities have pursued in relation to entrepreneurship and start-ups is the establishment of business incubators. International best practice has demonstrated their value. The European incubator benchmarking study (CSES, 2002) highlights that there are about 900 incubators in the EU generating approximately 40000 net new jobs annually and that incubators accelerate the start-up of new businesses and help maximise their growth potential in a way that is more difficult for alternative SME support structures to achieve.

However, incubators are not a panacea for entrepreneurship and job creation. The experience of incubators in the EU has been mixed. Therefore, the contribution of the above EC study was to prepare benchmarks for what constitutes successful incubators (see table below). It is important for Andalusia, having invested a large amount of time and funding, to assess the extent to which it is performing according to these benchmarks and, if it falls short of those standards, to consider what needs to be done to maximise efficiency in future. 


\section{Reasons for success}

The EC benchmarking study identified a number of critical quantitative and qualitative factors which should be considered in developing a successful incubator policy. Table 4.4 sets out some of the key issues that could be considered by the Andalusia region.

Table 4.4. Summary of key EU business incubator benchmarks

\begin{tabular}{llll}
\hline Setting Up and Operating & \multicolumn{1}{c}{ Average } & \multicolumn{1}{c}{ Range } & \multicolumn{1}{c}{ Benchmark } \\
\hline Average capital investment cost & EUR 3.7 million & EUR 1.5 to EUR $22 \mathrm{~m}$ & NA \\
Average operating costs & EUR 480000 p.a. & EUR 50000 to & NA \\
& & EUR $1.8 \mathrm{~m}$ & \\
Percentage of revenue from public subsidies & $37 \%$ & $0 \%$ to $100 \%$ & $25 \%$ \\
Incubator space & $3000 \mathrm{~m}^{2}$ & $90 \mathrm{~m}^{2}-41,000 \mathrm{~m}^{2}$ & $2000-4000 \mathrm{~m}^{2}$ \\
Number of incubator tenants & 27 firms & $1-120$ firms & $20-30$ \\
Incubator Functions & Average & Range & Benchmark \\
Incubator occupancy rates & $85 \%$ & $9 \%-100 \%$ & $85 \%$ \\
Length of tenancy & 35 months & 6 months-no max. & 3 years \\
Number of management staff & 2.3 managers & $1-9$ managers & 2 managers min \\
Ratio of incubator staff: tenants & $1: 14$ & $1: 2-1: 64$ & $1: 10-1: 20$ \\
Percentage of managers" time advising clients & $39 \%$ & $5 \%-80 \%$ & $50 \%$ \\
Evaluating Services and Impacts & Average & Range & Benchmark \\
Survival rates of tenant firms & $85 \%$ & $65 \%-100 \%$ & $85 \%$ \\
Average growth in client turnover & $20 \%$ p.a. (2001) & $5 \%$ to $100 \%$ p.a. & $25 \%$ \\
Average jobs per tenant company & 6.2 jobs per firm & 1 to 120 & NA \\
New graduate jobs per incubator p.a. & 41 jobs & 7 to 197 & NA \\
Cost per job (gross) & EUR 4400 & EUR 124 to & EUR 4000 to \\
\hline
\end{tabular}

Source: CSES, 2002.

The key qualitative policy issues that also need to be taken into consideration in assessing the nature and effectiveness of business incubation policies are highlighted in Box 4.1. 


\section{Box 4.1. Summary of key EU business incubator qualitative factors}

Setting up and operating

- Business incubators should be designed to support and be part of a broader strategic framework - either territorially orientated or focused on particular policy priorities (e.g. development of clusters), or a combination of these factors.

- Incubators should be promoted by an inclusive partnership of public and private sector stakeholders.

- During the development phase, it is important for the market to be tested and a business plan to be devised that can provide a framework for incubator operations.

- There are a number of different set up funding models but the evidence is that public support for the establishment of incubators will remain critical for the foreseeable future.

- There are different ways in which incubators cover their operating costs and whilst many incubators rely on public subsidies, there is a strong argument in favour of dependence on this source of revenue funding being minimised.

Incubator functions

- The provision of physical space is central to the incubator model. Standard good practices now exist with regard to the most appropriate configuration of incubator space.

- The value added of incubator operations lies increasingly in the type and quality of business support services provided to clients and developing this aspect of European incubator operations should be a key priority in the future.

- Business incubators should charge clients for the support services they provide but the level at which prices are pitched should be designed to minimise the risk of "crowding out" private sector providers.

- With regard to incubator operating procedures, it is essential that there is a clearly defined target market and that this is reflected in the admission criteria.

- Whilst achieving high occupancy rates is important to generate income, this consideration needs to be balanced against the importance of maintaining selective admission criteria.

- Adopting exit criteria that ensure a turnover of client companies is desirable even if the turnover of firms makes revenue levels from rental income and other services less certain.

- Aftercare and networking with firms that have left an incubator should be regarded as just as important as providing services to incubator tenants. 


\section{Box 4.1. Summary of key EU business incubator qualitative factors (continued)}

- The quality of the management team, and adoption of a business-like approach to running incubators and monitoring clients, is crucial to performance and best practices in this field are becoming standardised.

- The type of activities client companies are pursuing, in particular the technology/ knowledge intensity of these activities, is the key factor (rather than physical features, etc.) that should be used to differentiate one type of incubator from another.

Evaluating services and impacts

- The performance of business incubators should be judged primarily in terms of the results achieved, i.e. the impact they have on businesses, wider economic development and other priorities.

- In assessing the impact of incubators, there is a need to obtain feedback directly from client companies.

- Likewise, a distinction should be made between gross and net impacts achieved by business incubators.

- Although "new economy" incubators are currently out of favour, there are many lessons to be learnt that are relevant to the more "traditional" model (and vice-versa).

- Across Europe, there are a variety of different business incubator models and precise modalities should reflect local, regional and national circumstances and priorities.

- Similarly, although only limited comparisons are possible, the research confirms significant differences between the way in which European and US incubators operate and therefore scope for a sharing of experience and know-how.

- Overall, business incubators are a very cost-effective instrument for the promotion of public policy objectives.

Best practice and policy recommendations

- Business incubators should be encouraged to benchmark themselves against best practice standards and to take the steps required to achieve them.

- Benchmarking and best practice sharing should focus on the four key incubator service areas: entrepreneur training, business support, financing and technology support.

- Business incubators should be encouraged to periodically undertake impact assessments.

- A further priority should be for business incubators reduce their dependence on public subsidies.

- There is a need to "professionalise" the occupation of business incubator management. Source: CSES, 2002. 


\section{Relevance to Andalusia and considerations for adoption}

There is a need to establish a monitoring and evaluation (M\&E) mechanism for the incubation activities since they are one of the most extensive and expensive activities being pursued by Andalusia, as far as entrepreneurship and start-ups are concerned. The proposed evaluation against quantitative benchmarks would enable the region to assess the current incubator policy and whether there is a need for refinement, thus increasing policy effectiveness. To illustrate the point, the survival rate of firms reared in an incubator environment should be significantly higher than the business success rate amongst the wider SME community. The latter is estimated at $30-50 \%$ (over a 5 year period). The EC benchmark for the survival rate amongst tenant firms is set at $80-90 \%$. The survival rate quoted in the Andalusia region appears to be $50 \%$, suggesting that incubators are not operating as efficiently as might be hoped. Whilst survival rates are only one possible indicator of the performance of incubators and others might be equally of importance (for example, the extent to which incubators contribute to high-growth firms or the employment impact in terms of job creation), this suggests the necessity for an evaluation of the Andalusia incubator practice so far. This would provide a basis for change, especially in view of the need to transit to the next programming phase where the region is likely to benefit from a reduced level of EU Structural Funds.

\section{For further information}

Centre for Strategy \& Evaluation Services LLP

Westering House

17 Coombe Road

Otford, Kent TN14 5RJ

United Kingdom

Tel: +44 1959525122

Web site: www.cses.co.uk 


\section{References}

Andalusia Region (2005) Andalusia Innovation and Modernisation Plan.

Andalusia Region (2006) The Innovation and Modernisation Plan of Andalusia.

Andalusia Region (2007a) Andalusia Operational Programme 2007-2013

Andalusia Region (2007b) Research, Development and Innovation Plan of Andalusia (2007-2013).

Andalusia Region (2010a) Secretariat for Innovation presentation to OECD, April 2010.

Andalusia Region (2010b) Emprende presentation to OECD Mission, April 2010.

Andalusia Region (2010c) RETA presentation to OECD mission, April 2010.

Baumgartner, H. J. and Caliendo, M. (2007) Turning Unemployment into SelfEmployment: Effectiveness and Efficiency of Two Start-Up Programmes, DIW, Discussion Papers 671, Berlin.

CSES (2002) Benchmarking of Business Incubators, Final report, DG Enterprise, Brussels.

EC (2003) Green Paper: Entrepreneurship in Europe, Brussels.

EU (2010) Europe 2020: A European strategy for smart, sustainable and inclusive growth.

Global Entrepreneurship Monitor (2006) Andalusia.

OECD (2001) Fostering Entrepreneurship, OECD, Paris.

OECD (2003) Entrepreneurship and Local Economic Development: Programme and Policy Recommendations, OECD, Paris.

OECD (2009) Fostering Entrepreneurship in Eastern Germany, OECD, Paris.

Granados-Cabezas (2010) Diagnostic Report Chapter, this publication.

Wolfe, D. (2010) University-Industry Collaboration, this publication. 


\section{Chapter 5}

\section{SME development}

\section{Introduction}

SME development and growth is critical to fostering entrepreneurship, job creation and economic development in Andalusia as a result of the dominance of SMEs in the regional economy. However, the region is currently characterised by a small number of innovative and internationally competitive SMEs and a broader mass of firms operating in traditional sectors and supplying local markets. This chapter explores the character and nature of SME development in Andalusia, focusing specifically on levels of innovation, internationalisation and the quality of the support environment in the region, and the role played by RETA. It makes a number of policy recommendations regarding improving the support environment for the different types of SME before proposing a number of learning models that may offer important lessons for Andalusia.

\section{Policy issues}

Two issues are paramount with regard to SME performance and competitiveness in Andalusia: improving innovation and internationalisation. A central issue concerning the organisation is how to broaden innovation beyond the small number of SMEs that are currently involved in research and development or high technology activities. In this respect, there is a pyramid structure regarding innovation among SMEs. RETA estimates that there are currently 200 firms out of around 500000 in Andalusia engaged in research and development activities on a regular basis. There are a further 3000 who RETA has identified as having the potential to do more innovation while the regional government has set a target for having 5000 innovative SMEs and 100 firms that are described as global leaders. Beyond this grouping, a further policy concern relates to increasing more basic levels of innovation 
(e.g. use of information technology in routine business activities) within the mass of more traditional SMEs.

A second, but related set of issues, reflects the desire to internationalise the SME sector. Currently, the export performance of the Andalusia economy is dominated by a small number of firms (both SMEs and the handful of larger corporations that exist in the region). The regional internationalisation agency EXTENDA estimates that around 100 Andalusia firms are "international" in the sense of a sustained overseas presence. In part, the diagnosis of regional policymakers is that this relates to the firm size structure of the regional economy (see below) with an over-preponderance of very small firms.

Further policy issues can be identified that will be expanded upon below. First, the nature of SME policy and the appropriateness of the current focus upon innovation. How might innovation policy be adjusted to better support different types of SME? To what extent is a policy for increasing higher levels of innovation, particularly R\&D activities, among a core of SMEs, appropriate to the innovation needs of the vast majority of lower technology driven SMEs in more traditional sectors? International research confirms that in most countries SMEs are less innovative than larger firms (Asheim et al., 2003). SME innovation is often "defensive" in character, focusing upon strategies that help reduce costs or secure market niches because they lack the resources of larger firms to develop "offensive" strategies of new product or market development (Kaufman and Todtling, 2003). Perhaps a broader view of innovation processes, that recognises the significance of smaller scale and more incremental improvements in productivity alongside more high technology focused strategies, is required. Regarding the role of RETA itself, how effective have been its current policy programmes, particularly the use of technology agents as part of an outreach strategy towards both the more innovative and traditional SMEs?

A further set of issues arises from the internationalisation agenda. Even in the most open economies, SMEs are reluctant internationalists because they lack the capacities of larger firms, including the financial means, the managerial expertise and the logistical knowledge required to sustain a presence in international markets (Smallbone et al., 1999). For many SMEs, the risks involved in supplying international markets often outweigh the returns, and indeed, previous research is replete with examples of small firms who have had disastrous attempts at international expansion. Public policy can play an important role here in providing market information and knowledge, funding overseas trade missions to establish contracts, promoting local products at international trade fairs and so on, but more nuanced policies are also required if Andalusia wishes to raise the international presence of its SMEs in a more sustainable fashion. 


\section{Assessment of the region}

\section{SMEs in the Andalusia economy}

The Andalusia economy is dominated by SMEs with over 99\% of firms having less than 500 employees (see Table 5.1). This places it well below both the Spanish and the EU averages (Romero and Javier Santos, 2007). Of even greater significance is the disproportionate number of "micro firms" in the region either self-employed or employing less than 10 people - accounting for over $95 \%$ of enterprises. While the region experienced a high rate of new business start-ups and a significant increase in jobs during the period of economic growth from the mid 1990s up until the present economic downturn in 2007/2008, the continued lack of mittelstand firms, medium-sized firms between 50 and 500 employees, demonstrates an underlying structural problem.

Table 5.1. Size structure of firms in Andalusia, 2008

\begin{tabular}{lcc}
\hline Size of firm & \% of total enterprises & \% change 2007-8 \\
\hline Micro-enterprises & 95.06 & -1.73 \\
Self employed (no employees) & 51.57 & 0.38 \\
1-9 employees & 43.48 & -4.3 \\
Small firms (10-49) & 4.31 & -13.95 \\
Medium sized firms (50-499) & 0.55 & -11.68 \\
Large enterprises (+500) & 0.08 & -37.46 \\
\hline Total & 100.00 & -2.44 \\
\hline
\end{tabular}

Source: Consejo Economico y Social, 2009.

As policymakers within the region recognise, an imbalanced economic base and firm structure presents a structural problem and legacy of past development, with a failure to grow indigenous enterprises to a level that can contribute more significantly to employment creation and regional growth. The imbalances in the regional economy were further exacerbated in the boom period from the mid 1990s to the 2007 when there was a dramatic growth in small firms in the construction sector, largely driven by the speculative boom in property prices. This resulted in a shift of resources, particularly of capital and labour, from the more productive and internationally competitive sectors of the economy. The global economic downturn has probably worsened this situation: the most recent data available indicate that the larger firm sectors, including medium sized firms, have been more heavily affected than smaller enterprises seeing much greater percentage falls in their numbers (see table) with severe implications for loss of jobs. 
It is estimated that only $1.4 \%$ of Andalusian firms (a mix of both SMEs and larger firms) are involved in export markets, compared to the national average of 4\% (Consejo Economico y Social, 2009). Andalusia accounts for approximately $9 \%$ of Spanish exports, worth approximately EUR 14 billion, ranking it 5th behind the Madrid region, Catalonia, Pais Vasco and the Valencia region. Regional government officials suggest that around 16000 firms are involved in export markets, but only 3000 on a regular basis, as opposed to the 100 that are "international" (in the sense of having foreignbased establishments). Another 25000 serve national markets and the remainder predominantly serve local markets in Andalusia (Author's interviews). Despite this small base, exports increased as a proportion of the total activity in the regional economy over the decade $1995-2005$, rising from $20.8 \%$ to $24.9 \%$ of GDP (Consejo Economico y Social, 2009). The most recent evidence from EXTENDA suggests that the region's exports were holding up well compared to other Spanish regions in the face of the economic downturn. Broken down by sector, it is apparent that the agro-food sector, which is dominated by SMEs remains the leading source of export revenue, accounting for around $35 \%$ of total exports according to the most recent data, $19 \%$ of this total represented by unprocessed agricultural products and $16 \%$ from processed food and drink products (Junta de Andalucía, 2007). A considerable proportion of the region's exports are accounted for by large agri-food producers producing intensive low value added fruit such as strawberries and raspberries for northern European markets in artificial hothouse conditions in Almeria and Huelva. Minerals extraction, the aeronautical sector (Andalusia is home to part of the European Airbus project) and metal smelting are the other sectors that account for between $5-10 \%$ of exports.

\section{A typology of SMEs}

The region has a pronounced divide between a small number of nationally and internationally competitive firms and the remainder which are geared toward local markets and have low levels of productivity and competitiveness. Regional government agencies estimate that there are around 200 firms (both large and SMEs) that carry out research and development activities on an ongoing basis, a further 3000 firms described as being "innovative" but without a high degree of commitment to $\mathrm{R} \& \mathrm{D}$, and the remainder of a population of approximately 500000 SMEs. Of the latter, a recent survey carried out by RETA estimated that around 10000 might have the potential to become more innovative.

Beyond this innovation-based definition of SMEs, it is possible to identify a threefold typology of SMEs within the region based upon the types of activities they are engaged in and the type of markets they serve (see also Romero and Javier Santos, 2007). First, there are a small number of firms engaged in high 
technology activities, some of whom serve international markets, but many of which are involved primarily in local and national markets in sectors such as biotechnology, aeronautics, information technology and communications. Second, export oriented-firms in more traditional sectors such as the agri-food sector and minerals and metals. Third, the vast majority of lower technology SMEs in sectors that serve local markets. An important qualification needs to be made here however because many tourist-related sectors and construction activities are linked to the attraction and retention of global consumers and therefore have significant positive consequences for the region's balance of trade. Innovation policies should also focus upon how the interaction between these firms and the tourist population might better raise the profile of Andalusian business at the international level, through a focus upon raising productivity and quality standards. Developing effective innovation and internationalisation policies for Andalusia's SMEs therefore needs to recognise the diverse needs and different potentials of these three different segments of the economy.

\section{An analysis of the SME development policy environment}

Andalusia has a well established state-driven policy environment supporting and advising SMEs. Discussions with the various agencies also revealed a high degree of consensus regarding the problems facing SMEs in the region and therefore considerable synergies between government agencies and bodies in driving forward policy. The diagnosis of the issues facing SMEs broadly tie in with the findings of this report, correctly identifying the disjuncture between the small number of competitive SMEs and the remainder. One observation however from the SME perspective is that the dense thicket of organisations and agencies facing SMEs within the region is probably bewildering for less experienced firm owners. A recurring theme from meetings with economic actors in the region is that there is a significant chasm between the small number of more dynamic SMEs that are successful in obtaining funds from business support, because they know and are embedded in the system, and the vast majority of the population of firms that are excluded from these networks.

Aside from RETA, there are a plethora of other institutions advising SMEs. The most significant for existing SMEs are the Andalusia Employers Association (CEA), the main independent business association sub-divided into territorial and sectoral associations, and EXTENDA, the government body that promotes trade and exports. Through RETA and other agencies, there is an impressive level of support for the more innovative and internationally competitive SMEs (types 1 and 2 above) compared to the experience of other regions. The availability of EU funds in the recent past in particular mean that there has been a significant level of investment in high technology infrastructure and support, business start-up and venture capital for the more dynamic SMEs. 
In particular, there is a considerable level of public support, at different levels (EU, national, and regional), for the most innovative SMEs in Andalusia. As other parts of this report suggest, there is a well developed regional innovation system and also considerable effort expending on engendering an entrepreneurial culture in the regions with considerable support for new innovation-led firms. Since 2004, support for high tech SMEs has mainly been channelled through IDEA as the regional development agency administering technology parks, and RETA whose aim is to support the existing small core of high tech SMEs and encourage the second tier of SMEs to increase their levels of R\&D activity. At the core of the broader innovation policy are the 11 science and technology parks discussed elsewhere in this report, as well as a further 21 technology centres which have a more dedicated sectoral focus. RETA expresses the more widely held belief that clustering of high technology firms, described as Andalusia's "closeness" model is the most effective means of offering support to fast growing and technology dynamic SMEs. The employment impact is certainly significant in a region that had hitherto been lagging in terms of new technology sectors; the Andalusia Technology Park (PTA) in Malaga, for example, has 530 enterprises employing more than 10000 people. The focus upon particular sectors and clusters is appropriate - and chimes with wider recent experience of the best models for encouraging SME innovation - as we note elsewhere. Additionally, the parks provide excellent facilities and infrastructure for high-tech SMEs with a sophisticated approach to the different phases of early business growth by providing different types of business unit and varied levels of subsidy and support.

Because of its position as one of Europe's less favoured regions, Andalusia SMEs also have access to considerable amounts of development funding, for a range of activities, from starting up businesses, to support for $\mathrm{R} \& \mathrm{D}$, to help with identifying export markets. A major initiative is JEREMIE (EU fund for micro and medium businesses) which, in partnership with Andalusia banks, has EUR 90 million of support to allocate to SMEs. It is not concerned with business start-ups (for which there are other sources of funding). The fund is a relatively recent initiative, so it is too early to judge its impact, although its strategy is to work with firms in particular sectors (e.g. aeronautical, biotechnology, renewable energy) which are important in terms of targeting rather than risking a lower impact by spreading itself too thinly. Although the general focus is to be applauded, the policy of neglecting activities in traditional sectors, in favour of backing the in vogue "high tech sectors" might be in danger of missing opportunities based on the region's existing strengths - a wider problem of the thrust of the region's innovation policy. Additionally, the minimum levels of support given by the JEREMIE programme - of EUR 500000 - might be exclusionary for many of the smaller innovative firms.

With regard to improving innovation among the broader population of SMEs (type 3 in our typology), RETA employed 85 technology agents whose 
approach was to encourage innovation among firms. Although this approach has recently been discontinued because of a reconsideration of RETA's model of work, the broad objective of having "technology agents", providing "one-stop" shop style advice for firms, as a way of "rolling out" innovation to the broader SME population is itself innovative and appropriate. RETA's own analysis suggests that it has been successful in improving basic levels of innovation among more traditional SMEs (e.g. use of anti-virus software, computer-based invoicing, etc) reaching out to over 80000 firms since 2005. However, a concern here is with the types of individual being employed as agents: most are recent graduates from an engineering or science background who might have the technical competences but are unlikely to have the more practical skills and know-how to relate to traditional SME concerns. They may be able to provide the basic IT advice but are not best placed to deal with more generic and substantial productivity issues that firms face. International surveys of SMEs time and again find that there is often a mismatch between both the perceived and the undiagnosed problems facing SMEs and the kind of support available (Todtling and Kaufman, 2003). In the future, any regional organisation interested in re-launching this professional profile may want to widen the circle of advisers to include those with more business experience in particular sectors who are able to provide specific industry knowledge and practical problem-solving abilities.

Focusing more specifically on providing innovation support for SMEs, and in line with the types of SME that we have identified, Andalusia faces the following challenges.

- How to provide effective support to the more innovative SMEs to continue growth trajectory and expansion - creating more medium sized firms from the encouraging number of micro enterprises that are being created?

- How to identify ways of supporting the internationalisation of the SME sector by improving the overall levels of productivity and competitiveness?

- How to increase levels of innovation (which includes broader organisational innovation) across the broader population of SMEs?

\section{How to provide effective support to the more innovative SMEs}

While there is no doubt that firms have benefited from the excellent facilities and infrastructure available on these parks, there are doubts as to whether their "clustering" has fostered a more collaborative culture of learning and knowledge exchange. A recent study that explored the type and extent of collaboration between high tech SMEs on the Cartuja Technology Park in Seville found that $57 \%$ of respondents felt that there was a lack of 
a culture of cooperation in the park. While there was a relatively high level of collaboration with universities and government research centres $(30 \%)$ the level of collaboration with other SMEs was much lower (19\%), with a much higher level of collaboration with firms in other parts of the region (44\%). This in itself is not surprising and is in line with some earlier studies of science parks (Massey et al., 1992). Behind this analysis, however, a more significant issue seems to be a lack of trust and willingness to share ideas among many SMEs, which could be a barrier to many firms developing beyond the micro level, a finding also reported by firms based on PTA-Malaga.

However, it should be noted that where high technology firms are concerned, the most successful innovators are usually plugged into more global knowledge pipelines and networks (see for example the Scottish case study below) (Cumbers et al., 2003; Bathelt et al., 2004). The most dynamic firms are in this sense the ones that are able to capitalise on the local support environment, but also to access non-local sources of information and knowledge about new development and processes in their markets. Here too, there are reasons for concern. Only $38 \%$ of firms on the Cartuja Park had interactions with foreign businesses, a figure that compares unfavourably with a survey of the Scottish life sciences firms who were accessing local, national and global support on a fairly even basis, even at the earliest stages of the product life cycle (Birch and Cumbers, 2009). The impression is that much of the activity on the technology parks is still embedded within regional and national firm and innovation networks. In comparison, the high technology SMEs that have developed and expanded most successfully in Andalusia appear to be those that are to a large extent "born global" in the sense that the founders of firms are already from the very outset plugged into broader global knowledge and firm networks, through previous university or career experience. Existing policy agendas seeking to internationationalise these activities by developing links with foreign companies and universities should be encouraged and extended.

\section{How to identify ways of supporting the internationalisation of the SME sector}

Like most other European regions Andalusia has a well-developed external trade promotion agency which has been charged with enhancing the internationalisation of SMEs. EXTENDA, with 21 offices in 19 countries, has an impressive range of initiatives for a regional trade agency, although once again there are questions about the sustainability of the diverse activities with the expiry of EU funding. Of particular promise is the strategy of internationalisation in Latin America that is being pursued both by RETA and EXTENDA. The long established cultural and linguistic ties between Andalusia and the latter gives the region a decisive competitive advantage 
over other European regions. In an environment of shrinking business support, more targeting of SME activity in this direction should be encouraged, although not at the expense of protecting existing European markets.

Given the lack of internationally competitive firms, an over-emphasis upon internationalisation may run the risk of "running before you can walk" for many SMEs. Other policies which focus upon improving productivity, enhancing basic innovation processes (such as improving the quality and efficiency of production processes), strengthening linkages with larger Andalusia and foreign-owned companies within the region may be preferable for many more locally oriented SMEs. Additionally, the contraction in global economic demand from the recent downturn may make the penetration of international markets even harder for SMEs. Evidence from regional clusters elsewhere suggests that many of the more successful regions have a territorialised approach to internationalisation (Maskell, 1998, Cumbers et al, 2003) whereby SMEs are able to "piggyback" on the backs of larger customers into international markets. Existing policies that seek to strengthen the linkages between smaller firms and large companies (both locally-owned such as Abengoa and foreign-owned) should be encouraged and developed further as part of broader cluster-building strategies.

\section{How to increase levels of innovation across the broader population of SMEs}

Various studies have highlighted the unwillingness of SMEs to become involved in collaborative networks with other firms, often due to a lack of trust or fear of giving away important business innovation to competitors (Cumbers et al., 2003; Todtling and Kaufman, 2003). Yet, a widely recognised paradox is that if SMEs are to become more innovative and compete with larger firms, external cooperation and collaboration is essential to overcome size-related disadvantages. The Community Innovation Survey some time ago revealed the connection between the low level of external networking among SMEs and levels of innovation (Cooke et al., 2000). A critical issue for Andalusia SMEs in relation to raising innovation across the population of SMEs is to raise the levels of external networking among the different types of firm.

The cluster strategy is an appropriate one, although there is a degree of "overkill" in the number of sectors and initiatives that receive support at present. Around 25 clusters have been identified with the aim to create technology centres in each, a policy that seems over-ambitious and is likely to spread diminishing public resources (after 2014) too thinly. A more sensible strategy would be to focus public funding around the most promising sectors while finding ways of strengthening existing industry associations and bodies in other organisations. There is a discussion of 5-6 key strategic clusters that 
could become the focus of policy, including agro-food, biotechnology and health sciences, information technology, aeronauticals, renewable energy. However, there is a sense of unrealistic expectations of providing "world class" innovators in fashionable high-tech sectors rather than recognising existing regional strengths, some of which may lie in more traditional activities (e.g. the stone sector described in Box 5.1).

There are limitations to how much of a collaborative learning culture can be instilled on SMEs from top-down initiatives imposed by regional government agencies which tend to dominate the policy agenda in Andalusia. Surveys of SMEs in Andalusia and elsewhere constantly show that the most important source of both collaboration and innovation tend to be customers or suppliers in their own value chains rather than external research bodies (either public or private) (Cumbers et al., 2003). At the same time, regions that have been most successful in inculcating a better collective learning culture tend to be those that have developed sectorally based support organisations that can provide knowledge, training and consultancy needs for SMEs.

A good example of the latter, which has facilitated innovation in a traditional sector, is the Andalusia Stone Technology Centre (CTAP) (Jannson, 2007).

\section{Policy recommendations}

In their review of different European models to support innovation among SMEs, Asheim and Isaksen (2003) identify three types:

- regionalised national innovative systems, where the production structure and institutional supports are integrated into top-down forms of national innovation system, usually underpinned by linear concepts of innovation, a focus upon R\&D and the establishment of technopoles or science parks to facilitate innovation;

- embedded innovation networks, which are more decentralised, underpinned by particular socio-cultural relations operating within regions, bottom-up interactions between firms to create institutional support mechanisms and sustained by high levels of trust between firms;

- and a third type, referred to as a networked regional innovation system, that is also bottom-up, but involves the interaction between regional governance institutions and agencies with key firms on a planned basis to create close university-industry linkages to support innovation.

Examples of the first would include the Spanish regions as a whole in the 1990s where innovation efforts were dominated by technopole strategies emphasising physical infrastructure projects, underpinned by EU and national government funding (Isaksen, 2003). The second kind of model 


\section{Box 5.1. The Andalusia Stone Technology Centre}

Started in 2001, CTAP was the first sector-based technology centre created in Andalusia. The stone sector accounts for around 400 companies and a direct workforce of around 9000 people and is concentrated in the Macael marble region. After a period of decline up to the 1990s, there is evidence of renewed growth in the cluster, partly through the activities of CTAP. CTAP is significant because it developed from a proposal by firms within the sector, rather than being imposed from outside, although it has received EU support through the European Regional Development Fund (ERDF). Critically the management has been appointed largely from within the sector so has important tacit knowledge about the workings of the sector and the problems firms face. CTAP appears to be playing an important role in the developing and dissemination of new technology in the local cluster. It has also implemented a quality control initiative and an international benchmarking programme to learn best practice from other regions and countries.

Having said this, there remain problems with encouraging SMEs within the sector to become more innovative and the agency still relies on public support for the majority of its funds. There is a membership fee but (by 2007) private sources accounted for less that $50 \%$ of funds and only 50 organisations were members - including regional government agencies. The mass of SMEs seem to be marginal to its activities. If the centre is to be sustained, once the EU funding expires, it will need to generate funding from firms themselves. One reason for its failure to engage the more traditional SMEs might be the focus upon technological innovation within the centre. Although the centre is pursuing some important programmes, with regard to research and development, product and design, including interesting diversification initiatives involving new marble furniture projects and the use of international artists and designers, there is also a need to focus upon lower-level forms of innovation that might provide more practical benefits to the wider population of SMEs. These might include a focus on process innovation and the upgrading of the sector's knowledge base more generally, for example through support for vocational training programmes. Perhaps more could be done to understand the more immediate and routine needs of SMEs for improving the productivity of the sector and developing information about markets and best practice elsewhere.

Source: Jannson, 2007. 
is most often associated with the small firm networks of the "Third Italy", whereas the third model is associated with successful regions in Germany, Austria and the Nordic countries.

Commentary on the regional innovation system is made elsewhere in this report (see chapter on research organisations). Here, we confine our recommendations specifically to SME innovation support policy. The Andalusia system involves elements of the first and third models in this respect, with recent changes shifting the focus from a nationally and EU directed system to attempts to create a more networked regional system of SME support. Whilst such a policy shift is to be welcomed in trying to "roll out" innovation policies beyond the small subset of firms that are currently oriented towards research and development activities, it may fail to boost innovative activity in more traditional sectors. This is because the approach tends towards a linear and rather top-down model of innovation, where universities and public agencies are the main institutions through which the regional government is attempting to foster innovation.

For example, the policy of encouraging clustering of SMEs in technology parks and industrial estates is informed by recent research that highlights the importance of encouraging proximity between firms in the pursuit of innovation. Whilst this is a laudable aim, encouraging the physical clustering and co-presence of firms (as we have shown) is not in itself, sufficient to encourage higher levels of collaboration and interaction around innovation processes. To achieve this, policy needs to develop "softer" mechanisms that facilitate greater collaboration and trust among SMEs, such as using existing firm networks and sectoral associations to relay information and knowledge about best practice (CTAP is a good local model in this respect). For example, dedicated training seminars relating to industry specific skills and expertise would be forums for boosting collaboration and trust. More generally, stimulating innovation in the more traditional activities will require a different approach that builds upon existing models of grassroots collaboration (evident for example in the high level of cooperative activities in agri-food sectors) to create "bottom-up" forms of collective learning, characteristic of the industrial districts model cited above.

At a general level, SME policy should differentiate more between the different types of firm and the potential for innovation and internationalisation. Three key recommendations are advocated in this respect.

\section{Better assess the competitive prospects of local firms}

With regard to SMEs operating in high-tech sectors, RETA and the other actors in the regional innovation system need to use a more selective and targeted approach than at present. Rather than a "top-down" focus on pushing 
innovation and $R \& D$, and the focus upon creating new firms and capacity in what are viewed as knowledge-economy sectors such as IT and biotechnology, Andalusia needs to re-assess the competitive prospects of many of the firms in these sectors. For example, how many of the firms created in the new technology parks can be genuinely competitive at the international level? The evidence from export surveys suggests a limited number in this respect. Additionally, evidence suggests that while there has been success in creating new firms in technology-based sectors, few of these grow to a level where they are able to create sustainable jobs and create a broader impact. A useful exercise would be to conduct a competitiveness audit, identifying the following: five-year business growth performance; number of customers; geography of markets supplied to and change over time; evidence of collaborative networking; and the way that firms source external knowledge and information. These are all good indicators of the potential competitiveness of, and growth prospects of SMEs. More effort could be extended in developing linkages between smaller SMEs and larger firms building more effective collective learning networks both within but also outside the region. There are clearly good opportunities in sectors such as renewable energy and aerospace where the region already has established international lead firms, but there is limited evidence in other sectors.

\section{Address the lower level innovation needs of low-tech SMEs}

There should be greater dedicated support for innovation activities in the low technology SMEs involved in export markets. There is a plethora of institutions and organisations that already exist to promote collective learning activities, though these are often seen as remote from most SMEs because of their overt focus upon higher level forms of knowledge creation. Very often a lack of time of internal resources within the firm is a barrier to become involved in external networking activities. SME owners have to be efficient and selective in the way they engage with external actors, filtering the often massive amounts of information and knowledge now available with internet communications to meet their specific needs. Typically the smaller SMEs will identify innovation needs based on resolving day-to-day problems. Outside those firms involved in high tech activities or in design intensive markets, few are able or willing to commit resources to more "offensive" innovation strategies (Todtling and Kaufman, 2003). As the example of the stone cluster demonstrates, there are examples of good practice that can be built upon but more focus should be placed upon forms of process innovation that improve competitiveness and productivity in international markets. One means of achieving this would be through seminars and workshops on international best practice that are sector-based, but focus on broadly defined topics such as product development, marketing and branding strategies. To encourage SMEs, seminars should involve leading firms and successful entrepreneurs reflecting on their own experience, with a mix of contributors from within the region and also from external sources. 


\section{Devolve technological advice to the sectoral level more effectively}

The past approach to less innovative SMEs through the 85 RETA innovation agents is being reformed. In the future, technological advice needs to be rationalised but also devolved to the sectoral level more effectively. One option, would be to replace this profile with dedicated teams for each of the key sectors identified (a maximum of 10) to provide advice for SMEs. The personnel of these teams could then have a more diverse range of skills more suitable for SMEs, including specialist IT but also individuals with more tailored industry-specific knowledge. The agency interested in this would need to work with the relevant industry organisations to ensure more effective dialogue between the agents and the firms. The rather hierarchical and "top-down" model of SME support should be replaced by a flatter and more "negotiated" set of collective learning relationships, where SME sectoral representatives play a greater part in defining and agreeing the agenda and policy to foster greater technological innovation. More lower-level innovation support is also with regard to basic vocational training and technical support in areas such as product development, process innovation and marketing. With both of these kinds of initiative, decision-making should be devolved to SMEs themselves through private sectoral associations, rather than being imposed from above.

\section{Learning models}

\section{The Tuscan model of localised quality in the agri-food sector}

\section{Description of the approach}

Tuscany has become world-renowned as a centre for high quality food products, particularly its wine, olive oil and cured meats, which are predominantly organised around small-scale farms and producers. This reputation is however relatively recent and owes much to a new development model, based upon the regional government's Rural Development Plan launched in the 1990s (Morgan et al., 2006, chapter 4). Since this point, the region's agro-food complex has been successfully regenerated, establishing itself in international markets through a "Tuscan model" (Morgan et al 2006: 107) based upon supplying a diversified range of food products to both local and international markets in an industry that remains dominated by SMEs.

The core of the model was to develop competitive advantage through strengthening existing local assets and in particular the huge diversity of food products that existed in the region as a result of its lack of modernisation (Regione Toscana, 2000). Rather than attempting to rationalise food production into a few standard products, the regional approach took advantage of growing segmentation in food markets by recognising the potential for a 
strategy of food diversification. To promote this diversity, a priority for policy became developing sophisticated marketing networks that were capable of promoting the branding of Tuscan food products such as its olive oil, cheeses, wines and processed meats (Morgan et al., 2006). A critical additional ingredient was the establishment of "short supply chains" by developing closer links between the agricultural and food production and sectors and the growth in the local tourist sector in cities such as Florence and Siena.

\section{Rationale for the intervention}

Up until the late 1970s, rural Tuscany was a relatively backward and peripheral region. Like many rural regions in southern Europe in the post 1945 period, there were attempts made to modernise and industrialise Tuscany's agri-food sector. However, Tuscany's difficult physical terrain, allied to the continuing small-scale nature of farming, made rationalisation difficult. Farms were often too small for modern forms of mechanisation (Pratt, 1994). The availability of alternative employment in the growing economies of the nearby cities of Florence, Siena and Pisa resulted in an outflow of the farming population attracted by less arduous and more economically rewarding forms of employment.

By the early 1990s, modernisation efforts were judged to have failed with attempts to make the sector more efficient only resulting in crisis conditions in the industry. Individual food sectors were not large enough to be able to organise to serve mass markets on a national basis, whilst attempts to rationalise only served to reduce the regional diversity in products. The wider European Union Common Agricultural Policy had also failed to support smaller food producers, such as those in Tuscany, who remained geared to producing higher quality products for niche or more local markets.

\section{Reasons for success}

Perhaps the most important element in the Tuscan success story was the realisation that, rather than being detrimental to its economic development, the region's agricultural history and traditions could be important assets in a changing global food market. Rather than seeing the dominance of small and medium sized firms as a hindrance to modernisation, the plan recognised that there were important forms of traditional skill and knowledge of products embodied in the workers and owners of SMEs themselves. In turn this local knowledge was critical to developing and maintaining a huge diversity and high level of quality in food products. At the local level, initiatives were developed to both raise and protect food quality standards. A good example is the red wine, Brunello di Montalcino, produced in the area south of Siena. The area has been successful in establishing its own DOC (Denominaione 
d'Origine Controllata) which both restricts production of this type of wine to the area and maintains strict quality controls, administered through the Brunello Consortium which incorporates all local producers. The Consortium has a USD 1.1 million budget, $60 \%$ of which is spent on promoting the brand (Morgan et al., 2006, p. 102).

The promotion of high quality, small-scale food production also coincided with a wider trend of more environmentally conscious and "slow-food" based consumption patterns. A more knowledgeable type of consumer has also developed in Western Europe concerned with both the conditions under which food is produced, the consequences for health and environment, and the subsequent importance of the visibility of the food chain. Unlike many other agricultural regions in Western Europe, Tuscan food production, remaining largely geared towards supplying local markets, with short supply chains between producers and consumers meant that it could meet the demands of the new type of consumer (Morgan et al., 2006). The growth of tourism to the region from the late 1980s also brought Tuscan food products to the attention of a more global and discerning consumer and was an important element in further publicising the Tuscan model.

An important further factor in the region's successful regeneration of its agri-food sector has been the decentralisation of economic decision-making from the national level both to the regional and local level since the 1970s. This entailed that policies could be shaped by local agendas, prioritising particular local assets and in particular food products that could be the focus of productivity and innovation strategies. Thus the Rural Development Plans that was enacted at the end of the 1990s was heavily devolved to Tuscany's provinces which were able to develop their own local plans, managing the majority of the financial resources (Brunori, 2005). Morgan et al. (2006) also highlight the "broad stakeholder involvement" behind these initiatives so that a bottom-up rather than top-down approach has been pursued that encouraged SMEs to become more involved in strategic agendas.

\section{Obstacles and responses}

By the early 2000s the rural areas of Tuscany, were facing pressures from over-development and conflicts emerging between different social groups because wealthy incomers - attracted by the real and symbolic value of owning property and vineyards in the region - drove up land and housing prices in the region, displacing many local people. There are, as a result, growing tensions between local municipalities, who want to diversify economic development creating new job opportunities for local people, developing new housing and diversifying agriculture and many of the local consortia (e.g. Chianti Consorzio) dedicated to preserving the traditional rural way of life as part of their brand identity. It is too early to see how these debates will 
turn out but one response by the regional government, in line with broader changes in national legislation, has been to try to encourage greater collaboration between municipalities by stimulating the establishment of "rural districts" (Brunori and Ross, 2007) which might better represent the diverse interest groups whiles retaining a cohesive territorially based policy.

\section{Relevance to Andalusia and considerations for adoption}

Although many of the factors behind Tuscany's success are historically specific - in particular the continued fragmentation of farming land up until the 1970s and the decentralisation of government in the same period that led to regional development strategies tailored to local needs - there are important policy elements of the model that could be transferable to Andalusia. Like Tuscany, Andalusia has a number of world renowned food and drink products (e.g. olive oil, sherry) that could be more effectively linked to broader economic development objectives and act as a model for the marketing of lesser known specialist food products (e.g. Jambon Iberico). While there are important elements of the agri-food sector in Andalusia that are tied into a more modernised and intensive systems of production for international markets, the regional food production system is still dominated by small traditional forms of production that could benefit from targeting higher qualityconscious consumer market segments, or the growing demand in Spain and elsewhere for organic food products. The traditions of cooperative production and distribution in Andalusia's agri-food sector, allied to the existing decentralisation of economic development initiatives to the local level, also provide opportunities for the development of the kind of territorially based strategies that have made the Tuscan model successful. Indeed, Andalusia has its own models in this regard such as the Jerez and Montilla wine regions.

Tuscany also provides a good example of how a higher value added food strategy can be applied to a captive local tourist market that would benefit the more traditional SMEs that supply predominantly to local markets. In the Tuscan case, effective local marketing to international tourists has helped to globalise local food brands. Andalusia has both a mass tourist market along the coast, but also a growing market for cultural tourism in its historic cities such as Sevilla, Cordoba and Granada. Attempts could be made to better link high quality and traditional food products to these higher level tourist centres. The Tuscan model shows the importance of distinctive marketing and branding, and creating strong identification of products with local areas. Dedicated events such as food festivals, that bring the distinctive local food traditions of Andalusia to the attention of visitors to the region, could be held to market the products of the rural areas. 


\section{For further information}

www.arpat.toscana.it/

www.slowfood.com/

www.consorziobrunellodimontalcino.it/

Dr Roberta Sonnino, School of City and Regional Planning, Cardiff University, Glamorgan Building, King Edward VII Avenue, Cardiff, Wales, CF10 3W. Email: SonninoR@cardiff.ac.uk

Professor Gianluca Brunori, Department of Agronomy and Management of the Agro-ecosystem, Group of Agricultural and Environmental Economics, University of Pisa, Via del Borghetto, 80-56124 Pisa, Italy. Email: gbrunori@agr. unipi.it

\section{Danish low-tech clusters and the "village economy"}

\section{Description of the approach}

Confounding conventional analyses of globalisation, Denmark, with few natural resources and high production costs by international standards, has maintained an impressive level of international competitiveness in low technology manufacturing sectors. For example, Denmark is the third largest exporter of wooden furniture in the world after the United States and United Kingdom, producing 20 percent of the EU total (Maskell,1998). Similarly, Danish firms command 30\% of the world market for fir and mink products (Christensen, 2010). Denmark also continues to compete in basic food processing activities.

Continued presence in low technology sectors has been achieved without the establishment of a large-firm dominated economy. Denmark's low tech clusters are comprised predominantly of small firms manufacturing in design driven markets with a low minimum efficient scale of production. The wooden furniture industry, for example, employs 14000 people with an average firm size of 39, a figure that had stayed constant since the 1970s (Maskell,1998: 105). The fur industry is also SME dominated with over 2000 independent producers in a labour intensive sector that has 3000 direct employees but around 25000 indirect jobs in supporting and dependent industries (e.g. auction and sales houses). Industries tend also to lack vertical integration with highly developed divisions of labour existing between rather than within firms (Christensen, 2010; Maskell, 1998). The Danish model has been referred to as the "village economy" becomes it is founded upon clusters of SMEs whose competitive advantage is created by close-knit business cultures, interactions, and the exchange of specialist industry knowledge. 
For example, Danish SMEs in the wooden furniture industry have the highest productivity levels in the European Union but this is not built on investment in high technology or a high level of R\&D (Maskell, 1998). Instead, according to Danish researchers, competitive advantage is achieved through access to shared local knowledge, built up over time in particular local clusters.

\section{Rationale for the intervention}

As a small open economy with $50 \%$ of its economic activity accounted for by international trade, Denmark has traditionally lacked the ability to undertake interventionist industrial strategies and demand-side economic policies of larger countries. It has therefore developed a series of institutional arrangements over a long time period that underpins its relative economic success. A particular set of economic and social relationships between business and non-business actors (Maskell, 1997; Christensen, 2010) that have proved flexible in adjusting to changing exogenous circumstances over time have been relevant to the continuing success of Danish SMEs.

Despite this, in the late 1980s the Danish Government identified the threat of increased global competition to the position of its firms in international markets. Subsequently it developed its Network Programme to further encourage cooperation among firms (Seremetis, 1994) and the setting up of independent networks in particular sectors to encourage cooperation, particularly in the international marketing of products. The Danish Technology Institute also played a key role in the networking programme, receiving funding to develop a brokering model where an individual external to the potential network is responsible for guiding the inter-firm co-operation process.

\section{Reasons for success}

These interventions have been important in the continuing ability of Danish SMEs to compete in export markets. They have also built on a long tradition of collective organisation into business associations and trade unions in what is sometimes referred to as the "negotiated economy" (Amin and Thomas, 1996; Maskell, 1998): 80\% of workers are in trade unions while members of employer associations account for $55 \%$ of private sector employees (Anderson and Mailand, 2005). High levels of knowledge exchange between SMEs are underpinned by close-knit business communities in each sector. Denmark is characterised by a plethora of networks and strong industry associations, although these are usually independent of government which plays a limited role in economic development and industrial strategy.

Managers of SMEs share similar backgrounds and there are regular forums and opportunities for meeting to discuss common problems and issues. Such interactions do not necessarily encourage cooperation - especially 
among the smallest firms where rivalry is often quite acute - but they are important in building reputation and trust among SMEs. What Maskell refers to as the "Village" nature of the business environment "does not force the firms to cooperate if they are not so inclined, but which makes cooperation possible for firms that are" (1997, p.199). Cooperation typically involve certain types of knowledge exchange and support, commonly in technical problem solving activities that involve lending material and equipment and even labour in some cases (Maskell 1998; Christensen, 2010).

Finally, there are some more formal institutions and organisations that provide broader technical knowledge and advice to agri-food and manufacturing sectors. The agriculture and related manufacturing sectors have a long history, from the establishment of the Danish Technology Institute - founded over 90 years ago - in assisting agricultural and manufacturing activities realise high levels of productivity. Each sector has its own self-financed organisations that provide similar support in the form of knowledge generation and dissemination activities (Christensen et al., 2010).

Local tacit knowledge is also reproduced through a high level of commitment among firms to vocational training and apprenticeships; Danish firms spend $2.1 \%$ of their wage bill on training compared to $1.5 \%$ for the Netherlands or 1.8\% in Germany (Maskell, 1988). A tradition of long term specialist apprenticeships - between 5 and 10 years - has continued through the 2000s despite increased competitive pressures on firms from foreign low cost competition (Christensen, 2010). While most vocational trading is administered outwith the state, through collective agreement between the social partners, the Danish labour market model - often referred to as "Flexicurity" - also provides generous provision for vocational training and retraining both for those in work and the unemployed. This allied to the generous unemployment benefits available as part of the system is also seen as important in encouraging entrepreneurial and risk-taking behaviour (Anderson and Mailand, 2005).

Additionally, new firms tend to be established by skilled workers already with a background of working within particular industries, rather than those with professional managerial experience or entrepreneurial motives from the outside, thus helping to reinforce processes of collective knowledge exchange between SMEs (Maskell, 1998; Christensen, 2010). New start ups tend to stay within the cluster, thus, both taking advantage of, and reinforcing specialist, local production knowledge.

\section{Obstacles and responses}

Despite growing international competition from lower cost producers in China and Eastern European, Denmark's employment remained relatively stable up until 2007 but with the economic downturn and collapse of global 
demand in many key markets, unemployment has climbed from $3.6 \%$ to $5.9 \%$ in 2009, forecast to rise above $7 \%$ in 2010. The reliance of Danish SMEs on export markets clearly makes them especially vulnerable to the current downturn. In common with elsewhere, Danish SMEs have limited managerial and financial capabilities to internationalise their operations, so have been reliant in the past on larger multinational customers (e.g. IKEA in the furniture industry).

Additionally, some industries face ongoing problems of uncertainty arising from the consumer markets they serve. The wooden furniture industry has always been characterised by extreme fluctuations and rapidly changing market conditions with a lot of firm closures and high death rates of new start-ups. Financial vulnerability and low levels of managerial competence are also common problems (Maskell, 1998) and increasing competitive pressures on SMEs are making some of the sectoral-wide policies more difficult to finance and sustain, notably the technical support institutes in each cluster.

At present, it is not clear how the Danish model will respond to these external global pressures although its "flexicurity" labour market model whereby employers are given flexibility over the hiring and firing of labour while employees are given generous social protection and rights to retraining - has been attributed as a major factor in the resilience of Danish SMEs through past crises (Anderson and Mailand, 2005, Madsen, 2006).

\section{Relevance to Andalusia and considerations for adoption}

The Danish model is apposite for those Andalusia firms that we have identified as type 2 in the typology: i.e. international firms that are relatively low tech operating in traditional sectors. Encouraging greater cooperation and the sharing of resources, related to areas such as marketing and training, would provide considerable potential benefits for exporters. One policy that could be adopted is the mentoring approach, whereby a key individual is tasked with fostering more collaborative activities within individual sectors. Andalusia already has many of the local institutions at the sectoral level that could play the role in generating and sustaining the kinds of cooperation that are key to the success of Danish SMEs. However, a key element of the Danish model is organisations that have autonomy from the state but involve the key stakeholders in different sectors (e.g. businesses, labour unions, social economy organisations). Greater autonomy from the regional government in developing sector specific agendas would allow Andalusia SMEs to generate their own strategies with regard to innovation and productivity improvements. But this needs to be matched by the self financing of institutions that can support tacit knowledge production, in particular with regard to greater levels of vocational training, information gathering and more practical forms of business support. 
For further information

http://ideas.repec.org/p/aal/abbswp/96-6.html

www.druid.dk/

Danish Technology Institute: $w w w . d t i . d k$

Søren Christian Thomsen, SME and Business Development, Danish Technology Institute, Gregersensvej 3. DK - 2630 Taastrup.

\section{Scotland's Emergent Life Sciences Cluster}

\section{Description of the approach}

The Scottish Life Science sector has grown considerably over the last few years in terms of both new firm formation and employment creation (Birch and Cumbers, 2009). The UK has one of the strongest life sciences sector in Europe, and Scotland now represents the second largest cluster behind Cambridge (Scottish Government, 2009). By 2006 the Life Science Cluster was estimated to have a turnover of more than GBP 3 billion with more medical research being carried out per head than anywhere else in Europe.

Against a historical background of over-dependence on foreign owned firms and declining manufacturing activity, it represents an important boost to Scotland's knowledge economy and has risen in part due to a successful cluster strategy on the part of the regional development agency, Scottish Enterprise and the devolved Scottish Government which was established in 1999 (Leibovitz 2004; Rosiello 2004, Birch and Cumbers, 2009). It is one of the few sectors in Scotland to create highly skilled and professional jobs in recent years. Geographically, the sector is largely concentrated in the Central Belt between the three cities of Glasgow, Edinburgh and Aberdeen. The sector has proved itself internationally competitive and has strong international links. There are around 600 organisations employing 33000 people in the life sciences, which include the academic research base. Of these organisations, around 200 can be considered to be "core" life science firms involved in developing products and intellectual property in sectors ranging from healthcare, diagnostics, agriculture, and environmental services. The cluster is SME-dominated, with $60 \%$ independent firms and $26 \%$ spin-offs from public research organisations such as universities.

\section{Rationale for the intervention}

As a result of a number of failed attempts in the past to regenerate the region through industrial modernisation strategies and attracting foreign

direct investment, the region's enterprise development agency, Scottish 
Enterprise, embarked on a policy of identifying strategic clusters in the 1990s with a focus upon both identifying potential endogenous growth dynamics alongside the continuation of developing external links to key global commodity chains ad actors. The region's history and tradition at the forefront of medical sciences, going back to the eighteenth century Scottish Enlightenment, and the emergence of a fledgling life science industry in the late 1980s, stimulated by spin-off companies from three of Scotland's universities, led to the sector being prioritised as a strategic cluster. A number of related initiatives in the 1990s helped to support the growth of the sector (see below).

\section{Reasons for success}

In contrast to much of the claimed benefits of clusters theory, local interfirm collaboration is very limited with only $4 \%$ of firms having a relationship with another Scottish life science firm (Birch and Cumbers, 2009). However local factors and linkages have been important to the sector's success. In the first instance, the sector has clearly benefited from the presence of some important internationally renowned universities working in the field of medical, life and biological sciences. The Universities of Glasgow, Edinburgh, Dundee, and to a lesser extent Aberdeen have a long history and track record of research in these fields. The growth of a global biotechnology and life sciences industry over the past thirty years has therefore presented an opportunity for Scottish scientists and technologists to develop new patents, products and processes to supply a growing global market. Additionally to the supply of ideas and concepts from university research, the Scottish universities have produced generations of well-trained graduates to service the life sciences labour market: indeed Scotland produces a proportionately larger number of graduates from its universities than other parts of the UK. The public health service has also been an important consumer for new and innovative medical products, as well another source of funding and testing for research.

The institutional support has been considerable. Scottish Enterprise and the Scottish Government have provided substantial support for the cluster through grant funding (e.g. a Proof of Concept), co-funding (e.g. Co-investment Fund) and other financial schemes (e.g. ITI Life Sciences). Of particular note is the Intermediate Technology Institute - one of 4 within Scotland (the others being in IT, energy and media) - which provides funds to bridge the gap between early-stage research which is publicly funded and commercialised research. To date, it has invested around GBP 50 million and to a certain extent has been successful in its strategy of longer term investment to pick "winners" in scientific areas that it considers to have rapid growth potential. Another notable initiative has been the "Global Scot" programme, funded by Scottish Enterprise, which represents a worldwide network of leading Scots who provide advice, 
contacts, assistance and support for Scottish companies seeking to operate in international markets.

However, the cluster has also benefited from the global connections of both Scotland's academic community and the business community. The academic community is part of a much broader global network of scientific knowledge and has been an important contributor to key global breakthroughs in a diverse range of medical fields, most famously in the genetics area. Scottish-based firms are very well plugged into the commodity chains of the main European and United States pharmaceutical multinationals. The sector can in this sense be said to have been "born global" (Birch and Cumbers, 2009). There is also a wealth of experience and talent available as a result of the "Scottish Diaspora" that can be drawn on, not only through networks like Global Scot, but also directly through recruitment to firms. The skills and experience such returnees bring to firms are invaluable when operating in the global economy. Consequently the loss of Scottish graduates to other places need not be a problem, and as many return to Scotland later in their careers, can be seen as an important part of the global flows through which knowledge is transferred into the local cluster helping in the regeneration of the scientific knowledge base.

\section{Obstacles and responses}

As with many more peripheral regions, a key problem for life science SMEs has been the availability of venture capital, which is limited in Scotland: in the UK the south east of England tends to dominate the sector. There is a thriving business angel community in Scotland but there are limitations to finance the growth of life science firms. Therefore whilst Scotland has a good record in the growth of new firms in recent years, it has failed to generate sufficient medium sized and larger concerns to become global players. The sector faces the problem that many of the more successful firms are taken over by larger foreign companies with the dangers inherent in relocation (Birch and Cumbers, 2009). The limits of specifically "Scottish" latestage investment inhibit the achievement of a critical mass of medium and large firms which could provide the stability and market that smaller firms need. This is not so much a consequence of too few investors, but rather a lack of "lead" investors who can draw in others from outside Scotland.

Scotland also has a growing skill shortage in certain key areas which is partly the result of a lack of training by SMEs. To address this issue, the Scottish Government recently introduced a Life Sciences Modern Apprenticeship scheme which provides subsidies for SMEs to take on trainees. 


\section{Relevance to Andalusia and considerations for adoption}

There are important lessons from Scotland's experience that could be applied to Andalusia's growing high-tech SMEs. Scotland has a long record as a lagging region with a background of economic decline in the country's traditional manufacturing industries. Until recently, large parts of central and lowland Scotland were deemed worthy of considerable European regional assistance because of poor economic performance and social deprivation. It is therefore a "region" that can be considered "less-favoured" and with similar characteristics in this respect to Andalusia. Although predominantly an industrial region, it has a history of similar attempts at regional regeneration, driven in the past by initiatives to attract foreign direct investment. The focus more recently on key knowledge economy sectors and a series of cluster initiatives hold some important policy lessons for Andalusia which is now pursuing a similar course.

The successful capitalisation on the region's educational and scientific assets may also hold lessons for Andalusia which is similarly well provided with universities, although may lack the longer tradition of commercialisation of research and development of spin-off companies. There are also similarities in the regional public anchoring of knowledge-based SMEs. A major difference may be the greater global connections of Scotland's scientists and SME community, which as we have noted were very well connected up to broader knowledge and commercial networks from an early stage. To emulate this, Andalusia policy makers might want to develop a similar initiative to the Global Scot programme, though focused upon high tech activities, constructing a network of internationally recognised individuals from the business and scientific worlds who are able to advice and mentor locally based firms about penetrating and operating in global markets.

Scotland's funding initiatives might also hold important lessons for Andalusia in targeting support for R\&D activities more effectively. In particular, the more targeted approach of the ITIs in Scotland, which are focused upon just three sectors: Life Sciences, Energy and Techmedia, might be a model to adapt for Andalusia. With smaller resources in the future, investment in high tech activities should be directed at the most promising sectors that already display some international capability, rather than spreading resources too thinly. The EU JEREMIE programme could be integrated into an ITI strategy to "pick winners" in a more strategic manner.

\section{For further information}

www.scottish-enterprise.com/your-sector/life-sciences-sector

www.cppr.ac.uk/centres/cppr/researchthemes/trademobilitygeographicconcentration/ lifesciencecommoditychainsproject/ 
www.genomicsnetwork.ac.uk/innogen/publications

www.globalscot.com/

Irene Johnson, Director of International Networks, Scottish Enterprise, Atrium House, 50 Waterloo St, Glasgow, G2 6HQ. www.globalscot.com/ ContactUs/Contact.aspx

Joe Leibovitz, Research OfficerJoseph.Leibovitz@scotland.gsi.gov.uk St Andrews House, Regent Road, Edinburgh, EH1 3DG 


\section{References}

Anderson, S. and Mailand, M. 2005 The Danish Flexicurity Model: the role of the Collective Bargaining System. FAOS Working Paper, Copenhagen.

Asheim, B. Isaksen, A. Nauwelaers, C. and Todtling, F. (eds) 2003 Regional Innovation Policy for Small and Medium Enterprises. Edward Elgar, Cheltenham.

Asheim, B. and Isaksen, A. 2003 SMEs and the regional dimension. In Asheim, B. Isaksen, A. Nauwelaers, C. and Todtling, F. (eds) 2003 Regional Innovation Policy for Small and Medium Enterprises. Edward Elgar, Cheltenham, pp.21-48.

Bathelt, H. Malmberg, A. and Maskell, P. 2004 Clusters and knowledge: local buzz, global pipelines and the process of knowledge creation. Progress in Human Geography 28, 1, pp. 31-56.

Birch, K. and Cumbers, A. 2009 Strengthening the Life Sciences in Scotland. Policy Report, Centre for Public Policy for Regions, University of Glasgow.

Brunori, G. 2005 Rural Strategy in Tuscany. Unpublished manuscript.

Christensen, J.L. 2010 Low-tech, High Performing Clusters in Knowledge-based Economies. Paper presented at the DRUID Summer Conference, London, June.

Consejo Economico y Social 2009 Informe Sobre la Situacion Socioeconomica de Andalucia 2008, Sevilla, Consejo Economico y Social.

Cooke, P. Boekholt, P. and Todtling, F. 2000 The Governance of Innovation in Europe: Regional Perspectives on Global Competitiveness, London, Pinter.

Cumbers, A. Mackinnon, D. Chapman, K. (2003) Innovation, collaboration and learning in regional clusters: a study of SMEs in the Aberdeen oil complex. Environment and Planning A. 35 9, pp. 1689-1706.

Isaksen, A. 2003 National and regional contexts for innovation. In Asheim, B. Isaksen, A. Nauwelaers, C. and Todtling, F. (eds) 2003 Regional Innovation Policy for Small and Medium Enterprises. Edward Elgar, Cheltenham, pp. 49-778. 
Jannson, T 2007 The Andalusian Stone Technology Centre, unpublished document prepared for Technopolis Group on behalf of the European Commission, Macael, Andalusia.

Kaufman, A. and Todtling, F. 2003 Innovation patterns of SMEs. In Asheim, B. Isaksen, A. Nauwelaers, C. and Todtling, F. (eds) 2003 Regional Innovation Policy for Small and Medium Enterprises. Edward Elgar, Cheltenham, pp.78-118.

Leibovitz, J. 2004 Embryonic knowledge based clusters and cities: the case of biotechnology in Scotland. Urban Studies 41, 5-6, pp. 1133-1156.

Lorenzen, M. 1998 Specialisation and Localised Learning: Six Studies on the European Furniture Industry. Copenhagen Business School Press, Copenhagen.

Madsen, P.K 2006 Contribution to the EEO Automn Review: Flexicurity in Denmark, European Employment Observatory, Working Paper, University of Aalborg.

Maskell, P. 1997 Learning in the village economy of Denmark. In Braczyk, H.J. Cooke, P. and Heydenreich, M. (eds) Regional Innovation Systems. London, UCL Press.

Maskell, P. Eskelinen, H. Hannibalsson, I, Malmberg, A. and Vatne, E. 1998 Competitiveness, Localised Learning and Regional Development: Specialisation and Prosperity in Small Open Economies, London, Routledge.

Maskell, P. 1998 Successful low-tech industries in a high-cost environments: the case of the Danish furniture industry. European Urban and Regional Studies 5, 2, pp.99-118.

Massey, D. Quintas, P. and Wield, D 1992 High-Tech Fantasies. London, Routledge.

Morgan, K. Marsden, T. and Murdoch, J. 2006 Worlds of Food: Place, Power and Provenance in the Food Chain. Oxford, Oxford University Press.

Rosiello, A. 2004. Evaluating Scottish Enterprise's Cluster Policy in Life Sciences: A Descriptive Analysis. University of Edinburgh: Innogen Working Paper No.16.

Romero, I. and Javier Santos, F. 2007 Firm size and regional linkages: a typology of manufacturing establishments in southern Spain. Regional Studies 41, 5, pp. 571-84.

Seremetis, P.S. (1994) SMEs in technological networks: Italy, Denmark and the UK. European Planning Studies 2, 3, 375-83. 
Smallbone, D. Cumbers, A. Syrett, S. and Leigh, R. (1999) The Single Market Process and SMEs: some spatial and sectoral contrasts. Regional Studies 33, $1,51-62$.

Storper, M. 1995 The resurgence of regional economies, ten years later: the region as a nexus of untraded interdependencies. European Urban and Regional Studies 2, 2, 191-222.

Rosiello, A. 2004. Evaluating Scottish Enterprise's Cluster Policy in Life Sciences: A Descriptive Analysis. University of Edinburgh: Innogen Working Paper No.16.

Scottish Government 2009 Life Sciences Key Sector Report, Scottish Government, Edinburgh. 



\section{Conclusions}

Andalusia has undergone remarkable growth over the last decade. The catch-up process with the rest of Spain has been particularly significant since the mid 1990s. For instance, Andalusia's GDP grew in real terms by $20.2 \%$ between 2000 and 2005; employment rose at an annual rate of $6.6 \%$, as compared to only $4.7 \%$ nationally between 1997 and 2007; over the same time span, unemployment decreased at $4.7 \%$ annually, halving the number of the unemployed from 442000 to 212000 . Despite this positive record convergence has not yet been attained, and indeed Andalusia has never managed to overtake $80 \%$ of Spain's GDP per capita. The recent economic crisis has made things worse, striking Andalusia harder than the rest of Spain, which has been in itself severely hit by recession. ${ }^{1}$

Two different stages of development connote the recent economic history of Andalusia. The first wave of modernisation interested the region until the late 1990s, and was largely based on investments in infrastructure. The second wave of modernisation builds on the main principles set out in the 2000 EU Lisbon Agenda (i.e. the prioritisation of the knowledge-based economy with a view to making Europe the most competitive economy worldwide); hence, it emphasises the role of public and private investments in $\mathrm{R} \& \mathrm{D}$, improved tertiary education, fostered co-operation between industry and university, stronger entrepreneurship, etc.

As a result, these themes have assumed top importance in the policy agenda of the regional government, and the last EU-driven Andalusia Operational Programme for the period 2007-2013 earmarked EUR 2.38 billion (nearly one quarter of the total) for the promotion of the knowledge economy and for entrepreneurial development and business innovation. To achieve these objectives a number of strategies, programmes, and organisations have been deployed. Two strategies appear more relevant than others: the 2006 Innovation and Modernisation Plan for Andalusia (PIMA) - which stresses the importance of business enterprise R\&D (BERD) investments, industry-university technology transfer, and intermediate organisations such as technology centres and technology parks - and the Andalusia Plan for Research, Development and Innovation (PAIDI), which identifies the main 
actors of the regional innovation system in four types: (i) technology spaces (e.g. technology parks, science parks, etc.); (ii) knowledge-generation organisations (e.g. universities); (iii) knowledge-transfer organisations (e.g. technology centres); (iv) system-management organisations (e.g. IDEA, RETA, CTA, etc.).

This report has precisely analysed this system, i.e. the entrepreneurship and SME development support system of Andalusia, focusing on four main areas that are relevant for a thriving knowledge-based economy: (i) human capital and labour market; (ii) research organisations; (iii) entrepreneurship and start-ups; (iv) SME development. The main conclusions and policy recommendations for each of these themes make up the remainder of this chapter.

\section{Human capital and labour market}

Three key issues have emerged in the area of human capital and labour market: (i) today's knowledge-based economy put a premium on education; as a result, the regional government should seek to strengthen further participation in higher education; (ii) the potential contribution of vocational education and technical skills to entrepreneurship and innovation is not sufficiently appreciated in the region; (iii) entrepreneurship education is still at an incipient stage, in spite of the wide offer of training programmes for entrepreneurs.

The number of Andalusia's people aged between 25 and 34 with university and post-compulsory education degrees increased between 1998 and 2007 from $25.2 \%$ to $32.6 \%$, with Spain moving over the same period from $31.2 \%$ to $38.9 \%$. Despite this improvement, Andalusia universities have lost nearly 50000 students over the 1999-2009 decade. The boom of construction and tourism possibly explains this trend, as both do not require strong university competencies. However, in the knowledge-based economy there are greater returns from higher education. College graduates make up 29\% of the employed population in the region, but only $15 \%$ of the unemployed. Conversely, unemployment among young adults (aged 16-24) with just a high school diploma stood at stunning $56 \%$ at the end of 2009 . The recession has therefore taken a heavier toll on the youth with lower qualification than those with tertiary education.

There seems to be also a significant divide between the regional innovation system and the vocational education system. Being the current entrepreneurship and innovation strategies mainly based on the promotion of R\&D and industry-university technology transfer, the regional government is missing the possible contribution of vocational education to innovation through a more qualified and skilled workforce. This is shown, for instance, by the fact that the ministry of employment is not actively involved in the design of regional innovation and entrepreneurship strategies, although it is responsible 
for vocational education, self-employment programmes, and even for some entrepreneur training schemes. A by-product of this divide is that workforce development is not as aligned with cluster development as it could be. The Second Andalusia Plan for Vocational Education, currently being prepared by the Ministry of Education, is looking at closer co-operation with firms, and as part of this effort it should strive to bring workforce development in line with the sectoral priorities of the region.

Entrepreneurship education is not as strong in the region as it could be expected, given the emphasis placed by the regional government on entrepreneurship and business innovation. There is indeed a broad supply of entrepreneur training provided by a very heterogeneous array of actors (universities, technology centres, agencies such as ANDALUCIA EMPRENDEand RETA), but this is largely ad-hoc training dealing with specific aspects such as marketing, business internationalisation, ICT adoption, etc. There is a lack of programmes that tackle entrepreneurship in a more comprehensive and integrated way, looking at the broad set of skills that new entrepreneurs need to start up and grow their business. The natural setting for similar programmes would be the university, but amongst the ten public universities of Andalusia only the University of Malaga has recently established an elective entrepreneurship course that has, inter alia, poor attendance. The low take-up rate of this course may also flag that Andalusia's entrepreneurial culture remains feeble, although the regional government has spared no effort in its reinforcement over the last years.

\section{Contribution of research organisations}

The three key aspects with regard to the role of universities in the regional entrepreneurship and SME development system can be synthesised as follows: (i) Andalusia's public universities are the largest beneficiaries of R\&D funding, and have significantly influenced regional development strategies, with some unintended consequences on the alignment between university research priorities and the region's strategic priorities; (ii) the regional government favours an intellectual property approach where university research commercialisation is mainly pursued through patenting and technology licensing; other forms of technology transfer are consequently overlooked; (iii) there is room for strengthening linkages between university faculty and smaller firms, a niche in which RETA and other organisations could play a useful role.

In a region like Andalusia where the share of private $\mathrm{R} \& \mathrm{D}$ spending is still $33.6 \%$, well below the Spanish average of $45.5 \%$, public universities have been the primary source of R\&D spending in the region and the main beneficiaries of $R \& D$ regional funding, including through the recent PIMA agreement. This 
has entailed a privileged position for regional research universities, which have been able to influence significantly the strategic orientations of the regional government as regards R\&D and innovation. This can, however, represent a problem to the extent to which the higher the level of development of a region's academic system, the harder the regional government will find to impose an agenda that is more oriented towards the needs of the industry than towards the professional interests of the academic community. In a similar scenario, synergies between R\&D funding and industry development can be missed, which is what seems to have partly happened in Andalusia. A recent report prepared by the Andalusia Ministry of Education for the OECD underscores that there is not enough coordination between the research strategies of public universities and the strategic goals of regional economic and innovation plans, bringing the example of the lack of Andalusia universities prioritising research on biotechnologies, ICT or tourism, in spite of these being considered key sectors by the regional government. The university research agenda seems rather driven by the interests of the research groups, which is the main academic unit of reference for R\&D funding applications.

The commercialisation of university research is primarily pursued by the Andalusia government through the regional network of Technology Transfer Offices (OTRI), which are charged with facilitating the relationships between local firms and regional universities. The OTRI network prioritises patenting, technology licensing, and spin-offs as the main routes to research commercialisation, and some important results have indeed been achieved, with the University of Seville producing 24 patents over the last year. Nevertheless, there are some unbalances to address. First of all, the University of Seville clearly takes the lion's share in industry-university technology transfer, with half of private research contracts allocated to it (i.e. EUR 28 billion); apart from Malaga and Granada, the other regional universities have a very minor role in this activity. Secondly, universities and their OTRI offices need to look beyond a mere intellectual property approach. Different studies, both from the US and Spanish contexts, suggest that the primary focus on intellectual property mechanisms is misplaced, because the latter tend to be concentrated in specific scientific fields and be of relevance to a small proportion of the research community. Moreover, these mechanisms are of greater importance for firms that draw on the STI form of innovation - i.e. the mode that hinges more on scientific knowledge for industrial production (e.g. biotech, nanotech, ICT, etc.) - and even within these groups of firms, they are just a small part of a more complex and varied set of relationships that exist between the research community and firms. Business consulting, private research contracts, collaborative research, training of human resources and supervision of graduates are also important modes of knowledge transfer that OTRIs should consider more than has done so far. Through less R\&Dintensive forms of industry-university collaboration, the regional technology 
transfer offices will be able to reach out to a wider number of both faculty members and enterprises, especially those of smaller size that do not engage in R\&D but that would still benefit from a stronger collaboration with university (e.g. through consulting).

In this respect, RETA could play an important role by building up together with OTRI a faculty skills database that could be matched with the existing dataset of "innovative needs" of Andalusia firms. The two sources could be used to better address the needs of innovative firms, the future target of RETA's work. The collaboration between OTRI and RETA should not just focus on R\&D-intensive forms of collaboration, but explore the wider spectrum of industry-university collaborative options available.

\section{Entrepreneurship and start-ups}

Andalusia innovation and modernisation strategies (i.e. PIMA and PAIDI) stress the importance not only of R\&D investments and technology transfer, but also of new business start-ups and entrepreneurial culture as basic pillars of future economic development. Entrepreneurship promotion is therefore rightly at the top of Andalusia's concern, and one organisation in the regional institutional setting is specifically devoted to this aim (i.e. ANDALUCIA EMPRENDE). The three key elements that have arisen in this field during the review exercise are as follows: (i) despite remarkable strides in key entrepreneurship indicators, Andalusia has still margins for improvement as regards both business creation and entrepreneurial culture. Moreover, with a surging unemployment rate above the $25 \%$ threshold, it would be important to capture the potential of self-employment programmes for both reducing joblessness and increasing business activity rates; (ii) considering the large investments of Andalusia in business incubators, the regional government should engage in a more regular evaluation of this tool against current EU benchmarks; (iii) an unexplored area by the Andalusia government concerns the contribution of corporate spinoffs to innovation and local development, and how they could be favoured by policy.

The entrepreneurship performance of Andalusia has improved significantly over the last decade, with business density increasing from $51.3 \%$ to 63.7\% between 1999 and 2007 (Spain: 74.1\% in 2007). However, the crisis has again struck Andalusia more severely than the rest of Spain, with a neat annual business birth-death rate standing in 2008 at $-35.4 \%$, as compared to $-30 \%$ in Spain as a whole. Total entrepreneurial activity (i.e. the entrepreneurship potential measured as the number of people actively engaged in launching a new business) is also still lower in Andalusia than in the whole Spain. Meanwhile, the dramatic surge of the regional unemployment rate $(26 \%)$ urges the introduction of self-employment programmes. Self-employment 
has the potential to alleviate unemployment, enhance the long-term income of participants, and positively impact on their career prospects by improving employability. Currently, however, self-employment programmes are in the remit of the regional ministry of employment. As a result, co-ordination and co-operation between the ministry of employment and the Ministry of Economy, Innovation and Science would be crucial in this domain. This is all the more true because the success of self-employment schemes is highly dependent on the training of participants, who are often unfamiliar with business management practices.

Incubators are one of the most favoured tools of business development promotion in Andalusia. Only within the Malaga technology park (PTA) there are six of them. Surprisingly, though, a regular evaluation mechanism of their performance has not yet been set up. At least in the PTA, which is the largest and arguably amongst the most successful of Andalusia's technology parks, business incubation seems to follow a "cradle to grave" approach in which selected firms are assisted for a long time throughout five different stages of business development. This approach raises three types of concerns: (i) it distorts the market by penalising firms that are not among the few selected ones; (ii) it does not result in higher survival rates for tenant firms; (iii) it can actually hamper the long-term competitiveness of beneficiary firms by making them dependent on subsidised assistance, consulting and training.

Finally, while university spinoffs have received much attention, less has been given to corporate spinoffs. At the time of the peer review visit there did not seem to be many activities ongoing in this area, but again the effects of the crisis might change the scenario and prompt more redundant workers and employees to set up their own businesses. Here, the regional government could work closely with the Technological Corporation of Andalusia (CTA) to undertake a review of current levels of company spinoffs, existing barriers, and possible initiatives to spur this process. The involvement of the regional ministry of education should also be sought as the main government body responsible for vocational training in the region.

\section{SME development}

The industrial fabric of Andalusia is dominated by small firms, a feature that has been exacerbated by the weight of the construction industry in the regional economy. As of 2008, micro enterprises (less than 10 employees) accounted for $95 \%$, and small firms (10-50 employees) for $4.3 \%$ of the whole enterprise population, thus making up altogether over $99 \%$ of the total. The paucity of medium-sized firms (50-250 employees) points to an excessive business fragmentation that undermines the competitiveness of the region. Innovation and internationalisation are both key to the growth of Andalusia's 
small firms. Three key policy issues have arisen in this area: (i) innovative SMEs need to be supported so that they can continue to grow; (ii) the bulk of small firms have to be reached out through different forms of innovation, including non-technology intensive ones, and through the identification of clusters worth of support; (iii) small firms would benefit from a territorialised approach to business internationalisation.

Innovative firms in Andalusia have been supported by a wide range of policies and programmes, including accommodation in technology parks. Technology parks have been one of the main instruments for the promotion of business modernisation, the underlying rationale being that clustering of technology-intensive firms enhances their growth and expansion. While there is no doubt that firms have benefited from the excellent facilities and infrastructure available in these parks, it is more questionable whether "clustering" has fostered a more collaborative culture of learning and knowledge exchange. Indeed, few firms appear to develop collaborations with other firms co-located in the same park. Collaboration with foreign businesses is also relatively rare among technology park firms, at least compared to other European realities. Policies should help technology parks to develop external links, in that the most successful innovators in high-tech sectors are often plugged into knowledge flows and networks of global nature.

Andalusia innovation policies are aware of the necessity to reach out to the broader bulk of SMEs in the region. One of the main strategies concerns cluster development, which is an appropriate choice considering that small firms need to develop institutional linkages and businesses network to compensate for lower internal resources (financial and human) available for business development. However, the identification of 25 clusters appears overly ambitious and is likely to spread diminishing public resources (after 2013) too thinly. A more sensible strategy would be to focus public funding around the most promising sectors. There is a discussion of 5-6 key strategic clusters that could become the focus of policy, including agro-food, biotechnology and health sciences, information technology, aeronautics, and renewable energy. However, there is a sense of unrealistic expectations of providing "world class" innovators in fashionable sectors rather than recognising existing regional strengths, some of which may lie in more traditional activities, and build on them.

Finally, together with innovation, internationalisation is another pillar of the Andalusia strategy for SME development. The task of internationalising the regional economy is made complicated by the very different sectors that have an international potential in the region, some of them being traditional (e.g. agro-food), while others technology-intensive (e.g. renewable energies). Moreover, the focus has mainly been on export promotion, whereas foreign direct investment of local firms (e.g. through joint ventures with firms 
overseas) has received much less attention. Evidence suggests that many of the most successful regions have a territorialised approach to internationalisation whereby SMEs are able to piggyback on the backs of larger customers into international markets. Existing policies that seek to strengthen the linkages between SMEs and larger firms (both locally-owned and foreignowned) should be encouraged and developed further as part of broader cluster-building strategies.

\section{RETA}

This report has also looked at the role of RETA within the Andalusia innovation system. RETA was established in 2005, firstly, to coordinate the whole of actors of the regional innovation system and, secondly, to introduce traditional firms to innovation and R\&D activities. The first task has been performed primarily by coordinating technology parks and technology centres. As part of this effort, for example, RETA attracted from 2005 to 2009 EUR 370 million of government funds for R\&D investments by the firms hosted in the parks, corresponding to $24 \%$ of the national total. Thanks to RETA's support, regional technology parks have therefore been able to pull in much financial support and show significant dynamism.

The second task has been primarily fulfilled by a network of 85 "innovation agents", who were delocalised in different parts of the region, from industrial estates to technology parks, from technology centres to rural areas. Thanks to this network, over the last five years, the innovative needs of approximately 80000 firms have been assessed, with a view to signposting them to relevant public support schemes. Innovation agents have also been instrumental in delivering specific programmes such as NOVAPYME (i.e. ICT access for small firms), EVA (i.e. online business management training), and small-scale innovation vouchers, all of which have shown a good rate of take-up. Through this bottom-up approach to innovation RETA has favoured a socially cohesive approach to local development. More firms, including in peripheral areas and low-quality industrial estates, have been able to benefit from public innovation support and from the type of services firms hosted in technology parks generally benefit. This has enabled the regional government to extend the scope and outreach of its policies, which can be regarded as a success in itself.

This network has run effectively until mid-2010, when it was discontinued because it had fulfilled its original role of "democratising" innovation policies. This clearly poses a challenge to RETA, which needs to think of itself in a different guise from the past. As the peer review team visited the region, there were talks of RETA targeting both traditional and innovative firms in the future. More recently this double task has been streamlined, and RETA should 
only focus on innovative enterprises in the future. This is a welcome step. As a "slimmer" organisation, RETA needs to rationalise its mission, reducing the scope of work and focusing on a narrower but attainable target. Considering the close linkages that RETA maintains with technology parks, the decision of keeping a focus on innovative firms appear to be wise. This is all the more true because the needs of more traditional firms can continue to be addressed by other regional organisations such as ANDALUCIA EMPRENDE. A division of responsibility in this sense should avoid in the future some institutional overlapping that had characterised the past.

In accomplishing its new mission, RETA should bear in mind the main features of innovation in small firms. Small firms are reactive rather than proactive when it comes to innovation; they often innovate only if they need to overcome an obstacle with which they are faced. This obstacle can be of technological nature, but also of marketing or organisational type, which implies that intellectual property mechanisms may not be the most obvious solution to enhance SME innovation. Small firms have also very limited resources to invest in long-term projects and so largely benefit from knowledge spillovers from other firms and institutions. Last but not least, because they have limited search patterns, small firms tend to co-operate with partners that are local, which has indeed a positive effect on local economic development.

RETA's future will also depend on its ability to learn from its previous work. The experience of innovation agents has been interrupted, but it should be borne in mind in the future because it has epitomised a bottom-up approach to local development in which government representatives meet entrepreneurs in the shop floor to understand their needs, rather than expect them to come to their desk and provide one-size-fits-all solutions. In the future, if government funding were to allow it, the professional profile of "innovation agents" could be revamped and possibly taken up by another regional organisation like technology parks or technology centres. In this case, however, the new profile should have a stronger sector-based flavour reflecting regional cluster strategies, which seem to be moving from the 25 sectors previously identified to a more reasonable number of five or six.

Some of the work started by RETA could also be resumed and brought forward by other organisations (e.g. technology parks and technology centres). Two examples are SMEs" access to ICT and the "census" of innovative needs of small firms. The NOVAPYME programme run by RETA has introduced small and peripheral firms to the use of simple ICT solutions (e.g. electronic signature). This work could be followed up by ICT-specialised organisations assisting small firms to introduce more complex solutions such as e-commerce. Similarly, innovation agents have been instrumental in surveying the innovative needs of thousands of small firms. The value of this dataset should not be lost and could indeed be matched with another database 
collecting the skills of university faculty members so as to ease knowledge transfer between HEIs and firms, including of small size. The network of university technology transfer offices (OTRI) appears most suited to taking up this challenge together with RETA.

To summarise, the work done by RETA over the last years should be capitalised, if anything to enhance the cost-effectiveness of regional government policies. At the same time, RETA needs to streamline its role and functions, and the last steps seem to go in the right direction.

\section{Key future opportunities}

\section{Developing entrepreneurship skills to upgrade local industries}

Universities are being geared up to be conduits for knowledge and innovation in the new economy but as the OECD study reports, inappropriate class syllabi and the lack of awareness of business training needs and of the importance of new technology, call into question the effective use of the provision of high tech skills. Students still tend to go outside of the Andalusian public university system for advanced business-related training, and the experience of the University of Malaga's entrepreneurship programme show how entrepreneurship courses in the region tend to go undersubscribed. Balancing generic entrepreneurship development programmes with tailor-made initiatives aimed at Andalusia's strategic sectors is imperative. This means creating new entrepreneurship and innovation programmes for Andalusia's strong tourism industry together with the need to offer schemes that can help scale up its traditional agricultural industry and its fledging aerospace and renewable energy industries, possibly with the involvement of local large firms.

\section{Blending $R \& D$ investment and skills upgrading to broaden the scope of local innovation policies}

Overall, there appears to be a relatively poor connection between the innovation system and the vocational system at the regional level, which is reflected in the absence of a workforce capability development strategy tied to sector- or cluster-based needs. Promoting R\&D may be a wise long-term objective, but most small firms still rely on simpler problem-solving skills. Innovation is as much about of high technology as it is about organisational and incremental changes. Generic provision is welcome but not entirely at the expense of focused sector- or cluster-based needs. As an example, renewable energy is one of the main clusters defined by the Ministry of Economy, Innovation and Science; yet there is only one vocational training diploma in Andalusia included under the Energy and Water professional family. In order to foster this energy cluster, it will be important to involve SMEs in various 
part of the production chain. Some firms will require R\&D capabilities, while others will benefit from skilled workers trained in energy efficient technologies. Identifying and implementing programmes across the production value chains should help identify opportunities for new products, new connections, and a critical mass of high-proficiency oriented industry development.

\section{Pursuing a twofold strategy in industry-university collaboration}

Universities face the usual conundrum of, one the one hand, enhancing their own research capabilities to move up global university rankings which do not take institutional contributions to local economic development into consideration and, on the other hand, the need to make such a contribution through close interaction with local businesses. Where the industrial base is characterised by few technology-intensive firms and advanced technology sectors like in Andalusia, this conundrum cannot be resolved through a primary focus on R\&D. The need for a certain kind of ambidexterity where both R\&D activity focused on strategic growth areas and problem-solving or learning-oriented activities centred round the need for upgrading existing sectors could be given equal priority. This strategic dilemma is exacerbated by the deficiencies in intellectual property (IP) legislation and practice referred to above. The absence of clarity over form and content of intellectual property and the relative mismatch between IP provision and local industry needs, suggests that there is more to be gained from focused activity in both IPR-based and non-IPR areas of activity.

\section{Attracting talent as a component of the university's future strategies}

The organisational arrangements, especially for R\&D funding place a considerable emphasis on improving university capacity for research. The enhanced capabilities for university research can lead to regional universities being able to attract talent, both students and faculty, from elsewhere. Such an objective should be realised as best as possible as it will help develop and draw in to the region a greater pool of human capital. But an exclusive focus on such a strategy could be at odds with the actual requirements for the region in terms of its economic development today. Universities may not be able to resolve these difficulties themselves and this is where careful planning of the work of intermediary agencies can be particularly useful.

\section{Nurturing global connections to reinforce the innovative potential of local firms}

The extensive business support infrastructure is a potential source of advantage for regional SMEs. However, closer scrutiny shows that some of the essential softer aspects of SME development (e.g. collaborative learning 
and knowledge exchange) may have not been working in the region as well as hoped for. For example, the level of cooperation among firms within one of the main technology parks (Seville's Cartuja 93) was not as strong as expected; most hosted firms collaborated more intensively with external enterprises. It is difficult to judge whether this lack of collaboration is necessarily a negative aspect of SME development. High growth firms tend to be plugged in globally, and global connections were relatively incipient in most technology parks. This important tool of economic development in the region is still overly embedded within regional and national innovation networks, although it starts looking more convincingly for external collaborations that can be beneficial to the tenant firms.

\section{Improving the governance of public innovation efforts}

The continued investment in R\&D (from EUR 72 million in 1999 to EUR 243 million in 2005) might generate opportunities for which there is a time lag especially in regions with a relatively low technology antecedent. This is evinced in the increased recruitment of R\&D personnel, the quality improvement of traditional products, and chinks in the private sector armour highlighting better co-operation. Greater levels of coordination among agencies with a view to connecting human capital development with technological change and management capabilities could be a significant institutional task well worth achieving in the region.

\section{Fine-tuning internationalisation strategies}

There is promise in the strategy of internationalisation in Latin America that is being pursued both by RETA and EXTENDA, which capitalises on the long established cultural and linguistic ties between Andalusia and the latter that give the region a decisive competitive advantage over other European regions. The attractiveness of such ventures has to be measured by the level and capability of SME participation in international activity. By current standards relatively low levels of international activity among SME might suggest that connecting potentially resourceful SMEs to larger firm networks might be more productive than the direct identification of global markets. This is particularly important in situations where global market demand may have fallen or where firms are not geared up to take advantage of growing markets.

\section{Reconsidering the number and sectoral mix of cluster strategies}

Business clustering has brought significant advantages for smaller firms especially because of knowledge spillovers from one firm to another or from institutions to firms. However, a policy which promotes a raft of clusters 
may not be appropriate. A more rewarding strategy would be to focus public funding around the most promising and strategic sectors such as agro-food, biotechnology and health sciences, information technology, aeronautics, and renewable energy, while finding ways of strengthening existing industry associations and bodies in other organisations. Developing public policy in these strategic clusters by connecting human capital development, R\&D, general innovation support measures, IPR, new firm formation and global market orientation, hold the promise to be more effective than the current scattered strategy. Besides, it is important that future cluster strategies also build on current traditional sectors that are strong in the region, in addition to targeting R\&D-based sectors with future growth potential.

\section{Harnessing the entrepreneurship potential of the youth and migrant population}

The need for greater strategic direction becomes more significant when consideration is given to the problem of high levels of unemployment, especially youth unemployment in Andalusia. Entrepreneurship works when new firms are formed, when new skills are developed and deployed, and when new talent is able to work with new products and services. Wasted youth potential can have a profound adverse impact on entrepreneurship and economic development in the future. Diversity through immigration can also be a positive feature of regions as the success of Silicon Valley's many migrant entrepreneurs will testify. Andalusia currently benefits from jobs migrants mainly in relatively low-skill sectors. However, harnessing talent among these communities for work in growing sectors could open up opportunities for new products and markets. Together with a diverse student body and the identification of entrepreneurial talent in that community, much could be achieved by way of creating a globally connected high value economic region.

\section{Policy recommendations}

The analysis in this report has led to the formulation of the following key policy recommendations. 


\section{Box 6.1. Main policy recommendations}

Human capital and labour market

- Link training programmes more effectively with sectors in order to improve firm productivity and innovation, especially in the traditional sectors that are Andalusia's strengths.

- Work across the silos of business and employment agencies by connecting business incentives with job creation in strategic sectors.

- Refocus entrepreneurship education along the models of the best business schools, trying to attract immigrants and to exploit the advantage of Andalusia's geographical location.

- Train entrepreneurs for global e-commerce through, for instance, the development of a web localisation certificate programme.

Contribution of research organisations

- Build (RETA and OTRI) an integrated database of faculty research and consulting skills to match the existing survey of innovation needs of small firms.

- Establish co-operative education programmes engaging university students in alternating work terms with study terms throughout their undergraduate degrees.

- Stay abreast of recent developments in technology parks and consider moving the Andalusian model towards a format in which research occurs in "clouds" that virtually link together distributed and light research facilities. Consider the creation of virtual technology parks.

Entrepreneurship and start-ups

- Further develop entrepreneurial culture in the region, including by targeting the new unemployed through self-employment programmes.

- Set-up a business incubation monitoring and evaluation system that assesses the performance of Andalusia incubators against EU current benchmarks.

- Think of promoting corporate spin-offs as an alternative to university spinoffs with stronger industry and market knowledge.

SME development

- Re-assess the competitive prospects of firms in technology parks, and try to further develop their linkages with both co-located firms and external smaller firms.

- Devolve technological advice to the sectoral level by, for instance, designing a new profile of innovation agent with more industry-specific knowledge. Align this measure with a more focused cluster development strategy. 


\section{Box 6.1. Main policy recommendations (continued)}

- Address the lower-level innovation needs of SMEs through, for example, sector-based events on practical issues such as product development and marketing strategies. Involve in these events successful entrepreneurs, both from within the region and from outside.

- Apply a territorialised approach to business internationalisation whereby small firms internationalise their activities by "piggybacking” on the backs of large customers.

\section{RETA}

- Focus work on innovative firms, exploiting the privileged relationships with local technology parks. Target these firms through both long-term R\&D and short-term problem-solving activities.

- Look increasingly at workforce development and skills upgrading as channels for the promotion of innovation in the region. This will include involvement in future cooperative education programmes and retention of talented foreign students from local universities in technology parks.

- Ensure that best-practice policy principles are applied in local technology parks, including by strengthening the relationships of the latter with local universities.

\section{Note}

1. Suffice it to think that between 2007 and the first quarter of 2010, unemployment has soared from $11 \%$ to $27.2 \%$, only $3.5 \%$ below the 1996 value preceding the "phenomenal decade". 


\section{ORGANISATION FOR ECONOMIC CO-OPERATION AND DEVELOPMENT}

The OECD is a unique forum where governments work together to address the economic, social and environmental challenges of globalisation. The OECD is also at the forefront of efforts to understand and to help governments respond to new developments and concerns, such as corporate governance, the information economy and the challenges of an ageing population. The Organisation provides a setting where governments can compare policy experiences, seek answers to common problems, identify good practice and work to co-ordinate domestic and international policies.

The OECD member countries are: Australia, Austria, Belgium, Canada, Chile, the Czech Republic, Denmark, Estonia, Finland, France, Germany, Greece, Hungary, Iceland, Ireland, Israel, Italy, Japan, Korea, Luxembourg, Mexico, the Netherlands, New Zealand, Norway, Poland, Portugal, the Slovak Republic, Slovenia, Spain, Sweden, Switzerland, Turkey, the United Kingdom and the United States. The European Commission takes part in the work of the OECD.

OECD Publishing disseminates widely the results of the Organisation's statistics gathering and research on economic, social and environmental issues, as well as the conventions, guidelines and standards agreed by its members. 


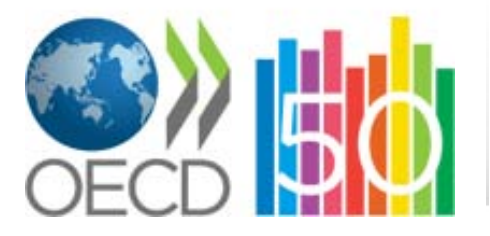

BETTER POLICIES FOR BETTER LIVES

Follow us

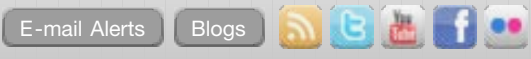

OECD Home About

OECD Home ' Spain , Entrepreneurship, SMEs and local development in Andalusia, Spain

\section{Entrepreneurship, SMEs and local development in Andalusia, Spain}

\section{Send}

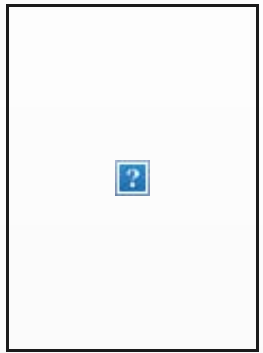

ISBN: 2079-4797

Publication Date: November 2010

Pages: 139

\author{
Table of contents $\mid$ How to Obtain this Publication | Contact
}

This report is part of the series of the OECD Reviews of Entrepreneurship, SMEs and Local Development, which assess in selected regions and localities the strengths and weaknesses of the local business environment and policies for entrepreneurship and SMEs, and make recommendations for improvement.

\section{Table of contents}

\section{Executive Summary}

Introduction

Chapter I: Economic and Institutional Overview of Andalusia

Chapter II: Human Capital and the Labour Market

Chapter III: The Contribution of Research Organisations

Chapter IV: Entrepreneurship and Start-ups

Chapter V: SME Development in Andalusia

Conclusions

\section{How to obtain this publication}

Readers can download the full version of this report by clicking on the link below:

Entrepreneurship. SMEs and local development in Andalusia. Spain (pdf, 1.84MB)

\section{Contact}

For further information, please contact the Mr Marco Marchese.

\section{Related documents:}

\$ LEED working paper series (English)

» SMEs, Entrepreneurship and Local Development in the Marche Region, Italy (English) 